\title{
Maximum Employment and the Participation Cycle
}

\author{
Bart Hobijn \\ Ayşegül Şahin \\ Arizona State University and FRB San Francisco \\ University of Texas at Austin and NBER*
}

Draft: August 3, 2021

Prepared for the 2021 Jackson Hole Economic Policy Symposium

\begin{abstract}
We investigate the source, magnitude, and unevenness of the procyclical forces that shape labor force participation, i.e., the participation cycle, which are important for the implementation of the maximum employment mandate. We show that these forces can be analyzed in real time using a flow decomposition of the changes in the labor force participation rate. The decomposition reveals that the source of the participation cycle is fluctuations in job-loss and job-finding $r$ a tes, $r$ a ther than cy clical m ovements in la bor force en try and exit rates. The magnitude of the participation cycle is large. Cyclical downward pressures on employment from participation are two-thirds that of unemployment. Moreover, the participation cycle delays the recovery in employment because it lags the unemployment cycle. It also amplifies the un evenness of the im pact of $r$ e cessions. Groups that s ee large increases in their unemployment rates also experience more pronounced participation cycles. Despite differences in their magnitudes, the source of the participation cycle is the same for all groups. Application of our method to the COVID-19 Recession suggests that, as of June 2021, the bulk of the drop in the participation rate since the onset of the pandemic is cyclical and that the cyclical recovery in participation likely will trail that of the unemployment rate.
\end{abstract}

JEL classification c o des: J 6, J20.

Keywords: COVID-19, labor force participation, labor supply.

${ }^{*}$ We would like to thank Jordan Krussell for his research assistance. The views expressed in this paper are those of the authors and do not necessarily reflect those of the institutions with which they are affiliated with. 
"... conditions under which there will be afforded useful employment for those able, willing, and seeking work, and to promote maximum employment ..."

(Employment Act of 1946)

\section{Introduction}

In August 2020 the Federal Open Market Committee (FOMC) amended its longer-run goals and monetary policy strategy by rephrasing the maximum employment part of its dual mandate as " $a$ broadbased and inclusive goal that is not directly measurable" (Federal Open Market Committee, 2020). Ever since the inception of the statement on its longer-run goals in 2012 the FOMC has refrained from defining a specific target, like the natural rate of unemployment, for its maximum employment mandate. The Committee's broad definition of maximum employment is in line with the historical conceptual discussion about full employment that originated with Keynes (1936).

Maximum employment is determined by the fraction of labor supply that is unmet by labor demand in the absence of business-cycle fluctuations, i.e., the natural rate of unemployment, and the level of labor supply that is unaffected by the business cycle, i.e., the trend participation rate. ${ }^{1}$ The emphasis often is on the unemployment rate when shortfalls from maximum employment are discussed. However, there are substantial procyclical pressures on participation, especially when the labor market is strong, which was first pointed out by Perry (1971) and Okun (1973). They analyzed increases in the labor force participation rate at the tail end of business cycles in response to declines in the unemployment rate. Their analyses identified as a simple rule of thumb what we refer to as the Perry-Okun rule in the rest of this paper: A 1-percentage-point decline of the unemployment rate in a hot labor market results in cyclical upward pressure of 0.65 percentage point on the participation rate.

Since these insightful studies in the early 1970s, the U.S. labor market experienced several important changes. These changes in demographics and labor supply behavior by cohorts have made it hard to construct real-time estimates of the trend participation rate. In fact, over the past 15 years the order of magnitude of disagreement between different estimates of trend participation as well as of revisions of these estimates has been much larger than the disagreement about and revisions of estimates of the natural rate of unemployment. This disagreement poses a substantial practical challenge for the implementation of the FOMC's maximum employment mandate. This challenge can be met partially with a real-time estimate

\footnotetext{
${ }^{1}$ Throughout this paper we ignore cyclical fluctuations in hours worked per person, e.g. Faberman et al. (2020).
} 
that shines a light on the source and magnitude of the cyclical forces that shape the dynamics of labor supply and the participation rate as well as on the unevenness in these forces across different groups of workers in the labor market.

Our contribution in this paper is to provide such an estimate based on a stock-flow decomposition of the dynamics of the labor force participation rate (LFPR) into parts due to changes in the six flow transition probabilities between employment, unemployment, and nonparticipation that builds on Elsby et al. (2019). This decomposition is straightforward to implement in real time with data from monthly releases by the Bureau of Labor Statistics (BLS). For our analysis we aggregate the results of our decomposition into two components: the entry and exit component and the cycle component.

The entry and exit component captures the part of changes in the participation rate that can be traced back to changes in the probabilities of workers flowing across the participation margin, i.e., into and out of the labor force. This component puts upward pressure on participation at the beginning of recessions when the likelihood that the employed and unemployed drop out of the labor force goes down. ${ }^{2}$ Mostly, however, it captures the time-varying long-run trend behavior of the participation rate. The procyclical pressures on the participation rate come from the cycle component, which we call the participation cycle in the rest of this paper. These are the pressures exerted on labor force participation by job-loss (flows from employment to unemployment), and job-finding (flows from unemployment to employment).

At first glance, it might sound puzzling that the flows that do not involve crossing the participation margin are the source of the procyclicality of the labor force participation rate. The intuition comes from recognizing that those who are unemployed are substantially more likely to drop out of the labor force than the employed. Specifically, the exit rate from the labor force for the unemployed averaged around 25 percent in 1978-2019. This is almost an order of magnitude larger than the labor force exit rate of employed workers which averaged 2.8 percent during the same period. The difference in these exit rates from the labor force creates a wedge that we refer to as the attachment wedge. The higher the fraction of the labor force that is unemployed, i.e., the higher the unemployment rate, the more likely workers are to drop out of the labor force in the future, which lowers the participation rate going forward. Since

\footnotetext{
${ }^{2}$ Krusell et al. (2017), and Cairó et al. (2021) discuss why it is hard to capture this empirical regularity in three-state labor-market models with search frictions. Those models typically imply that people are more likely to drop out of the labor force when their labor market opportunities deteriorate in a weakening labor market. This observation builds on other research (Veracierto, 2008; Shimer, 2013) that struggles with the puzzle why such models result in a procyclical unemployment rate when a participation margin is included. Possible explanations are worker heterogeneity (Krusell et al. , 2017), the procyclicality of the opportunity cost of employment (Chodorow-Reich and Karabarbounis, 2016), and wage rigidities (Shimer, 2013; Cairó et al. , 2021).
} 
movements in job-loss and job-finding are the main drivers of fluctuations in the unemployment rate (Elsby et al. , 2015), the unemployment cycle and the participation cycle are closely tied together.

In terms of magnitude, we find that the procyclical forces that affect the labor supply during business cycles are large. Our analysis reveals that the downward pressure that the participation cycle puts on the employment-to-population (EPOP) ratio is about two-thirds that of the unemployment cycle. Moreover, the participation cycle lags the unemployment cycle. On average, the participation cycle bottoms out nine months after the unemployment rate peaks. This lag is even longer for deeper recessions. The participation and unemployment cycles tend to converge during labor market recoveries, moving in tandem especially in later phases of expansions. When the unemployment rate gets close to or is below its natural rate, declines in unemployment and cyclical upward pressures on participation have about the same effect on the EPOP ratio. This observation is consistent with the Perry-Okun rule that during strong labor markets a 1-percentage-point decline in the unemployment rate results in cyclical upward pressure of 0.65 percentage point on the participation rate. Using a very different methodology and more recent data we find a rule of thumb very similar to Perry (1971) and Okun (1973).

Despite the similarity in the estimates, there is one crucial distinction between our analysis and the earlier work by Perry (1971) and Okun (1973). Our results establish that increases in employment stability for those in the labor force during strong labor markets put upward pressure on participation. That is, the reductions in job-loss and increases in job-finding when labor market conditions improve result in fewer and shorter periods of unemployment (see Marston, 1976), which reduces the likelihood that participants drop out of the labor force. This new finding stands in stark contrast to the narrative about the procyclicality of the LFPR that marginalized workers disproportionately drop out of the labor market during recessions and only re-enter in the latter part of the expansion. As we show, there is little support in the data for this narrative, which has prevailed since Perry (1971) and Okun (1973), who attributed the procyclicality of the participation rate to women and young workers entering the labor force at a higher rate when unemployment is low. ${ }^{3}$ Since the mechanism we identify works through employment stability instead of labor force reentry, its effects are more broadbased.

The source of the upward pressures on participation during expansions has important policy implications especially in light of the maximum employment mandate being a broadbased and inclusive goal. If the prevailing view were true, progress towards maximum employment when

\footnotetext{
${ }^{3}$ This narrative has been reiterated in several papers, e.g. Clark and Summers (1981) and Aaronson et al. (2019).
} 
the labor market is hot and the unemployment rate is low mainly would be made through the re-entry into the labor force of workers from marginalized groups. Therefore, it would be important for policymakers to focus on movements in the participation rates of the groups of workers that bear the brunt of labor market downturns when the unemployment rate is low. Instead, our results suggest there is little need to shift the attention from the unemployment to the participation rate, especially of marginalized groups, at the tail end of expansions because the same forces are at play for all groups in the labor market. For all groups, the Perry-Okun rule is a reasonable rule of thumb. This means that, during the latter stages of the business cycle when the unemployment rate is low, cyclical upward pressures on participation move almost in lockstep with changes in unemployment rates. This is because for all groups the main procyclical forces on participation are driven by fluctuations in job-loss and job-finding rates that also account for the bulk of the movements in the unemployment rate.

However, the magnitude of the participation cycle is highly uneven across groups as a consequence of the differences in the cyclicality and levels of unemployment rates. We find that the participation cycle amplifies the well-documented unevenness of recessions, as captured by different increases in group-specific unemployment rates. ${ }^{4}$ Groups with a higher increase in the incidence of unemployment also have larger procyclical pressures on their participation rate. Therefore, the groups hardest hit during recessions have the largest cyclical upward pressures on participation during recoveries and expansions. This includes low-skilled workers and workers who identify as Black, or African American, and Hispanic. Our new finding complements Wolfers' discussion of Aaronson et al. (2019) where he shows that disadvantaged groups with higher unemployment rates also tend to have more cyclical unemployment rates. We identify another mechanism where differences in unemployment rates have uneven effects.

The results and implications we discussed so far all are based on data for recessions before the COVID pandemic. The challenge, of course, is that the amendment of the FOMC's long-run goals came during a pandemic that was accompanied by an historic increase in the unemployment rate and an unprecedented drop in the LFPR. Figure 1 shows how the unemployment rate jumped from its 50-year low of 3.5 percent to 14.7 percent and the participation rate declined from its post Great-Recession peak of 63.4 percent to 60.2 percent in a matter of weeks in early 2020. While the unemployment rate retreated relatively quickly to around 5.9 percent, the participation rate remains almost 2 percentage points below its pre-pandemic level as of June 2021.

The extraordinary circumstances during the pandemic resulted in large shifts in both labor demand and labor supply, the cyclical and structural parts of which have been even harder

\footnotetext{
${ }^{4}$ See for example, Elsby et al. (2010), Hoynes et al. (2012) and Aaronson et al. (2019).
} 
to disentangle than during previous recessions. We apply the lessons we learned about the participation cycle from earlier recessions to the COVID Recession. They result in the estimate that 1.5 percentage points of the 1.7-percentage-point decline in the participation rate from February 2020 to June 2021 is due to the cyclical drag on the participation rate associated with the deterioration of job-loss and job-finding prospects since the onset of the pandemic. This result holds not just for the aggregate data. For all groups in our sample, the bulk of the decline in their participation rates is due to the participation cycle.

As we write this paper, the labor market in June 2021 resembles, in many respects, fall 2014. Using the post-2014 expansion as a baseline, we show that the participation cycle in coming years is likely to lag the unemployment cycle. During the upcoming recovery, cyclical factors affecting the labor supply will be a more of a drag on employment than those captured by the unemployment rate. This observation holds even if the recovery in the labor market is considerably faster than the post-2014 period, bringing the unemployment rate to 3.8 percent by the end of 2022 .

Section 2 summarizes the significance of labor supply in historical discussions of full employment. Section 3 analyzes the joint evolution of unemployment, participation and employment during 1948-2019. Section 4 introduces the concept of the participation cycle using a formal stock-flow decomposition, and presents its estimate for 1978-2019. Section 5 examines the unevenness in the participation cycle and discusses its importance for the maximum employment mandate. Section 6 focuses on the COVID-19 Recession and Section 7 concludes with policy implications.

\section{Brief History of Full Employment and Labor Supply}

The Employment Act of 1946 explicitly states that the federal government should "promote maximum employment." Thirty-one years after the Employment Act was passed, the Federal Reserve Act was amended to reflect this objective as part of the triple mandate of monetary policy consisting of "maximum employment, stable prices, and moderate long-term interest rates." Because interest rates are used as a means to an end, the Federal Reserve Act often is referred to as the dual mandate of maximum employment and price stability.

Despite its significance and appeal as a guiding principle for monetary policy, and federal government policies more generally, maximum employment has remained an elusive target. The difficulty in assessing the level of full employment arises not only from measurement challenges but also from a lack of a widely accepted definition. ${ }^{5}$ This is reflected in the August 2020

\footnotetext{
"Throughout, we use "maximum employment" and "full employment" interchangeably.
} 
statement by the FOMC on Longer-Run Goals and Monetary Policy Strategy, Federal Open Market Committee (2020). Its defines the maximum level of employment as "... a broadbased and inclusive goal that is not directly measurable and changes over time owing largely to nonmonetary factors that affect the structure and dynamics of the labor market. Consequently, it would not be appropriate to specify a fixed goal for employment; rather, the Committee's policy decisions must be informed by assessments of the shortfalls of employment from its maximum level, recognizing that such assessments are necessarily uncertain and subject to revision. The Committee considers a wide range of indicators in making these assessments."

At first, it might seem disappointing that the FOMC did not define a "fixed goal" for employment as it did for price stability. For example, it could have adopted the goal of a natural rate of unemployment, Friedman (1968), or a Non-Accelerating Inflation Rate of Unemployment (NAIRU), Modigliani and Papademos (1975). ${ }^{6}$ However, the broad definition of maximum employment used by the FOMC is in line with the historical evolution of the concept of full employment.

Keynes' General Theory (Keynes, 1936) offers two definitions of full employment. In the first case, full employment is defined as the maximum level of aggregate demand, "a situation in which aggregate employment is inelastic in response to an increase in the effective demand for its output." In the second, full employment corresponds to the level of employment, which entails "the equality of the real wage to the marginal disutility of employment." Each definition recognizes the importance of labor supply considerations and allows for the possibility of shifts in the level of maximum employment as the trade-off between working and nonparticipation varies over time.

Keynes' concept of full employment provides a benchmark for macroeconomic stabilization policies. Even early scholars of such policies took into account their effect on the supply of labor. For example, Robinson's "The Problem of Full Employment" (Robinson, 1943) provides an insightful discussion of the trade-offs in pursuing a full employment policy, especially in its reference to the changing attachment of workers to the labor force as labor market conditions improve.

In the late 1950's, the emphasis shifted from full employment to the level of unemployment as the policy benchmark. This mostly was due to the emergence of the Phillips curve, which captured the empirical negative relationship between the unemployment rate and nominal wage growth (Phillips, 1958) as well as inflation (Samuelson and Solow, 1960). This shift in focus resulted in Friedman's (Friedman, 1968) influential definition of the natural rate of unemployment in 1968 as "the level that would be ground out by the Walrasian system of general equilibrium

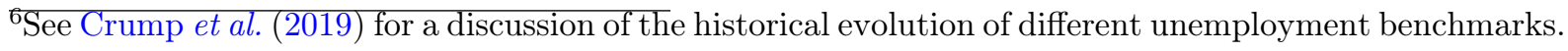


equations, provided there is imbedded in them the actual structural characteristics of labor and commodity markets, including market imperfections, stochastic variability in demands and supplies, the cost of gathering information about job vacancies and labor availability, the costs of mobility, and so on."

While Friedman advocated for the natural rate of unemployment, rather than the level of maximum employment, as the appropriate policy benchmark, he recognized labor supply factors in his definition of the natural rate, just like Keynes did in his two definitions of full employment and Lucas and Rapping (1969) did in their seminal work on the role of labor supply in fluctuations in hours worked. Friedman, in his 1968 Presidential address, wrote "To avoid misunderstanding, let me emphasize that by using the term "natural" rate of unemployment, I do not mean to suggest that it is immutable and unchangeable.... Improvements in employment exchanges, in availability of information about job vacancies and labor supply, and so on, would tend to lower the natural rate of unemployment."

Even though the emphasis in both policy discussions and academic research has been on the unemployment rate as the policy benchmark in recent decades, members of the FOMC have made clear that measures of the labor supply are followed closely as part of the "wide range of indicators" in making policy assessments. This has been particularly true in the decade following the Great Recession. During that period there was a confluence of two forces driving labor supply. The first was the long-run trend in the LFPR related to the aging of the population, flattening of the female labor force participation, and an increase in recipients of disability insurance. The second reflected the decline in the number of job seekers due to a lack of job market opportunities in the wake of the deepest post-war recession in U.S. history. The complex interaction of trend and cyclical factors required policymakers to make "... difficult judgments about the magnitudes of the cyclical and structural influences affecting labor market variables, including labor force participation" (Yellen, 2014)

The sudden and drastic drop in the LFPR at the onset of the pandemic in 2020 has made these judgments even more important in the wake of the COVID-19 Recession than after the Great Recession. It has led policymakers to consider the unemployment rate corrected for changes in labor force participation as a measure of labor market slack (Powell, 2021). The next section puts this historical discussion in a quantitative context by examining the joint evolution of the employment-to-population ratio, the unemployment rate and the participation rate. 


\section{The Mild Procyclicality of Labor Supply}

Two important concepts have guided policy in the measurement of progress towards fulfilling the employment mandate. The first is the fraction of the population that is employed.Known as the employment-to-population (EPOP) ratio, it is the headline measure in which the level of maximum employment is most directly defined. The second is the unemployment rate, $u$. These two concepts are linked through the labor force participation rate (LFPR), which is the fraction of the population that either is employed or not employed and actively searching for a job.

In this section, we first introduce a simple accounting identity similar to the decomposition considered in Clark and Summers (1981) to show that the role of the participation margin in employment fluctuations was muted in earlier business cycles as a consequence of the trend rise in the female participation rate. However, it has emerged as a force to be reckoned with during the expansions in the 2000's after the female LFPR flattened at the end of the 20th century. The procyclicality of the participation rate during the last 20 years has resulted in numerous studies aimed at separating its cyclical and trend components. In the second part of the section, we provide an empirical meta analysis of these studies to show that the disagreement about the level of trend participation is an order of magnitude larger than that about the natural rate of unemployment.

\subsection{Sources of Employment Fluctuations in the Post-War Period}

A simple accounting identity defines the level of employment as a share of the population, $E P O P_{t}$, as the fraction of the labor supply that is met by demand: $\left(1-u_{t}\right)$, times the supply of labor as a share of the population, $L F P R_{t}$ :

$$
E P O P_{t}=\left(1-u_{t}\right) \times L F P R_{t} .
$$

Using this equation we can split changes in the level of employment into parts due to fluctuations in labor demand relative to supply (an unemployment term) and due to changes in labor supply (a participation term):

$$
\Delta E P O P_{t}=E P O P_{t}-E P O P_{t-1}=\underbrace{-\overline{L F P R}_{t} \Delta u_{t}}_{\text {unemployment term }}+\underbrace{\left(1-\bar{u}_{t}\right) \Delta L F P R_{t}}_{\text {participation term }} .
$$

The changes in the unemployment rate and the participation rate are weighted by averages of these variables defined as $\overline{L F P R}_{t}=1 / 2\left[L F P R_{t}+L F P R_{t-1}\right]$ and $\bar{u}_{t}=1 / 2\left[u_{t}+u_{t-1}\right]$. 
When there is little change in the participation rate, i.e., $\triangle L F P R_{t} \approx 0$, then the $E P O P_{t}$ ratio moves in lockstep with the negative of the unemployment rate. In that case, a 1-percentagepoint increase in the unemployment rate decreases EPOP ratio by about two-thirds of a point given that the participation rate has been in the range of 60 to 68 percent in the last five decades. This was a reasonable rule of thumb from 1948 until 1970, during which the participation rate fluctuated in a narrow band between 58.1 and 60.5 percent.

Figure 2 decomposes the cumulative changes in the EPOP ratio over each business cycle except the COVID-19 Recession, starting with the trough in the unemployment rate depicted by a dashed vertical line, into the contributions of the unemployment and LFPR terms in (2). ${ }^{7}$ For all the business cycles before 1973, changes in the EPOP ratio almost perfectly align with the contribution of the unemployment rate. Put differently, the bulk of the movements in the EPOP ratio over the business cycle were attributable to the unemployment term. It was this empirical regularity that led scholars like Friedman and Modigliani and Papademos to focus on the unemployment rate and ignore cyclical fluctuations in the labor supply for the assessment of maximum employment. However, it is important to recognize that the relative constancy of the LFPR for the total population during that period masked important underlying trends in labor supply. Panels (b) and (c) of Figure 2 illustrate this by splitting panel (a) up by gender.

For men before the 1960's, most of the movements in the EPOP ratio were due to movements in the unemployment rate as panel (b) of Figure 2 shows. ${ }^{8}$ However, as documented in Juhn (1992), in the 1960's the participation rate for men started to decline, i.e., $\Delta L F P R_{t}<0$, and this change in the labor supply became an important driver of the changes in their EPOP ratio.

For women, whose LFPR steadily rose from 1948 through 2000, the pattern was substantially different from men's until 2000. This upward trend, i.e., $\triangle L F P R_{t}>0$, is reflected in the positive cumulative contribution of participation to the EPOP ratio for every business cycle during that period as seen in panel (c) of Figure 2. For women, most of the movements in the EPOP ratio were due to movements along the participation margin while the contribution of unemployment fluctuations was negligible. The rule of thumb that changes in EPOP ratio over the business cycle largely can be traced to changes in the unemployment rate was never applicable for women in the second half the 20th Century.

Since the turn of the century, labor force participation rates for men and women both have trended downward driven mostly by the aging of the baby boom cohort, as analyzed in detail in Aaronson et al. (2006), Braun et al. (2014), and Aaronson et al. (2014). However, as can be

\footnotetext{
${ }^{7}$ Because the COVID-19 Recession is such an outlier in terms of participation, we devote a separate section (Section 6) to it.

${ }^{8}$ This is consistent with the results in Table 1.6 in Pencavel (1987) that documents that LFPR for men in prime-age groups did not significantly co-move with the unemployment cycle from 1955-1982.
} 
seen from panel (a) of Figure 2, during the latter parts of the expansions after the 2001 and 2007 recessions the LFPR bucked this trend and put upward pressure on the EPOP ratio. Because the increase in the participation rate at the tail end of these expansions went counter to the structural factors that drive the underlying long-run trend, it became clear that this reflected a procyclical response in participation. The behavior of the participation rate in the past two labor market expansions has highlighted a marked, but mild, procyclicality of the labor supply and forced policy makers to make the difficult judgments about the relative importance of the cyclical and structural forces affecting participation eluded to by Yellen (2014).

Equation (2) reveals why it is important to make these judgments for the implementation of policy. Because $\left(1-\bar{u}_{t}\right) \approx 1.5 \times \overline{L F P R}_{t}$, a 1-percentage-point cyclical movement in the participation rate is equivalent to about a 1.5 percentage point shift in the unemployment rate. Common practice is to measure the magnitude of cyclical movements in participation as the gap between the actual LFPR and its trend level. This trend level, however, is very hard to estimate. This is what we discuss in the next subsection.

\subsection{Estimates of the Cyclical and Trend Components of Participation}

Starting with the trailblazing work by Perry (1971), it has become common practice to analyze labor force participation separately for different demographic groups due to differences in their participation behavior. Specifically, gender and age are recognized widely as important drivers of labor supply behavior. ${ }^{9}$ Most studies on labor supply built on this insight and identified the cyclical component of the LFPR as the deviation from an estimated trend that is constructed by aggregating across different demographic groups.

This methodology is similar to what is used to estimate the natural rate of unemployment. ${ }^{10}$ However, there is one important distinction between demographic analyses of the unemployment rate and the participation rate. Long-run average unemployment rates for different demographic groups have been relatively constant over the past decades. As a result, demographically-adjusted unemployment rates fare well in capturing medium-term trends in the aggregate unemployment rate. This not the case, however, for the LFPR. As Juhn and Potter (2006) point out, a large part of the medium- and long-run trends in the participation rate is due to changes in the labor supply choices within the same gender and age groups over time. ${ }^{11}$ This observation underscores the need for introducing cohort effects in studies of par-

\footnotetext{
${ }^{9}$ See for example, Keane (2011), and references therein.

${ }^{10}$ See Perry (1970), Summers (1986), Shimer (1998), Brauer (2007), Barnichon and Mesters (2018) and Crump et al. (2019).

${ }^{11}$ This is particularly true for workers younger than 25 , prime-age women, and persons older than 65 . For example, the participation rate of workers older than 55 years old started to rise in mid-1990s as their share
} 
ticipation behavior. Very similar methods used to take into account these time-varying trends by cohort result in very different estimates of trend participation at the same point in time and to large revisions of the estimates over time. We illustrate this by comparing the estimates of trend LFPR by government agencies, the Federal Reserve, and from several academic papers.

The BLS publishes projections of the LFPR that extrapolate the historical trends in participation by detailed age-gender groups and then aggregate them to obtain a forecast of the participation rate over the next 10 years (Toossi, 2011). Panel (a) of Figure 3 plots 10 vintages of the BLS forecast as well as the actual LFPR. ${ }^{12}$ It shows how changes in the estimated trend led to marked revisions in the forecast from 2000-2010. Since 2010, cyclical movements in the participation rate, like its weakness between 2009 and 2014, have driven most of the forecast revisions. For example, the forecast for the LFPR in 2024 was more than 1 percentage point lower in the 2012 vintage than in the 2019 vintage. The BLS forecasts are of limited use to policy makers, however, because they do not distinguish between trend and cycle components of the LFPR.

Both the Congressional Budget Office (CBO) and the Federal Reserve produce estimates of the trend participation rate. Revisions in these trend estimates have been of the same order of magnitude as those in the BLS forecast. This can be gleaned from panel (b) of Figure 3, which plots several vintages of these estimates as well as a number of estimates from various research papers. The figure shows that the CBO trend estimates, i.e., the lines with the dots, have moved up and down with the participation cycle during the expansion after the Great Recession in the same way as the BLS estimates did. ${ }^{13}$ For example, the 2015 estimate of the 2024 trend level of participation was about three quarters of a percentage point lower than the 2021 estimate. This is the equivalent of a 1.2-percentage-point revision in the CBO's estimate of the natural rate of unemployment. For comparison, the natural rate of unemployment for 2024 was revised downwards by the CBO from 5.2 in its 2015 estimate to 4.8 in its 2021 estimate by only 0.4 percentage points. Thus, revisions to the CBO's trend estimate of participation are more important for its assessment of the trend EPOP ratio than those of the estimated natural rate of unemployment.

The same is true for the estimates by the Federal Reserve. Lines indicated with squares in panel (b) of Figure 3 show the estimates of the trend participation rate from the January 2011 and January 2015 Tealbooks. The estimate of the trend level of the participation rate in 2013 was more than a percentage point higher in the 2011 Tealbook than in the 2015 Tealbook, the

in the population started to increase alleviating the downward pressure on participation due to aging of the population.

${ }^{12}$ Figure C.1 in the Appendix shows some results for the BLS forecast for detailed demographic groups.

${ }^{13}$ The CBO's estimate of trend participation is known as the potential labor force participation rate. 
equivalent of a 1.6-percentage-point revision of the natural rate of unemployment.

A comparison of studies that all build their estimates of trend participation using cohort analyses reveals several reasons for the large revisions of, and uncertainty around, estimates of the trend participation rate. The lines indicated with stars and triangles in panel (b) of Figure 3 show estimated trend participation rates from five such studies. ${ }^{14}$ While the details of the methodology across these cohort analyses differ slightly, they all rely on a similar regression framework to separate the cyclical and trend components of participation across cohorts. The dependent variable is either an indicator of whether an individual is a labor market participant or the participation rate of a gender-age group. The explanatory variables fall into four categories. The first is an age effect and the second a cohort effect. These two effects are identified only under specific parametric assumptions and the most common assumption made is that they are additive. The third group of variables captures specific factors that affect workers' participation decisions, like family structure, education, life expectancy, and generosity of Social Security benefits. The final group captures the state of the business cycle, often measured in terms of the unemployment gap. The fluctuations in participation explained by the latter group of variables are what is assumed to be the cyclical component of participation for the specific group and the other part is assumed to be the trend component. ${ }^{15}$

Although the broad specification is similar across these studies, minor differences in specification yield economically meaningful differences in results for two main reasons. First, since the framework is reduced-form by design, the parameters do not have a specific structural interpretation and the parameter estimates change substantially when new data, especially for an additional recession, become available. For example, as Coile and Levine (2011) document, workers' retirement decisions depend on both the unemployment rate and the performance of the stock market. Since stock market valuations are generally not included in the participation regressions, the cyclical coefficients on the unemployment gap will change depending on the relative movement of the unemployment rate and equity markets in a recession. Second, cohort effects are necessary for the model to explain long-run trends in line with the observation by Juhn and Potter (2006). However, they need to be extrapolated for the construction of trend participation going forward, which requires taking a stand on younger cohorts' participation behavior later in their life cycles. Therefore, projections of participation trends are sensitive to how cohort effects are extrapolated.

\footnotetext{
${ }^{14}$ These are Aaronson et al. (2006), Aaronson et al. (2012), Zandweghe (2012), Aaronson et al. (2014), and Hornstein et al. (2018). Aaronson et al. (2014) present three estimates, which are all included in the figure. Other studies present cohort analyses of trends in labor supply without a specific estimate of the aggregate trend, e.g. Kudlyak (2013).

${ }^{15}$ See Hall's comments on Aaronson et al. (2014) for a discussion of the limitations of this identifying assumption.
} 
The three estimates from Aaronson et al. (2014), i.e., the lines starting with the stars in 2014, in Figure 3, are especially useful to demonstrate the sensitivity of trend participation estimates to differences in methodology. ${ }^{16}$ The bottom line is the baseline trend estimate from the paper. The other two lines use parameter estimates from data through 2007, rather than 2014, and keep cohort effects constant for incoming cohorts. These differences in methodology and parameter estimates result in trend LFPR estimates for 2024 that are between 1.5 and 2.0 percentage points higher than in the baseline case. This is the equivalent of a 2.5 - to 3.2-percentage-point change in the natural rate of unemployment.

An alternative approach to distinguish between the cycle and trend in the participation rate is to apply a statistical filter to the aggregate data. ${ }^{17}$ The application of the Hodrick-Prescott filter (HP filter) (Hodrick and Prescott, 1997) to the LFPR is very revealing. Figure 4 plots the actual and estimated trend participation rate from 1948 to 2021. It shows that the LFPR is above trend in the latter part of almost all expansions in the postwar period revealing a mildly procyclical pattern. ${ }^{18}$ Unfortunately, the HP filter is only of limited use for the realtime analysis of time series for policy purposes. Its estimates of the relative magnitude of the trend and cycle are highly sensitive to the choice of smoothing parameter, chosen in Figure 4, according to Ravn and Uhlig (2002). Moreover, the real-time estimate of the cycle is sensitive to the state of the cycle at the endpoint of the time series (e.g., Mise et al. , 2005; Hamilton, 2018). For example, the large decline in the labor force participation rate at the onset of the pandemic in 2020 is likely to have biased the trend estimate in Figure 4 downwards and the trend estimate probably will be revised upward when the participation rate recovers. Other filtering methods suffer from similar issues.

Numerous studies also have documented the procyclicality of the participation rate, either at the national level or at the state level. Using a structural VAR, Tüzemen and Zandweghe (2018) and Cairó et al. (2021) uncover a significant response of the LFPR to labor productivity shocks at the national level. Bengali et al. (2013) and Erceg and Levin (2014) show that states with higher increases in their unemployment rates in the Great Recession also had steeper declines in their participation rates. Cajner et al. (2021) show that there is a persistent decline in the participation rate in states with disproportionate declines in output. The results in Tüzemen and Zandweghe (2018), Cairó et al. (2021), and Cajner et al. (2021) confirm that the cycle in the participation rate tends to be more persistent than that of the unemployment

\footnotetext{
${ }^{16}$ These lines are taken from Figure 13, page 248, in Aaronson et al. (2014).

${ }^{17}$ See Veracierto (2008), Rogerson and Shimer (2011), Shimer (2013), and Krusell et al. (2017), for example.

${ }^{18}$ This is not specific to the application of the HP filter. See, for example, Zandweghe (2012) for similar results using the Beveridge and Nelson (1981) decomposition and Council of Economic Advisers (2014) for an alternative detrending method based on leads and lags of the unemployment gap. James Stock's discussion of Aaronson et al. (2014) uses a similar detrending method.
} 
rate. This pattern is consistent with the recovery in participation at the end of the expansions after the 2001 and 2008 recessions and with the results obtained with the HP filter in Figure 4. The methodologies used in these studies are highly informative in understanding labor supply behavior, but are not amenable to real-time assessment of the gap between the actual and trend participation rate.

To summarize, there is ample evidence of a notable mild procyclical component in the LFPR. But the methods used to quantify this component are only of limited use for the realtime assessment needed for policy decisions. As a result, the uncertainty about the trend component of participation has been an order of magnitude larger than that about the natural rate of unemployment. In the next section, we introduce a flow-based methodology to assess the state of the participation cycle in real time. Our method relies on measuring the specific drivers that shape the path of the participation rate rather than extracting the trend component of the LFPR.

\section{The Cyclical Forces Shaping Labor Force Participation}

In this section, we develop a measure of the participation cycle and compute it for the 1978-2019 period. Our starting point is the observation that the dynamics of the EPOP ratio, LFPR, and unemployment all are driven by the same six flows between the labor force states of employment $(E)$, unemployment $(U)$, and nonparticipation $(N)$. Thi joint dynamics allows us to quantify how changes in labor market opportunities - as measured by job loss and job finding ratestranslate into LFPR fluctuations. Additionally, our framework provides an assessment of the importance of labor force entry and exits in driving labor force participation rate changes both over the business cycle and in the long-run.

The methodology we employ builds on Elsby et al. (2019) and decomposes the evolution of shares of the population in each labor force state, $\{E, U, N\}$, into parts due to changes in each of the six different labor market flow rates between these three states. ${ }^{19}$ A smaller number of papers take into account all six labor force status flows, as we do here, for the analysis of the dynamics of unemployment. ${ }^{20}$ We find this decomposition a useful addition to existing methods used to quantify the participation cycle because it has three advantages. First, it explicitly takes into account how the dynamics of the unemployment and participation rates are jointly

\footnotetext{
${ }^{19}$ Flow decompositions of the evolution of the unemployment rate, rather than the participation rate, have been used extensively in both the academic literature as well as for real-time analysis of the labor market for policy purposes. Most of these analyses decompose the fluctuations in unemployment into parts due to inflows (separations/job loss) and outflows (job finding). See, for example, Shimer (2005), Fujita and Ramey (2006), Elsby et al. (2009), Daly et al. (2009), Şahin et al. (2021).

${ }^{20}$ See Barnichon and Nekarda (2012) and Elsby et al. (2015).
} 
determined by the same economic forces. Secondly, by tracing changes in the participation rate to changes in labor market flows it helps identify the economic mechanisms that shape the participation cycle. Finally, the decomposition is easily implementable in real-time using data generally released on the first Friday of the month after the reference month.

We start our analysis with an overview of the magnitude of gross flows in subsection 4.1 and introduce our decomposition in subsection 4.2. In subsection 4.3 we provide the main intuition behind the forces the decomposition identifies and discuss why the source of the participation cycle is job-loss and job-finding rates, rather than flow rates across the participation margin. In the final subsection of this part, we show that the magnitude of the cyclical pressures on employment coming from participation are about two-thirds of those coming from unemployment and that they lag the unemployment cycle by several months.

\subsection{Flow Dynamics of the Labor Market}

It has become second nature for many macroeconomists to think of the evolution of the stocks of the number of employed, unemployed and nonparticipants as the result of gross worker flows between them. However, for someone not used to this, it is important get a sense of the sheer numbers involved. Figure 5 shows these flows for June 2021. From May 2021 to June 2021 the number of unemployed persons increased by 168,000 people, from 9.3 to 9.5 million. A naive interpretation is that no one found a job that month and 168,000 people lost their jobs. In fact, the number persons that found a job, in that they were unemployed in the second week of May and employed in the second week of June 2021, was 2.1 million and 1.8 million lost their jobs. This can be seen from the flows associated with the arrows from $U$ to $E$ and from $U$ to $E$ respectively in Figure 5.

The labor force, depicted by the ellipse in Figure 5, is made up of those employed $E$ and unemployed $U$, and those who are not in the labor force are known as nonparticipants, $N$. We often tend to think of nonparticipation as a very persistent state. In fact, from May to June 2021 the number of nonparticipants changed by only 22,000. However, considering net changes is misleading. Figure 5 shows that 13.4 million people crossed the participation margin that month despite only a small change in the stock of workers who are not in the labor force.

Another important observation is the origins of these flows that occur at the participation margin. Even though the unemployed made up only 5.9 percent of the labor force, flows between unemployment and nonparticipation and vice versa accounted for about a third of those across the participation margin. This reflects that unemployed are less attached to the labor force than those who have a job. This difference in the labor force attachments within the labor force 
is the crux of the results in the rest of this paper. The intuition is simple. When someone finds a job and moves from unemployment to employment, she is more likely to remain in the labor force going forward.

For our decomposition, we express the size of the flows in terms of the share of persons in the origin of the flow at the beginning of the month. For example, 2.1 million of the 9.3 million unemployed persons in May 2021 were employed in June 2021. That implies a jobfinding probability, which we denote by $P_{U, E}$, of 23 percent. There are six such transition probabilities associated with the monthly flow arrows in Figure 5. Figure 6 plots these six transition probabilities from 1978 through 2019. We discuss 2020 and 2021 in more detail in Section $6 .^{21}$

Panels (a) and (b) in the figure show the rates of job-loss and job-finding, respectively. These are the within labor-force flows in Figure 5. In the early parts of a recession job losses spike, which cause $P_{E, U}$ in panel (a) to increase and the unemployment rate to run up quickly in most recessions. During the recovery, the job-finding rate, $P_{U, E}$, only recovers slowly. These patterns in job-loss and job-finding have been analyzes extensively. ${ }^{22}$

Panels (c) and (d) of Figure 6 show the flow rates out of the labor force. For the rest of this paper, the most important thing to note about these flow rates is that they tend to decline during recessions. This especially is true for those from unemployment to nonparticipation. Therefore, on average, both the pools of employed and unemployed get more attached to the labor force during recessions.

Panels (e) and (f) of Figure 6 show that the cyclicality of entry flows into employment and unemployment offset each other. When the economy is strong, labor market entrants are more likely to find a job without going through a spell of unemployment. During a weak labor market the opposite is true. These offsetting cyclical flows imply that the overall entry flow rate into the labor force is not very cyclical at all.

To quantify how these fluctuations in the labor force status transition rates translate into cyclical forces that drive the participation rate, we use a formal decomposition that we introduce in the next subsection.

\footnotetext{
${ }^{21}$ Figures C. 2 and C. 3 in the Appendix show the same rates by gender.

${ }^{22}$ Shimer (2005), Elsby et al. (2009), Crump et al. (2019) analyze unemployment fluctuations in a two-state framework. Marston (1976), Blanchard et al. (1990), Barnichon and Nekarda (2012), Elsby et al. (2015), and Krusell et al. (2017) consider these margins in a three-state framework.
} 


\subsection{Six-Flow Decomposition of the Participation Rate}

The state of the labor market can be summarized by two shares, the share of the population that is employed in month $t$, which we denote by $E_{t}$, and the share that is unemployed, $U_{t}$ in Figure 5. The share of nonparticipants, $N_{t}$, is simply implied by the constraint that the three shares add up to one. The transition probabilities determine the evolution of these shares according to the following two equations ${ }^{23}$

$$
\begin{aligned}
& E_{t}=\left(1-P_{E, U, t}-P_{E, N, t}\right) E_{t-1}+P_{U, E, t} U_{t-1}+P_{N, E, t}\left(1-E_{t-1}-U_{t-1}\right), \text { and } \\
& U_{t}=\left(1-P_{U, E, t}-P_{U, N, t}\right) U_{t-1}+P_{E, U, t} E_{t-1}+P_{N, U, t}\left(1-E_{t-1}-U_{t-1}\right) .
\end{aligned}
$$

For the purpose of our decomposition it is easier to write these equations in matrix form. The state of the labor is represented by the vector

$$
\boldsymbol{s}_{t}=\left[\begin{array}{ll}
E_{t} & U_{t}
\end{array}\right]^{\prime}
$$

Given this definition, equations (3)-(4) can be written as

$$
\Delta s_{t}=s_{t}-s_{t-1}=\boldsymbol{d}_{t}+\boldsymbol{P}_{t} \boldsymbol{s}_{t-1}
$$

where

$$
\boldsymbol{d}_{t}=\left[\begin{array}{c}
P_{N, E, t} \\
P_{N, U, t}
\end{array}\right] \text {, and } \boldsymbol{P}_{t}=\left[\begin{array}{cc}
-P_{E, N, t}-P_{E, U, t}-P_{N, E, t} & P_{U, E, t}-P_{N, E, t} \\
P_{E, U, t}-P_{N, U, t} & -P_{U, E, t}-P_{U, N, t}-P_{N, U, t}
\end{array}\right] \text {. }
$$

For our decomposition we split the movements of the stocks into two parts. The first part is the changes in the long-run value of the state vector if the current flow probabilities remain unchanged. This often is referred to as the flow steady-state and it is the value $\overline{\boldsymbol{s}}_{t}$ for which $\Delta \boldsymbol{s}_{t}=\mathbf{0}$. For given matrices $\boldsymbol{d}_{t}$ and $\boldsymbol{P}_{t}$, it is equal to

$$
\overline{\boldsymbol{s}}_{t}=-\boldsymbol{P}_{t}^{-1} \boldsymbol{d}_{t}
$$

The second part is the changes in deviations from the steady state, $\left(\boldsymbol{s}_{t-1}-\overline{\boldsymbol{s}}_{t-1}\right)$. The change in the state vector is related to these two parts as follows

$$
\Delta s_{t}=\boldsymbol{P}_{t}\left(\boldsymbol{s}_{t-1}-\overline{\boldsymbol{s}}_{t}\right)=\boldsymbol{P}_{t}\left(\boldsymbol{s}_{t-1}-\overline{\boldsymbol{s}}_{t-1}\right)-\boldsymbol{P}_{t}\left(\overline{\boldsymbol{s}}_{t}-\overline{\boldsymbol{s}}_{t-1}\right) .
$$

\footnotetext{
${ }^{23}$ The estimated transition probabilities in Figure 6 are margin adjusted, using the method in Elsby et al. (2015) to satisfy these equations.
} 
Rearranging terms in (9), we can write the current deviation from the steady state as a function of the current change in the state vector. That is,

$$
\begin{aligned}
\left(\boldsymbol{s}_{t}-\overline{\boldsymbol{s}}_{t}\right) & =\left(\boldsymbol{I}+\boldsymbol{P}_{t}\right)\left(\boldsymbol{s}_{t-1}-\overline{\boldsymbol{s}}_{t-1}\right)-\left(\boldsymbol{I}+\boldsymbol{P}_{t}\right)\left(\overline{\boldsymbol{s}}_{t}-\overline{\boldsymbol{s}}_{t-1}\right) \\
& =\left(\boldsymbol{I}+\boldsymbol{P}_{t}\right) \boldsymbol{P}_{t}^{-1} \Delta \boldsymbol{s}_{t}
\end{aligned}
$$

This allows us to write the current change in the state as the sum of the transitional dynamics through the past change in the state and the changes in the steady state.

$$
\Delta \boldsymbol{s}_{t}=\boldsymbol{P}_{t}\left(\boldsymbol{I}+\boldsymbol{P}_{t-1}\right) \boldsymbol{P}_{t-1}^{-1} \Delta \boldsymbol{s}_{t-1}-\boldsymbol{P}_{t} \Delta \overline{\boldsymbol{s}}_{t}
$$

The final step is to attribute the changes in the steady state, i.e., $\Delta \overline{\boldsymbol{s}}_{t}$ to changes in the different matrices made up of transition probabilities. For this, we use that

$$
\Delta \boldsymbol{d}_{t}=-\frac{1}{2} \Delta \boldsymbol{P}_{t}\left(\overline{\boldsymbol{s}}_{t}+\overline{\boldsymbol{s}}_{t-1}\right)-\frac{1}{2}\left(\boldsymbol{P}_{t}+\boldsymbol{P}_{t-1}\right) \Delta \overline{\boldsymbol{s}}_{t}
$$

where

$$
\Delta \boldsymbol{d}_{t}=\sum_{s \in\{E, U, N\}} \sum_{s^{\prime} \in\{E, U, N\}} \frac{\partial \boldsymbol{d}_{t}}{\partial P_{s, s^{\prime}, t}} \Delta P_{s, s^{\prime}, t} \text {, and } \Delta \boldsymbol{P}_{t}=\sum_{s \in\{E, U, N\}} \sum_{s^{\prime} \in\{E, U, N\}} \frac{\partial \boldsymbol{P}_{t}}{\partial P_{s, s^{\prime}, t}} \Delta P_{s, s^{\prime}, t} .
$$

Using this we can trace the change in the steady state back to changes in the flow transitions that drive $\Delta \boldsymbol{d}_{t}$ and $\Delta \boldsymbol{P}_{t}$, which yields

$$
\Delta \overline{\boldsymbol{s}}_{t}=\left[\frac{1}{2}\left(\boldsymbol{P}_{t}+\boldsymbol{P}_{t-1}\right)\right]^{-1}\left[-\Delta \boldsymbol{d}_{t}-\frac{1}{2} \Delta \boldsymbol{P}_{t}\left(\overline{\boldsymbol{s}}_{t}+\overline{\boldsymbol{s}}_{t-1}\right)\right] .
$$

Combining equations (11) and (14), we write the change in the state vector as the sum of transitional dynamics plus the changes in the steady state attributable to the six different flow transition probabilities.

$$
\Delta \boldsymbol{s}_{t}=\boldsymbol{P}_{t}\left(\boldsymbol{I}+\boldsymbol{P}_{t-1}\right) \boldsymbol{P}_{t-1}^{-1} \Delta \boldsymbol{s}_{t-1}+\boldsymbol{P}_{t}\left(\boldsymbol{P}_{t}+\boldsymbol{P}_{t-1}\right)^{-1}\left[2 \Delta \boldsymbol{d}_{t}+\Delta \boldsymbol{P}_{t}\left(\overline{\boldsymbol{s}}_{t}+\overline{\boldsymbol{s}}_{t-1}\right)\right]
$$

This is a decomposition of changes in the state vector $\boldsymbol{s}_{t}$. The labor force participation rate is

$$
L F P R_{t}=E_{t}+U_{t}=\iota_{2}^{\prime} s_{t}
$$

where $\boldsymbol{\iota}_{2}$ is the 2 -dimensional summation operator, i.e., a column vector with ones. The de- 
composition we use for the $L F P R_{t}$ is

$$
\Delta L F P R_{t}=\boldsymbol{\iota}_{2}^{\prime} \boldsymbol{P}_{t}\left(\boldsymbol{I}+\boldsymbol{P}_{t-1}\right) \boldsymbol{P}_{t-1}^{-1} \Delta \boldsymbol{s}_{t-1}+\boldsymbol{\iota}_{2}^{\prime} \boldsymbol{P}_{t}\left(\boldsymbol{P}_{t}+\boldsymbol{P}_{t-1}\right)^{-1}\left[2 \Delta \boldsymbol{d}_{t}+\Delta \boldsymbol{P}_{t}\left(\overline{\boldsymbol{s}}_{t}+\overline{\boldsymbol{s}}_{t-1}\right)\right]
$$

While the expression looks complicated, the decomposition is intuitive. The labor force participation rate changes because the flows that shape it vary over time, resulting in changes in its flow-steady-state level. Moreover, there are transitional dynamics that take place as the stocks constantly try to catch up with the time-varying flow steady-state. The first term in (17) captures the extent to which the labor market is still catching up to previous changes in the steady state while the second term reflects how the current changes in the flow transition rates affect the flow steady-state of the labor market.

\subsection{Job-Loss and Job-Finding as the Driver of the Participation Cycle}

Our decomposition in (17) splits changes in the LFPR into contributions from changes in each of the six respective labor market flows and their past changes. In that respect, it goes beyond decomposing the changes in the participation rate due to contemporaneous changes in labor force exits and entry. While it is possible to track the effect of each of the six flows separately, it is clearer to group them into two categories: entry and exit and the cycle. ${ }^{24}$ Entry and exit capture the direct effect of labor force entry and exit while the cycle captures how past and present changes in job-finding and job loss - shifts within the labor force - affect the participation rate.

Entry and Exit. The entry component sums the effect of changes in the rates at which individuals flow into the labor force, $P_{N, E}$ and $P_{N, U}$ plotted in Figure 6, on the LFPR. Everything else equal, an increase in these rates puts upward pressure on the flow steady-state LFPR. The exit component captures the effect of changes in the rates at which people leave the labor force, both from employment $\left(P_{E, N}\right)$ as well as from unemployment $\left(P_{U, N}\right)$. Our decomposition captures the direct effect as well as the lagged effect of the transitional dynamics of the labor market adjusting to past changes in the flow steady state. It measures the cumulative effect of the changes in the flow rates plotted in panels (c), (d), (e) and (f) of Figure 6 on the LFPR.

Cycle. The cycle component, which we call the participation cycle in the rest of this paper, measures how changes in the job-loss $\left(P_{E, U}\right)$ and job-finding $\left(P_{U, E}\right)$ rates, plotted in panels (a) and (b) of Figure 6, affect movements in the participation rate. These are the flows within the labor force that most studies ignore since they have no direct effect on the contemporaneous

\footnotetext{
${ }^{24}$ For reference, we have included the results for all six flows in Figure C.4 in the Appendix
} 
LFPR. It might sound puzzling that these flows, that do not involve crossing the participation margin, affect the dynamics of the participation rate. The intuition comes from recognizing the stark differences in labor force attachment of unemployed and employed workers. As we have shown in Figure 5, the unemployed are less attached to the labor force than the employed. Specifically, $P_{U, N}$ which averages around 25 percent is multiple times larger than $P_{E, N}$, which averages 2.8 percent. Therefore, the higher the fraction of the labor force that is unemployed, i.e., the higher the unemployment rate, the more likely workers are to drop out of the labor force in the future. This mechanism, which works through the labor force attachment channel, puts downward pressure on the participation rate going forward when the unemployment rate increases.

Figure 7 plots the cumulative contribution of the entry/exit and cycle to the change in the LFPR since the start of 1978 for the total population for 1978-2019 in panel (a). ${ }^{25}$ The entry/exit component is the main driver of the long-run trend in the LFPR. Interestingly, it also exhibits a countercyclical pattern putting upward pressure on the LFPR during recessions and a downward pressure later in expansions. This finding challenges the popular view that the procyclicality of the participation rate has its origins in discouraged workers leaving the labor force during recessions and re-entering the labor force as labor market conditions improve. We find that the net contribution of labor force entry and exit is not procyclical at all. On the contrary, the entry/exit component is decisively countercyclical, pushing against the procyclical forces we identify.

It is the exit component that is responsible for the upward trend in participation from 1978 through 2000, largely driven by women (panel (c)). ${ }^{26}$ The increase in labor force participation among women was not because women was not because those who were not part of the labor force became more likely to join. Instead, it was driven by the increased attachment to the labor force of those women who already were part of it. ${ }^{27}$ While the entry component was relatively muted for women until the 2000s, it accounts for most of the decline since early 2000 in the participation rate of both men and women. ${ }^{28}$

To better visualize business-cycle variation, Figure 8 plots the cumulative contribution of the entry/exit and cycle components quantified by the decomposition for each business cycle

\footnotetext{
${ }^{25}$ We examine the COVID-19 Recession in Section 6

${ }^{26}$ Figure C.5 in the Appendix splits the entry and exit component in Figure 7 up into its two components.

${ }^{27}$ This is consistent with the main driver of the rise in the female labor force participation rate being increased participation of married women with children. Women started to work longer into their pregnancies and were able to keep their positions due to changes in social norms, more widespread availability of maternity leave, and advances in maternal health and childcare. As labor market interruptions declined, women's labor force attachment gradually increased, as shown in Albanesi and Şahin (2018).

${ }^{28}$ While we do not focus on the likely explanations for this pattern, the literature identified changing demographics and changes in eligibility for disability insurance as likely drivers of this pattern.
} 
starting at the trough in the unemployment rate, indicated by the vertical dashed lines. The figure reveals that the entry/exit component played no role in the procyclical fluctuations in participation. As we saw in panels (c) and (d) of Figure 6, both the average unemployed and employed worker are more attached to the labor force during recessions than during expansions. This decline in exit rate from participation in downturns puts upward pressure on the participation rate during recessions and in the earlier parts of expansions.

The mild procyclicality of the LFPR is due to the participation cycle. It is strongly procyclical and does not have a discernible trend. Therefore, it reveals the source of the procyclical pressures on participation: The rise in the unemployment rate at the onset of recessions puts downward pressure on participation because the likelihood that those in the labor force remain attached declines. This is because the composition of the labor force shifts towards unemployed workers who are less attached than the employed. In the later stages of expansions, workers in the labor force become more attached to the labor force as the pool of unemployed shrinks. This rise in attachment, which is achieved through lower job loss rates and better job finding prospects, puts upward pressure on the participation rate.

Attachment Wedge. If those who are unemployed were as attached to the labor force as the employed, then the cyclical component would have no effect on participation. To understand this, it is important to realize that the current change in the LFPR is a distributed lag of current and past changes in the flow steady-state. ${ }^{29}$ Because this lag structure is complicated, we focus on the change in the flow steady-state due to changes in the job-loss and job-finding rates, which we denote by $\triangle \overline{L F P R}_{t}^{c}$, to explain the intuition for what drives the cycle component in our decomposition. In Appendix A, we show that this equals

$$
\Delta \overline{L F P R}_{t}^{c}=-\frac{1}{D_{t}} \overline{\operatorname{LFPR}}_{t}\left(\bar{P}_{U, N, t}-\bar{P}_{E, N, t}\right)\left(\left(1-\bar{u}_{t}\right) \Delta P_{E, U, t}-\bar{u}_{t} \Delta P_{U, E, t}\right),
$$

where $\overline{L F P R}_{t}$ is the flow steady-state labor force participation rate and $\bar{u}_{t}$ is the flow steadystate unemployment rate, both averaged across periods $t$ and $t-1 . D_{t}$ is the determinant of $\overline{\boldsymbol{P}}_{t}=1 / 2\left(\boldsymbol{P}_{t}+\boldsymbol{P}_{t-1}\right), \bar{P}_{E, N, t}=1 / 2\left(P_{E, N, t}+P_{E, N, t-1}\right)$, and $\bar{P}_{U, N, t}=1 / 2\left(P_{U, N, t}+P_{U, N, t-1}\right){ }^{30}$ The third and fourth terms of this expression are the ones that matter the most for the intuition of what drives the participation cycle.

The third term is the difference between the rate that unemployed and employed workers leave the labor force: $\left(\bar{P}_{U, N, t}-\bar{P}_{E, N, t}\right)$. We refer to this term as the attachment wedge. It captures the difference in the attachment to the labor force of those unemployed versus those

\footnotetext{
${ }^{29}$ See Appendix A for a derivation of this lag expression.

${ }^{30}$ The determinant $D_{t}$ is positive in all periods for the observed transition probabilities in the data.
} 
employed. It is positive because the employed are more attached to the labor force than the unemployed, i.e., $\bar{P}_{U, N, t}>\bar{P}_{E, N, t}$. A positive attachment wedge is necessary for a procyclical participation cycle.

The fourth term, $\left(\left(1-\bar{u}_{t}\right) \Delta P_{E, U, t}-\bar{u}_{t} \Delta P_{U, E, t}\right)$, is the change in the flow steady-state unemployment rate due to changes in the job-loss and job-finding rates. It captures the shift in the composition of the labor force between unemployed and employed that is solely due to movements of persons between these two states and not due to movements across the participation margin.

Equation (18) is important because it shows that, to understand the procyclicality of the participation rate, it is essential to study the likelihood of workers exiting the labor force rather than workers entering the labor force. This likelihood is affected by the labor force status of individuals within the labor force since there is a quantitatively important attachment wedge between the unemployed and employed.

\subsection{The Magnitude of the Participation and Unemployment Cycles}

Now that we have identified the source and magnitude of procylical pressures on the participation rate, we can assess their effect on cyclical fluctuations on employment. As we discussed in Section 3, the cyclical pressures on the EPOP ratio come from both participation and unemployment. Therefore, it is natural to compare the impact of the participation cycle on the EPOP ratio with fluctuations in the unemployment rate, i.e., the unemployment cycle. To assess the relative importance of the participation and unemployment cycles, we first define the cyclical change in the employment-to-population ratio, $\triangle E P O P_{t}^{c}$, by rewriting equation (2) as

$$
\Delta E P O P_{t}^{c}=\underbrace{-\overline{L F P R}_{t} \Delta u_{t}}_{\text {unemployment cycle }}+\underbrace{\left(1-\bar{u}_{t}\right) \Delta L F P R_{t}^{c}}_{\text {participation cycle }},
$$

where $u_{t}$ is the unemployment rate and $L F P R_{t}^{c}$ is the cycle component from our decomposition.

Figure 9 plots the cumulative contribution to the change in the EPOP ratio of each of the two terms: the first one is the unemployment cycle defined as the change in the unemployment rate relative to its trough and the second term is the participation cycle. The figure shows that, even though the LFPR is only mildly procyclical, the procyclical forces that shape labor supply are of only slightly smaller magnitude than those captured in the unemployment cycle. Across the recessions in the figure, the trough in the participation cycle is, on average, about two-thirds that of the unemployment cycle. It also lags the unemployment trough by nine months, on average. This lag is longer during deeper recessions. 
We find that the cyclical pressures from participation and unemployment on the EPOP ratio are about the same later in expansions. This can be seen from both lines going up at about the same rate. Using Equation (19), this observation implies that, in the later stages of expansions,

$$
\Delta L F P R_{t}^{c} \approx \frac{\overline{L F P R}_{t}}{1-\bar{u}_{t}} \Delta u_{t} \approx 0.65 \Delta u_{t} .
$$

Therefore in a strong economy, at the end of an expansion, a 1-percentage-point decline in the unemployment rate results in cyclical upward pressure on the participation rate of 0.65 percentage point. Note that this is very similar to the estimates of Perry and Okun from the early 1970s. They argued that a reduction of the unemployment rate from 5 to 4 percent would increase the participation rate by 0.65 (see Perry, 1971, page 540) and (see Okun, 1973, page 211). We refer to this rule of thumb as the Perry-Okun rule.

A comparison of the results in panels (b) and (c) of Figure 9 also shows that the qualitative properties of the cyclical forces affecting employment are very similar across genders. The most notable difference is that for women those related to participation are relatively more important than for men. This can be seen from the relative size of the troughs in the unemployment cycle and participation cycle lines in panels (b) and (c) in the figure. ${ }^{31}$ For both men and women, Perry-Okun rule is a reasonable approximation. Equation (20) implies that a 1-percent decline in the unemployment rate at the tail end of the expansion results in cyclical pressures on the labor force participation rate equal to $L F P R_{t} /\left(1-u_{t}\right)$ percentage points. For men, this would be around 0.70 percentage point, and for women 0.6 percentage point due to differences in their LFPRs.

Even though our results are in line with the Perry-Okun rule, the source of the cyclical increase in the participation rate is different from what they emphasized half a century ago. Okun's explanation was that a high-pressure economy generates "... additional jobs for people who do not actively seek work in a slack labor market but nonetheless take jobs when they become available." If this were the case we would see a substantial increase in the contribution of the entry component of our decomposition late in the cycle. But that is not the case. Instead, it appears that a tight labor market keeps people employed who likely would leave the labor force if they lost their jobs.

The fact that increases in participation in tight labor markets are not because entry rates into participation increase when the unemployment rate is close to or below its natural rate but rather because exits out of the labor force decline already was emphasized by Elsby et al.

\footnotetext{
${ }^{31}$ The results in the figure suggest that the relative importance of the participation margin during the depth of recessions has increased since 1994. However, this is due to the effect of the 1994 Current Population Survey (CPS) redesign on the estimated transition probabilities.
} 
(2019) and Barnichon (2019). Our analysis provides an important nuance to this observation. Namely, what is crucial for understanding fluctuations in exits out of labor is the evolution of the composition of the labor force, in terms of unemployed versus employed. This composition is driven mainly by job-loss and job-finding rates, which are the margins that monetary policy likely has the most influence on, as argued by White (White, 2018).

\section{Unevenness and the Maximum Employment Mandate}

We have emphasized that the aggregate procyclical forces on participation, i.e., the participation cycle, satisfy the Perry-Okun rule. Both Perry and Okun conjectured that the reason for this procyclical upward pressure was that the favorable job opportunities and higher wages in a hot labor market draw in marginally attached workers who stay on the sidelines of the labor market when it is weak. They emphasized that these marginal workers are disproportionately young workers, women, and Black men.

This conjecture is at the heart of the prevailing narrative about the labor-market effect of running a "hot" economy: The uneven effect of recessions across groups pushes the most marginalized workers out of the labor force and they only rejoin when labor-market conditions are very favorable near the end of an expansion. ${ }^{32}$ If this prevailing narrative were correct, then it would make sense for policy makers to shift their attention from the aggregate unemployment rate to the participation rates of marginalized groups in the later stages of expansions to assess progress toward the goal of maximum employment - especially in light of the broadbased and inclusive nature of the mandate. In this section we argue that, even though some groups are affected by recessions more than others, such a shift is not necessary.

In subsection 5.1 we show that the participation cycle amplifies the unemployment cycle: groups that experience higher increases in their unemployment rates during recessions also face more cyclical downward pressures on participation. However, in spite of the differential effect of recessions on different groups, the core forces that put upward pressure on their participation rates when the labor market is strong are the same ones that drive down their unemployment rates. Therefore, there is no need to shift attention from the unemployment rate to the participation rates of marginalized groups. Declines in unemployment naturally result in upward pressures on participation for all groups -including the marginalized ones.

\footnotetext{
${ }^{32}$ See, for example, Clark and Summers (1981) and Aaronson et al. (2019), for reiterations of this narrative.
} 


\subsection{Heterogeneity in Unemployment and Participation Cycles}

To put the unevenness in the participation cycle across groups in context, we first consider crossgroup differentials in the incidence and increases in unemployment over the business cycle. It is well known that these differentials are large. ${ }^{33}$ Columns " $\vec{u}$ " and " $\Delta u$ " in Table 1, confirm that groups with higher average unemployment rates tend to see larger increases in these rates during recessions as emphasized by Justin Wolfers in his discussion of Aaronson et al. (2019). This is true for men, workers 16-24 years old, workers with less formal education, and Black and Hispanic workers.

Figure 11 plots the cyclical run ups and declines in unemployment rates by business cycle for all groups by topic. It shows that those groups that see large increases in their unemployment rates at the onset of recessions tend to see steep declines in their unemployment rates in expansions. The question relevant for our analysis, of course, is to what extent these improvements in unemployment rates translate into upward pressures on participation rates. As we discussed in the previous section, what is crucial for the transmission of improvements in job-loss and job-finding to increases in the participation rate is the attachment wedge. Table 1 also reports the average attachment wedge, as well as average participation rates, for the groups we analyze over our sample period. The attachment wedge is positive for all groups and those with higher participation rates tend to have lower attachment wedges. These positive attachment wedges imply that the participation cycle results in procyclical pressures on the participation rate for all groups.

To compare the relative importance of unemployment fluctuations and the participation cycle for employment, we convert them into percentage point changes in the EPOP ratio. In particular, we use equation (19) to define the cyclical change in the EPOP ratio, $\triangle E P O P_{i, t}^{c}$ for each group $i$, as

$$
\Delta E P O P_{i, t}^{c}=\underbrace{-\overline{L F P R}_{i, t} \Delta u_{i, t}}_{\text {unemployment cycle }}+\underbrace{\left(1-\bar{u}_{i, t}\right) \Delta L F P R_{i, t}^{c}}_{\text {participation cycle }} .
$$

Four main findings emerge from the comparison of the unemployment and participation cycles across groups:

The participation cycle is large for all groups. The columns " $\Delta u$ cycle trough" and "LFPR $R^{c}$ trough" in Table 1 contain the average troughs in the unemployment and participation cycles across recession by group. The "trough ratio" reports the ratio of these two columns. At the depth of recessions, the downward pressure that the participation cycle puts on the EPOP ratio varies between 45 to 80 percent of the unemployment cycle across groups.

\footnotetext{
${ }^{33}$ See Perry (1971), Perry (1972), Clark and Summers (1981), Elsby et al. (2010), Hoynes et al. (2012) and more recently Aaronson et al. (2019).
} 
The participation cycle amplifies the unevenness in the unemployment cycle. The participation cycle amplifies the unevenness in the unemployment cycles across groups as seen by comparing columns " $\Delta u$ cycle trough" and " $L F P R^{c}$ trough" in Table 1. Groups with higher increases in their unemployment rates, i.e., lower troughs in their unemployment cycles, also have lower troughs in their participation cycles. This can also be seen by comparing the time series in Figures 12 and 13.

We find that both the unemployment and participation cycles for women are more muted than for men as panels (a) in Figures 12 and 13 show. This finding is consistent with recessions typically considered as mancessions due to men being more likely to work in cyclically sensitive sectors such as construction and manufacturing as analyzed in Şahin et al. (2010). However, in relative terms, the participation cycle makes up a larger part of the cyclical employment shortfall in recessions for women than for men. The marginalized groups that are often referred to in the prevailing narrative about procyclical upward pressures on participation when the labor market strong, such as young workers, those with a high school degree or less, as well as Black and Hispanic workers, all have both outsized unemployment and participation cycles compared with their counterparts. ${ }^{34}$

The participation cycle prolongs the employment cycle. The participation cycle lags the unemployment cycle for all groups and therefore prolongs the employment cycle. This can be seen from the column " $L F P R^{c}$ lag" in Table 1. Younger workers' unemployment and participation cycles typically bounce back faster while workers older than 55 experience prolonged participation cycles. ${ }^{35}$

The recovery of the participation cycle is uneven. The final observation from comparing the results in Table 1 and time series in Figures 12 and 13 is that the groups that experience deeper unemployment and participation cycles also see larger upward pressures on their participation rates during the latter parts of recoveries. This is especially notable for workers with a high school diploma as well as Black and Hispanic workers during the 2014-19 period. Consistent with the evidence in Aaronson et al. (2019), the groups hardest hit during recessions have the largest cyclical upward pressures on participation during recoveries and expansions. It also is noteworthy that the improvements in both unemployment and participation cycles flatten

\footnotetext{
${ }^{34}$ According to panels (b) in Figures 12 and 13, while the unemployment cycle is deeper for younger workers, the participation cycle is the most important for prime-age workers. The differences by educational attainment in panels (c) of Figures 12 and 13 imply that both unemployment and participation cycles are shallower for more educated workers. Panels (d) in Figures 12 and 13 show that the participation cycles by race and ethnicity vary less than unemployment cycles with the exception of end of expansions when the cyclical upward pressure is more pronounced for Black and Hispanic workers.

${ }^{35}$ Comparisons of these lags across groups are less accurate due to the noisy nature of the group-specific monthly labor market flows data.
} 
out for more educated workers earlier than for workers with less formal education.

\subsection{Employment Stability and the "Temperature" of the Economy}

Our earlier findings about differences in the incidence of unemployment and procyclicality of participation across groups largely are in line with the facts emphasized in support of the prevailing narrative that upward pressures on participation during a "hot" labor market come from marginalized groups of workers. However, instead of marginalized workers being drawn into the labor force when the labor market is strong, it is the increased employment stability for those in the labor force that reduces the likelihood of current participants dropping out. The procyclical upward pressures on participation during strong labor markets come from the cycle component and not from the entry and exit component in our decomposition. This is one of the qualitative properties of the cyclical forces that drive participation that is common across all groups that we consider. If it were marginalized workers (re-)entering the labor force, then this would be reflected by changes in the entry rates from nonparticipation, especially for young workers, women, and Blacks and African Americans. But this is not the case.

Clark and Summers (1981) take the prevailing narrative even a step further. They argue that marginal workers that enter the labor market when it is tight put upward pressure on the unemployment rate. This simply is incorrect. As we showed when we discussed Figure 6 in Section 4 , the total entry rate from nonparticipation into the labor force does not fluctuate over the business cycle. However, those that do enter are more likely to enter into employment directly rather than unemployment when the labor market is strong. Such labor force entries lower the unemployment rate rather than raise it, as suggested by Clark and Summers (1981).

The emphasis on groups of marginalized workers in the prevailing narrative suggests that their procyclical pressures on participation are different in origin from those of other workers. If the source of procyclical upward pressures on participation is marginalized workers rejoining the labor force, then these pressures should increase or dissipate depending on whether the share of marginalized workers goes up or down over time. Because of this, Perry noted that his rule of thumb is not time invariant and wrote that "the effect of unemployment on the overall labor force participation rate varies through time with the changing composition of the work force." (see Perry, 1971, page 540). Little did he know, however, that his rule of thumb still would be appropriate 50 years later after a rise in participation by women, the aging of the work force and increased diversity of the working-age population.

The Perry-Okun rule has held up over time and also approximately holds for each of the groups that we analyze. As we discussed in Section 4, the Perry-Okun rule holds if the changes 
in the unemployment and participation cycles are approximately equal during times when the labor market is strong. Figure 9 shows that this has been true for the last four labor market expansions. Contrary to Perry's assumption, his rule of thumb has held up over time, in spite of major changes in the composition of the working-age population. This is a consequence of the different mechanism at play rather than the entry mechanism Perry and Okun emphasized.

What is even more remarkable is that the Perry-Okun rule holds approximately for all groups that we analyze. This is shown in Table 2. It shows that the average deviations from the PerryOkun rule in terms of percentage points in the EPOP ratio are close to zero for all groups we distinguish. These deviations are measured as the average difference between the sum of the two terms on the right-hand side of (21) over 12 months during periods when the labor market is expanding and the unemployment rate is lower than the natural rate plus 0.5 percentage point. ${ }^{36}$ For all groups we consider, when the labor market is strong the procyclical upward pressure on the participation rate is approximately equal to $L F P R_{i, t} /\left(1-u_{i, t}\right)$ percentage points for a 1-percentage-point decline in the unemployment rate.

Our decomposition clearly points to the source of this upward pressure: the participation cycle. It reflects that those in the labor force endure fewer and shorter employment interruptions when the job-loss rate $\left(P_{E, U}\right)$ goes down, the job-finding rate $\left(P_{U, E}\right)$ increases, and the unemployment rate declines. This increased employment stability during a "hot" labor market reduces the likelihood that people drop out of the labor force.

The employment-stability mechanism that we identify provides an explanation for how declines in the unemployment rate push the participation rate upward at the tail end of expansions that is very different from the prevailing narrative about the re-entry of marginalized workers. The latter emphasizes the importance of unevenness, in the sense of some groups being more marginalized than others, while, as we have shown in Table 2, our employment-stability mechanism is at play for all groups in our data. Therefore, the improvements in the participation rate in expansions are not limited to the pool of discouraged or marginal workers that often are referred to as a measure of sidelined workers.

\section{COVID-19 Recession}

So far, we have limited our analysis of the participation cycle to the pre-COVID-19 recessions in our sample. An extensive body of research has analyzed the labor market effect of the

\footnotetext{
${ }^{36}$ The specific measure of the natural rate that we use is the CBO's Noncyclical Rate of Unemployment (NRoU). The mathematical details of this definition are in Appendix A.
} 
COVID-19 pandemic that caused unprecedented and abrupt disruptions in the labor market. ${ }^{37}$ Our focus in this section is not to repeat the analyses in these insightful papers but rather to show how our method can be used for the real-time assessment of the participation cycle at the time we wrote this paper, in July 2021, 15 months after the start of the pandemic.

The pandemic resulted in a very short but deep recession, starting in March 2021 and ending in May 2021, that was characterized by unprecedented swings in labor demand and labor supply. The unemployment rate increased from 3.5 percent to 14.8 percent in two months while the participation rate dropped from 63.3 percent to 60.2 percent. Since the end of the recession, the unemployment rate has declined to 5.9 percent and participation rate has partially recovered to 61.6 percent.

The results from our decomposition are only meaningful when changes in flow rates are relatively small and persistent - as it was the case until the COVID-19 Recession. In subsection 6.1 we show that the unprecedented ups and downs of the labor market in 2020 were driven by very large changes in flow rates, making our decomposition ineffective for assessing monthto-month changes in the participation cycle from February through December 2020. However, since the start of 2021, movements in labor market flow rates have stabilized. As a result, the unemployment rate, the LFPR and the EPOP ratio were very close to their flow steady-state values in June 2021. This allows us to infer the change in the participation cycle between February 2020 and June 2021 by decomposing the change in the flow steady-state LFPR over that period.

In subsection 6.2 we present the results from this decomposition which show that almost all of the decline in the participation rate since the onset of the pandemic is due to changes in job-loss and job-finding rates and thus accounted for by the participation cycle. This is not only true in the aggregate, but also for all of the groups we consider. In subsection 6.3 we show that these similarities in the source of the participation declines across groups is indicative of a broader pattern: The very uneven effect of COVID-19 on different groups in 2020 largely has subsided in 2021.

A longer-run historical comparison, in subsection 6.4, reveals that both the unemployment rate and participation cycle in June 2021 are comparable with those in the early fall of 2014. Using the labor market expansion after 2014 as a baseline, we show that the participation cycle is likely to lag the recovery in the unemployment rate in coming years, just like it did in previous recoveries.

\footnotetext{
${ }^{37}$ See for example Alon et al. (2021), Bartik et al. (2020), Cajner et al. (2020), Forsythe et al. (2020), Ganong et al. (2020).
} 


\subsection{Unprecedented Changes in Labor Market Flows in 2020}

The labor market dynamics in the United States during the six months after the start of the pandemic in 2020 were an enormous historical outlier. This can be seen from Figure 14, which plots the time series of the six labor market flows starting in 2007 to facilitate the comparison with the Great Recession. ${ }^{38}$

The changes in job-loss and job-finding rates from March 2020 through August 2020 were multiple orders of magnitude higher than any previous changes. Panel (a) of Figure 14 shows the sharp unprecedented increase in the employment-to-unemployment flow rate that coincided with the job losses associated with the broad implementation of lockdowns in the United States. During the lockdown very few workers got hired as well, resulting in a drop in the job-finding rate as seen in panel (b) of Figure 14. The job-loss rate fell and the job-finding rate rebounded quickly as many workers on temporary layoff returned to their pre-pandemic jobs (Forsythe et al. , 2020). For the rest of our analysis in this section it is important to note that the declines in the job-loss rate, $P_{E, U}$, since April 2020 only partly offset its historical increase. The job-loss rate in June 2021 remains elevated compared with February 2020. In addition, the job-finding rate, $P_{U, E}$, is substantially lower in June 2021 than it was right before the pandemic in February 2020.

Panels (c) and (d) of Figure 14 show the evolution of exits from the labor force. Exit rates from the labor force both from employment and unemployment jumped to record highs at the onset of the pandemic. However, these record levels of outflows from the labor force were only temporary. In 2021, the rate at which workers flow from employment to nonparticipation, $P_{E, N}$, has been hovering around the average level from the year before the pandemic as panel (c) of Figure 14 shows. Those who are unemployed in June 2021 are, on average, more attached to the labor force than those who were unemployed right before the recession. This can be seen from panel (d) in Figure 14, that shows that the peak in $P_{U, N}$ in April 2021 was followed by a sharp reversal. Declines in $P_{U, N}$ are common during recessions. They tend to reflect that the increased incidence of unemployment during recessions skews the composition of the unemployed towards those with a higher level of labor-force attachment (Elsby et al. , 2015). In addition, the increased coverage and generosity of unemployment insurance implemented as part of the Coronavirus Aid, Relief, and Economic Security Act (CARES Act) is likely to have resulted in declines in exits out of the labor force from unemployment. ${ }^{39}$

Panels (e) and (f) of Figure 14 plots the entry rates into employment and unemployment

\footnotetext{
${ }^{38}$ For a longer historical comparison, please refer to Figure 6.

${ }^{39}$ See Farber et al. (2015) for an analysis of the effect of UI extensions on $P_{U, N}$ in the wake of the Great Recession.
} 
from nonparticipation. The drop in the entry rate into employment, $P_{N, E}$ in panel (e) of Figure 14, shows that entry into employment from out of the labor force was subdued during the lockdowns. As the economy partially reopened in the latter half of the summer of 2020, entry into the labor force picked up, mostly from persons entering into unemployment, shown in panel (f) of Figure 14, rather than employment. It is important to emphasize for what is to come is that the total entry rate into the labor force in June 2021 is similar to that in February 2020. The difference is that a larger share of the labor force entries occurs into unemployment rather than employment. This reflects the deterioration in labor market conditions that labor force entrants faced in the summer of 2021 compared with the beginning of 2020.

The large swings in flow rates from March 2020 through August 2020 resulted in large movements in the flow steady-state unemployment-to-population (UPOP), LFPR, and EPOP ratio. While there were economically significant differences between flow steady-state and actual values of these stocks in the historical data, these deviations never have been as large as during the COVID-19 Recession. Figure 15 plots the actual and flow steady-state values for these three respective stocks. The figure reveals that the pandemic had an especially large effect on labor supply. Panel (b) of Figure 15 shows that if workers continued to flow between labor market states at the rates they did at the onset of the pandemic, the participation rate would have settled down at its April 2020 flow steady-state, $\overline{L F P R}_{t}$, value of 29.6 percent. The actual participation rate reached a low of 60.2 percent in April 2020, 3.2 percentage points lower than in February 2020. The flow steady-state LFPR rebounded in May and June 2020, peaking at 69.1 percent as workers re-entered the labor force when the economy partially reopened.

These swings in $\overline{L F P R}_{t}$ are problematic for our decomposition. Our decomposition splits up the changes in the flow steady-state UPOP and EPOP ratio up into parts due the different flow rates, using equation (14). As can be seen from (14), it evaluates the contributions of the changes in the flows at the average flow steady-state, ${ }^{1} / 2\left(\bar{s}_{t}+\overline{\boldsymbol{s}}_{t-1}\right)$, in the two periods between which the change in the labor market is evaluated. This approach works well and provides clearly interpretable results if the flow steady-state, $\overline{\boldsymbol{s}}_{t}$, does not change much as is the case in the historical data. However, the swings in the flow steady-state stocks, especially EPOP ratio and LFPR, between February 2020 and December 2020 are of an order of magnitude larger, making the results of our decomposition of the month-to-month changes in the LFPR hard to interpret during that period. For this reason, we do not present such results for the period from February 2020 until June 2021.

Instead, we pursue another approach, inspired by the observation in Figure 15 that, in spite of all the fluctuations between February 2020 and June 2021, the actual UPOP and EPOP ratios were close to their flow steady-state values both at the beginning and end of that period. 
Thus, the bulk of the changes in the labor market since the beginning of the pandemic is captured by changes in the flow steady-state. With that in mind, we decompose the changes in the flow steady-state from February 2020 until June 2021 to examine their flow origins.

\subsection{Bulk of Decline in Participation Since Start of Pandemic Cyclical}

We do not base our comparison of the pre-pandemic labor market with the current one on two specific reference months given that flow steady-states fluctuate month by month partly because of measurement error in the transition probabilities. Instead, we evaluate the difference between the flow steady-state implied by the average flow rates over the six months before the pandemic, $s^{b}$, and that consistent with the average flow rates over the first six months of 2021, $s^{a}$.

Using (14), we split this difference up as follows

$$
\overline{\boldsymbol{s}}^{a}-\overline{\boldsymbol{s}}^{b}=\left[\frac{1}{2}\left(\boldsymbol{P}^{a}+\boldsymbol{P}^{b}\right)\right]^{-1}\left[-\left(\boldsymbol{d}^{a}-\boldsymbol{d}^{b}\right)-\frac{1}{2}\left(\boldsymbol{P}^{a}-\boldsymbol{P}^{b}\right)\left(\overline{\boldsymbol{s}}^{a}+\overline{\boldsymbol{s}}^{b}\right)\right],
$$

where $\left(\boldsymbol{d}^{a}-\boldsymbol{d}^{b}\right)$ and $\left(\boldsymbol{P}^{a}-\boldsymbol{P}^{b}\right)$ capture the changes in the six average flow transition probabilities between labor market states from before the pandemic to the first half of 2021 .

The results of this decomposition are summarized in the first row of the top half of Table 3. It reveals that the cycle component accounts for 1.5 percentage points of the 1.7 percentage points of the decline in the LFPR relative to its pre-pandemic level. The contribution of entry and exit is quantitatively negligible and -0.2 percentage point of the actual change is not accounted for by the movement in the flow steady-state. Therefore, the main source of the decline in the participation rate since the onset of the pandemic is the deterioration of job-loss and job-finding rates, not entry and exit rates from the labor force.

The irrelevance of entry and exit rates for the assessment of the current shortfall in participation might sound contradictory to the discussions about workers leaving the labor force for health concerns, retirements, and child- and elderly-care responsibilities during the pandemic. All of these are reflected in the flow rates we discussed in the context of Figure 14. However, our results in Table 3 exploit the fact that the LFPR currently is close to its flow steady state. Which implies, independent of what flow rates were in the past, that if the flow rates remained at their current level, the LFPR would barely change going forward. Moreover, this implies that future changes in the participation rate will be driven by changes in the flow rates rather than by their path over the past 15 months. 


\subsection{Uneven Effect of COVID-19 Largely Has Subsided}

The sudden and unexpected COVID Recession had unequal adverse effects on different groups of the workforce, especially at its onset in early 2020. As we documented in Section 5, recessions always tend to have an uneven impact across groups in the labor market. However, the nature of the shock in the COVID recession affected several groups that typically are less affected by business cycle fluctuations at the onset of the recession. The age-biased health risk imposed by the novel coronavirus and change in the trade-off between market work and home production likely were reasons for these patterns. Despite these uneven effects, there was a broad-based quick reversal of the effects of the shock in unemployment and labor force participation rates. Figures 16 and 17 plot the changes in unemployment and participation rates by groups, organized by topic, for the COVID pandemic together with the Great Recession. These figures reveal the differential adverse effects of the abrupt shock in early 2020. Women and workers older than 55-who typically are less prone to cyclical fluctuations in the labor market-were more adversely affected in early 2020.

A well-known stylized fact about U.S. recessions is their disproportionate effect on the employment of men. The COVID Recession deviated from the so-called man-cession pattern and has been labeled as the she-cession. ${ }^{40}$ The unemployment rate for women increased 12.7 percentage points while the rate for men increased 9.2 percentage points. This divergence, however, was short-lived. As of June 2021, the unemployment rates of both men and women are about 2.5 percentage points higher than in February 2020.

Recessions typically have more adverse effects on the labor market outcomes of younger workers. The same happened during the COVID-19 Recession. Workers ages 16 to 24 experienced the sharpest increase in their unemployment rates and the biggest drop in their participation rates. However, there were some striking differences between the COVID-19 Recession and the Great Recession. The outcomes of younger workers recovered faster than for older workers. This is in sharp contrast to the Great Recession. While the LFPR of workers 55 and older increased throughout, the LFPR of those 16-24 remained depressed.

The effects of the COVID-19 Recession also varied by race and ethnicity, especially at the beginning of the pandemic. The unemployment rate increased from 4.4\% in February 2020 to 18.9\% in April for Hispanic workers, which was substantially higher than the increase for white and Black workers. The decline in the unemployment rate also was uneven, with the increase in the unemployment rate being more persistent for Black workers.

Our steady-state decomposition reported on the top half of Table 3 digs deeper into origins

\footnotetext{
${ }^{40}$ See Alon et al. (2021) for a detailed analysis of gender differences in labor market outcomes in the COVID19 Recession.
} 
of the depressed participation rates which is common to all groups. We find that for all groups, a bulk of the declines in participation is due to the participation cycle varying from at least 50 percent to almost 100 percent. While bulk of the shortfall in the LFPR can be attributable to the cycle for all groups, we find that for women, workers older than 55, workers with high school diploma, Black, and Hispanic workers, there is weakness in excess of what we attribute to the cycle. This is consistent with the July 2021 Monetary Policy Report (Board of Governors of the Federal Reserve System, 2021), which identified retirements and care-giving responsibilities as the primary reasons for remaining shortfall in labor force participation rate.

The health risks associated with the pandemic have accelerated labor force exits into retirement in 2020 and are now reflected by a 0.6 percentage point drag from net entry on the participation rate for workers older than 55. For many workers retirement is not a fully-absorbing state. Faberman et al. (2020) and Ameriks et al. (2020) document the desire of many retirees to work at flexible jobs with lower hours. That desire is still subdued by the ongoing health crisis. Hence, there is still a lingering drag on participation, compared to February 2020, from the low entry rate of older workers. Ongoing family responsibilities are having a similar effect on the entry rate for women. In addition to the shortfall due to net entry, for all these groups the actual decline in the participation rate substantially exceeds that of the flow steady-state that we decompose. This suggests that, contrary to for the whole population, these groups face upward pressures on their participation rates coming from continued transitional dynamics from the large shocks to the flow rates in 2020.

Despite this unevenness at the onset of the recession - part of which was specific to the COVID-19 Recession - the sharp increase in unemployment and the drastic drop in the LFPR partially reversed for all groups we analyze. Interestingly, the labor market outcomes as of June 2021 exhibit a less uneven pattern than in the recovery period from the Great Recession. The sources of the elevated unemployment rates and depressed participation rates also are similar across groups.

\subsection{Similarities Between Spring 2021 and Fall 2014}

After the quick partial reversal of the negative labor-market effect of the pandemic, the state of the labor market in June 2021, 15 months after its start, resembles that of September 2014, 81 months after the start of the Great Recession. At 5.9 percent, the unemployment rate in June 2021 is the same as in September 2014. Figure 14 shows that the current levels of the flow rates also are comparable with those in September 2014. The main difference is that the participation rate is 1.2 percentage points lower now than in the fall of 2014. This lower level of 
the participation rate, however, is not because the deterioration in the participation cycle during the COVID-19 Recession is much larger than the cyclical gains made during the extended labor market recovery from 2014 through 2019. Showing this requires decomposing the change in the flow steady-state LFPR between the early fall of 2014 and the first half of 2021 in the same way we did earlier for that between February 2020 and June 2021. The results are reported in the bottom half of Table 3. The "cycle" column of the row labeled "Total" shows that the estimated cyclical downward pressures on participation in 2021 are 0.4 percentage points lower than those in 2014.

This finding has three important implications. First of all, in spite of a lower participation rate, the cyclical downward pressures on participation in 2021 are close to in 2014. Thus, the similarities between early fall 2014 and the summer of 2021 extend beyond the unemployment and labor market flow rates to the participation cycle.

The second is that it provides information about the average annual trend decline in LFPR. If the participation cycle now is comparable with that in September 2014, as the table suggests, then this implies that most of the 1.2-percentage-point decline in the participation rate from September 2014 through June 2021 is due to the secular downward trend in the participation rate. This observation suggests that the annual average decline in trend participation was about 0.17 percentage points a year during that period. ${ }^{41}$ This is in line with the estimate of the $\mathrm{CBO}$ of around 0.2 percentage points a year and slightly lower than the cohort-based estimates presented in Figure $3{ }^{42}$

The third implication is that the cyclical gains in participation that accumulated from 2014 through 2019 have not completely been erased by the COVID-19 Recession. On the contrary, the results by group in the "cycle" column of the second half of Table 3 show that cyclical downward pressures on the participation rates of young workers, those with less than a high school education, as well as Black or African Americans are all estimated to be a percentage point or more lower now than in the wake of the Great Recession. Put differently, the expansionary labor market in the 2014-2019 period helped create employment stability for these groups, which increased their attachment to the labor force. Even though the COVID-19 shock brought the participation cycle to a similar point as in September 2014, these groups still carried over part of the gains of the previous expansion, as evident in the differences in the cycle component in the second half of Table 3.

\footnotetext{
${ }^{41}$ This assumes that the participation cycle in September 2014 is the same as in June 2021. If one assumes that the participation cycle now is 0.4 higher, which is our point estimate in Table 3, then this would imply a 0.11 percentage point annual trend decline in participation.

${ }^{42}$ The analysis by Aaronson et al. (2006), Aaronson et al. (2012), Zandweghe (2012), Aaronson et al. (2014), and Hornstein et al. (2018) imply average annual trend declines in the LFPR of between 0.25 to 0.30 percentage points.
} 
Motivated by the similarities between September 2014 and June 2021 that we pointed out, we consider two projections for the unemployment and labor force participation rates and their cyclical contributions to the EPOP ratio. These projections use the state of the labor market as of June 2021 as the starting point and trace how the participation cycle would evolve as the unemployment rate reaches to 3.5 percent, albeit at different paces. ${ }^{43}$ They use the joint dynamics of flows we observed in the 2014-19 period as a benchmark. We do not consider these projections as forecasts since there are still many reasons to believe that the dynamics will evolve differently. These projections are shown in Figure 18.

The first projection, labeled "Post-2014 recovery" is constructed under the assumption that from June 2021 onwards the flow rates follow the same path as they did from September 2014 through February 2020. ${ }^{44}$ The blue line in panel (a) of Figure 18 shows that, for this path of the flow rates, the unemployment rate declines from 5.9 percent in June 2021 to 3.5 percent at the end of 2026. The solid lines in panel (b) of Figure 18 show the unemployment and participation cycles implied by this path. The starting points of the lines are determined by our estimate that, currently (in June 2021) the unemployment and the participation cycles each put downward pressure of 1.5 percentage points on the EPOP ratio compared with February 2020. Thus, the current total cyclical shortfall in employment is 3 percent of the civilian noninstitutionalized population. That is, about 7.8 million persons are not employed in June 2021 who would be employed if the cyclical pressures on employment were the same as right before the pandemic. This amounts to about 7.25 million nonfarm payroll jobs. In this scenario, the downward cyclical pressures on the EPOP dissipate more slowly than after 2014. This is because the participation cycle lags the unemployment cycle more in this scenario than it did in the wake of the Great Recession. In fact, our projections suggest that the participation cycle does not reach the same level in this scenario as it did in the strong labor market of 2018 and 2019. Consistent with the Perry-Okun rule, improvements in both cycles, as reflected in the slope of their lines, are of the same order of magnitude starting in 2024.

In spite of all the similarities between September 2014 and June 2021, there are also noteworthy differences. The COVID-19 Recession was an outlier in terms of the extensive use of temporary layoffs by employers. At the onset of the pandemic in April 2020, 77.9 percent of the unemployed reported being on temporary layoff. While this ratio declined to 19 percent

\footnotetext{
${ }^{43}$ We project the unemployment rate to decline to its pre-pandemic levels in both scenarios given the prevailing view that there is little increase in the natural rate of unemployment. For example, Crump et al. (2021) estimate that the natural rate of unemployment is 4.2 percent in 2021; the CBO's Noncyclical Rate of Unemployment (NROU) is 4.5 percent for 2021Q1 and the SEP estimates for longer-run unemployment rate ranged between 3.5 percent to 4.5 percent in June 2021.

${ }^{44}$ The exact path we choose includes a correction for the current deviation of the flow rates from those in September 2014, as explained in equations (38)-(40) in the Appendix.
} 
in June 2021, as these workers have been gradually recalled to their jobs, it remains elevated compared to September 2014 when it was 10.2 percent. In addition, employer-side measures suggest a potentially faster recovery than the Great Recession. Layoffs implied by the BLS' Job Openings and Labor Turnover Survey (JOLTS) are lower than the transition rate of workers from employment to unemployment would suggest. Moreover, the vacancy rate was at its historical high in May 2021.

These factors suggest the potential for a more accelerated recovery compared with the Great Recession, as penciled in in the Survey of Economic Projections (SEP) of the FOMC. In September 2014, projections for the unemployment rate for the fourth quarter of 2016 were between 5.1 percent and 5.4 percent according to the SEP. At that time, the FOMC projected, on average, a decline of less than 1 percentage point in the unemployment rate within two years, reflecting the expectations for a prolonged recovery in the labor market. On the contrary, the median unemployment rate projection for the fourth quarter of 2022 was 3.8 percent according to the SEP released in June 2021. This is a decline of more than 2 percentage points in the unemployment rate in less than one and a half years.

With the SEP in mind, our second projection is based on a scenario in which the labor market recovers three times as fast as it did after September 2014. It is labeled "Accelerated post-2014 recovery" in Figure 18. Panel (a) of Figure 18 shows that the unemployment rate declines much faster under this scenario, to 3.8 percent at the end of 2022 and 3.5 percent at the end of 2023. The dashed lines in panel (b) of Figure 18 show that the participation cycle will lag the unemployment cycle even more in this accelerated recovery. This reflects the fact that the adjustment dynamics of the participation rate in response to changes in flow rates are much slower than those of the unemployment rate. In this case, the Perry-Okun rule does not provide a good rule of thumb. Instead, one might have to rely on a real-time assessment of the participation cycle using the methods in this paper for the assessment of progress toward the maximum employment mandate, even in the latter stages of the recovery.

These projections are by no means meant as forecasts. Instead, they show that the participation cycle is likely to trail the unemployment cycle in coming years and that the lag in the participation cycle is bound to be longer the faster the recovery. In both of our scenarios cyclical factors affecting the labor supply are more of a drag on employment in coming years than those captured by the unemployment rate. 


\section{$7 \quad$ Policy Implications}

The measure of the participation cycle that we introduced in this paper complements the many other indicators used to assess the shortfall of employment from its maximum level. It provides an estimate of the procyclical forces underlying the labor supply due to fluctuations in employment stability associated with changes in job-loss and job-finding rates. The measurement of the participation cycle does not require an estimate of the trend participation rate. Rather, it is derived from cyclical deteriorations and improvements in job opportunities that affect labor force participation.

Because of the relative simplicity with which it can be constructed, it is possible to compute measures of the participation cycle not only for the aggregate but also for many subgroups in the labor market. Doing so reveals how the uneven effect of recessions across demographic groups is amplified by the labor-supply channel. Even groups who experience muted increases in their unemployment rates during recessions, such as workers older than 55, experience prolonged participation cycles. The participation cycle lags the unemployment cycle for all groups since it takes time to build up labor force attachment as job opportunities become more abundant. Interestingly, since the cyclical upward pressures on participation originate from increased labor force attachment rather than labor force entry, their positive effect carry over to subsequent business cycles, especially for marginalized groups.

While there are large differences in the magnitude of the participation cycle across groups in the earlier part of expansions, both the aggregate as well as the group-specific participation cycles tend to move closely together with their respective unemployment rates in the latter part of labor market expansions. This is because the two flow rates that drive the participation cycle are the same ones that drive the bulk of unemployment fluctuations. Any policy that affects the incidence of job-loss and the opportunities to find jobs, thus, will have both an effect on the unemployment rate as well as affect the cyclical part of the labor supply. Moreover, the improvement of the participation cycle is, therefore, not limited to workers who are classified as marginal workers or discouraged workers but rather tied to the improvements in job opportunities for all workers both in and out of the labor force. That is why the participation cycle is larger for groups with higher unemployment rates and why for groups with lower and less cyclical unemployment rates, such as workers with college education, the participation cycle flattens at the end of long expansions as the group's unemployment rate approaches its frictional level. It is important to emphasize that this clear link between the cyclical pressures on the participation rate and the unemployment rate that we identify does not imply that one should expect the participation rate to return to its pre-recession level when the unemployment 
rate does. This is because, in addition to the cyclical forces we quantify, there also are long-run shifts in labor supply that affect the participation rate. Isolating the participation cycle allows us to assess the importance of cyclical factors without having to take a stand on these long-run shifts in labor supply.

Even though we show that the unemployment cycle and participation cycle move closely together, especially in the latter parts of labor market expansions, we do not advocate that the FOMC solely focus on the unemployment rate for the implementation of its maximum employment mandate. The unemployment cycle itself is influenced by many "nonmonetary factors that affect the structure and dynamics of the labor market" (Federal Open Market Committee, 2020), such as rising labor force attachment among women and dual aging of workers and firms, which are analyzed extensively in Crump et al. (2019). Such factors determine both long- and short-run fluctuations in the natural rate of unemployment as well as shifts in labor supply on which monetary stimulus has no effect. These include the reasons for the large unevenness in long-run labor market outcomes, like, for example, workplace discrimination, child-care policies, the nature of employment contracts and stability, and the differential impact of climate change on jobs and employment. Therefore, it is imperative that the FOMC continues to consider the wide range of indicators and issues that are relevant for its assessment of the extent to which there is room for monetary policy to make progress towards its goal of maximum employment. 


\section{References}

Aaronson, Daniel, Davis, Jonathan, and Hu, Luojia. 2012. Explaining the decline in the U.S. labor force participation rate. Chicago Fed Letter.

Aaronson, Stephanie, Fallick, Bruce, Figura, Andrew, Pingle, Jonathan, and Wascher, William. 2006. The Recent Decline in the Labor Force Participation Rate and Its Implications for Potential Labor Supply. Brookings Papers on Economic Activity, 37(1), 69-154.

Aaronson, Stephanie, Cajner, Tomaz, Fallick, Bruce, Galbis-Reig, Felix, Smith, Christopher, and Wascher, William. 2014. Labor Force Participation: Recent Developments and Future Prospects. Brookings Papers on Economic Activity, 45(2 (Fall)), 197-275.

Aaronson, Stephanie R, Daly, Mary C, Wascher, William L, and Wilcox, David W. 2019. Okun Revisited: Who Benefits Most from a Strong Economy? Brookings Papers on Economic Activity, 2019(1), 333-404.

Albanesi, Stefania, and Şahin, Ayşegül. 2018. The Gender Unemployment Gap. Review of Economic Dynamics, 30, 47-67.

Alon, Titan, Coskun, Sena, Doepke, Matthias, Koll, David, and Tertilt, Michèle. 2021 (April). From Mancession to Shecession: Women's Employment in Regular and Pandemic Recessions. Working Paper 28632. National Bureau of Economic Research.

Ameriks, John, Briggs, Joseph, Caplin, Andrew, Lee, Minjoon, Shapiro, Matthew D, and Tonetti, Christopher. 2020. Older Americans Would Work Longer if Jobs Were Flexible. American Economic Journal: Macroeconomics, 12(1), 174-209.

Barnichon, Regis. 2019. Is the Hot Economy Pulling New Workers into the Labor Force? FRBSF Economic Letter.

Barnichon, Regis, and Mesters, Geert. 2018. On the Demographic Adjustment of Unemployment. The Review of Economics and Statistics, 100(2), 219-231.

Barnichon, Regis, and Nekarda, Christopher J. 2012. The Ins and Outs of Forecasting Unemployment: Using Labor Force Flows to Forecast the Labor Market. Brookings Papers on Economic Activity, 43(2 (Fall)), 83-131.

Bartik, Alexander W, Bertrand, Marianne, Lin, Feng, Rothstein, Jesse, and Unrath, Matt. 2020. Measuring the Labor Market at the Onset of the COVID-19 Crisis. Brookings Papers on Economic Activity-Special Edition: COVID-19 and the Economy. 
Bengali, Leila, Daly, Mary C., and Valletta, Robert G. 2013. Will Labor Force Participation Bounce Back? FRBSF Economic Letter.

Beveridge, Stephen, and Nelson, Charles R. 1981. A New Approach to Decomposition of Economic Time Series into Permanent and Transitory Components with Particular Attention to Measurement of the 'Business Cycle'. Journal of Monetary Economics, 7(2), 151-174.

Blanchard, Olivier Jean, Diamond, Peter, Hall, Robert E., and Murphy, Kevin. 1990. The Cyclical Behavior of the Gross Flows of U.S. Workers. Brookings Papers on Economic Activity, 1990(2), 85-155.

Board of Governors of the Federal Reserve System. 2021. Monetary Policy Report.

Brauer, David. 2007. The Natural Rate of Unemployment.

Braun, Steve, Coglianese, John, Furman, Jason, Stevenson, Betsey, and Stock, James. 2014. Understanding the Decline in the Labor Force Participation Rate in the United States. Tech. rept.

Cairó, Isabel, Fujita, Shigeru, and Morales-Jiménez, Camilo. 2021. The Cyclicality of Labor Force Participation Flows: The Role of Labor Supply Elasticities and Wage Rigidity. Review of Economic Dynamics.

Cajner, Tomaz, Crane, Leland D, Decker, Ryan A, Grigsby, John, Hamins-Puertolas, Adrian, Hurst, Erik, Kurz, Christopher, and Yildirmaz, Ahu. 2020. The US labor market during the beginning of the pandemic recession. Tech. rept. National Bureau of Economic Research.

Cajner, Tomaz, Coglianese, John, and Montes, Joshua. 2021. The Long-Lived Cyclicality of the Labor Force Participation Rate.

Chodorow-Reich, Gabriel, and Karabarbounis, Loukas. 2016. The Cyclicality of the Opportunity Cost of Employment. Journal of Political Economy, 124(6), 1563-1618.

Clark, Kim B., and Summers, Lawrence. 1981. Demographic Differences in Cyclical Employment Variation. Journal of Human Resources, 16(1), 61-79.

Coile, Courtney C, and Levine, Phillip B. 2011. The Market Crash and Mass Layoffs: How the Current Economic Crisis May Affect Retirement. The B.E. Journal of Economic Analysis and Policy, 11(1). 
Council of Economic Advisers. 2014. The Labor Force Participation Rate Since 2007: Causes and Policy Implications.

Crump, Richard K., Eusepi, Stefano, Giannoni, Marc, and Şahin, Ayşegül. 2019. A Unified Approach to Measuring u*. Brookings Papers on Economic Activity, May.

Crump, Richard K., Eusepi, Stefano, Giannoni, Marc, and Şahin, Ayşegül. 2021. A Unified Approach to Measuring $u^{*}$ : An Update in Covid Times. Tech. rept.

Daly, Mary C., Hobijn, Bart, and Kwok, Joyce. 2009. Jobless Recovery Redux? FRBSF Economic Letter.

Elsby, Michael, Hobijn, Bart, Karahan, Fatih, Koşar, Gizem, and Şahin, Ayşegül. 2019. Flow Origins of Labor Force Participation Fluctuations. AEA Papers and Proceedings, 109(May), 461-464.

Elsby, Michael W. L., Michaels, Ryan, and Solon, Gary. 2009. The Ins and Outs of Cyclical Unemployment. American Economic Journal: Macroeconomics, 1(1), 84-110.

Elsby, Michael W. L., Hobijn, Bart, and Şahin, Ayşegül. 2010. The Labor Market in the Great Recession. Brookings Papers on Economic Activity, 41(1 (Spring), 1-69.

Elsby, Michael W.L., Hobijn, Bart, and Şahin, Ayşegül. 2015. On the Importance of the Participation Margin for Labor Market Fluctuations. Journal of Monetary Economics, 72(C), $64-82$.

Erceg, Christopher J., and Levin, Andrew T. 2014. Labor Force Participation and Monetary Policy in the Wake of the Great Recession. Journal of Money, Credit and Banking, 46(S2), $3-49$.

Faberman, R. Jason, Mueller, Andreas I., Şahin, Ayşegül, and Topa, Giorgio. 2020. The Shadow Margins of Labor Market Slack. Journal of Money, Credit and Banking, 52(S2), 355-391.

Farber, Henry S., Rothstein, Jesse, and Valletta, Robert G. 2015. The Effect of Extended Unemployment Insurance Benefits: Evidence from the 2012-2013 Phase-Out. American Economic Review, 105(5), 171-76.

Federal Open Market Committee. 2020. 2020 Statement on Longer-Run Goals and Monetary Policy Strategy (August 27 2020). 
Flood, Sarah, King, Miriam, Rodgers, Renae, Ruggles, Steven, and Warren, J. Robert. 2020. Integrated Public Use Microdata Series, Current Population Survey, Version 8.0 [dataset]. University of Minnesota.

Forsythe, Eliza, Kahn, Lisa B, Lange, Fabian, and Wiczer, David. 2020. Labor Demand in the Time of COVID-19: Evidence from Vacancy Postings and UI Claims. Journal of Public Economics, 189, 104238.

Friedman, Milton. 1968. The Role of Monetary Policy. The American Economic Review, 58(1), $1-17$.

Fujita, Shigeru, and Ramey, Garey. 2006. The Cyclicality of Job Loss and Hiring. Tech. rept.

Ganong, Peter, Noel, Pascal, and Vavra, Joseph. 2020. U.S. unemployment Insurance Replacement Rates During the Pandemic. Journal of Public Economics, 191, 104273.

Hamilton, James D. 2018. Why You Should Never Use the Hodrick-Prescott Filter. The Review of Economics and Statistics, 100(5), 831-843.

Hodrick, Robert J., and Prescott, Edward C. 1997. Postwar U.S. Business Cycles: An Empirical Investigation. Journal of Money, Credit and Banking, 29(1), 1-16.

Hornstein, Andreas, Kudlyak, Marianna, and Schweinert, Annemarie. 2018. The Labor Force Participation Rate Trend and Its Projections. FRBSF Economic Letter.

Hoynes, Hilary, Miller, Douglas L, and Schaller, Jessamyn. 2012. Who Suffers During Recessions? Journal of Economic Perspectives, 26(3), 27-48.

Juhn, Chinhui. 1992. Decline of Male Labor Market Participation: The Role of Declining Market Opportunities. The Quarterly Journal of Economics, 107(1), 79-121.

Juhn, Chinhui, and Potter, Simon. 2006. Changes in Labor Force Participation in the United States. Journal of Economic Perspectives, 20(3), 27-46.

Keane, Michael P. 2011. Labor Supply and Taxes: A Survey. Journal of Economic Literature, 49(4), 961-1075.

Keynes, John M. 1936. The General Theory of Employment, Interest and Money. Macmillan.

Krusell, Per, Mukoyama, Toshihiko, Rogerson, Richard, and Şahin, Ayşegül. 2017. Gross Worker Flows Over the Business Cycle. American Economic Review, 107(11), 3447-3476. 
Kudlyak, Marianna. 2013. A Cohort Model of Labor Force Participation. Economic Quarterly, $25-43$.

Lucas, Robert, and Rapping, Leonard A. 1969. Real Wages, Employment, and Inflation. Journal of Political Economy, 77(5), 721-754.

Marston, Stephen T. 1976. Employment Instability and High Unemployment Rates. Brookings Papers on Economic Activity, 1976(1), 169-210.

Mise, Emi, Kim, Tae-Hwan, and Newbold, Paul. 2005. On Suboptimality of the Hodrick-Prescott Filter at Time Series Endpoints. Journal of Macroeconomics, 27(1), 53-67.

Modigliani, Franco, and Papademos, Lucas. 1975. Targets for Monetary Policy in the Coming Year. Brookings Papers on Economic Activity, 1975(1), 141-165.

Okun, Arthur M. 1973. Upward Mobility in a High-Pressure Economy. Brookings Papers on Economic Activity, 1973(1), 207-261.

Pencavel, John. 1987. Labor Supply of Men: A Survey. Chap. 1, pages 3-102 of: Ashenfelter, O., and Layard, R. (eds), Handbook of Labor Economics. Handbook of Labor Economics, vol. 1. Elsevier.

Perry, George L. 1970. Changing Labor Markets and Inflation. Brookings Papers on Economic Activity, 1(3), 411-448.

Perry, George L. 1971. Labor Force Structure, Potential Output, and Productivity. Brookings Papers on Economic Activity, 3(3), 533-578.

Perry, George L. 1972. Unemployment Flows in the U.S. Labor Market. Brookings Papers on Economic Activity, 2(2), 245-292.

Phillips, A. W. 1958. The Relation between Unemployment and the Rate of Change of Money Wage Rates in the United Kingdom, 1861-1957. Economica, 25(100), 283-299.

Polivka, Anne E., and Miller, Stephen M. 1998. The CPS after the Redesign: Refocusing the Economic Lens. Pages 249-289 of: Labor Statistics Measurement Issues. NBER Chapters. National Bureau of Economic Research, Inc.

Powell, Jerome H. 2021. Getting Back to a Strong Labor Market.

Ravn, Morten O., and Uhlig, Harald. 2002. On Adjusting the Hodrick-Prescott Filter for the Frequency of Observations. The Review of Economics and Statistics, 84(2), 371-375. 
Robinson, Joan. 1943. The Problem of Full Employment. Study outline. Workers' Educational Assoc., and the Workers' Trade Union Committee.

Rogerson, Richard, and Shimer, Robert. 2011. Chapter 7 - Search in Macroeconomic Models of the Labor Market. Handbook of Labor Economics, vol. 4. Elsevier.

Şahin, Ayşegül, Song, Joseph, and Hobijn, Bart. 2010. The Unemployment Gender Gap During the 2007 Recession. Current Issues in Economics and Finance, 16(2).

Şahin, Ayşegül, Tasci, Murat, and Yan, Jin. 2021 (February). Unemployment in the Time of COVID-19: A Flow-Based Approach to Real-time Unemployment Projections. Working Paper 28445. National Bureau of Economic Research.

Samuelson, Paul A., and Solow, Robert M. 1960. Analytical Aspects of Anti-Inflation Policy. The American Economic Review, 50(2), 177-194.

Shimer, Robert. 1998. Why Is the U.S. Unemployment Rate So Much Lower? NBER Macroeconomics Annual, 13, 11-61.

Shimer, Robert. 2005. The Cyclical Behavior of Equilibrium Unemployment and Vacancies. American Economic Review, 95(1), 25-49.

Shimer, Robert. 2013. Job Search, Labor-Force Participation, and Wage Rigidities. Econometric Society Monographs, vol. 2. Cambridge University Press. Page 197-234.

Summers, Lawrence H. 1986. Why is the Unemployment Rate So Very High Near Full Employment? Brookings Papers on Economic Activity, 17(2), 339-396.

Toossi, Mitra. 2011. A Behavioral Model for Projecting the Labor Force Participation Rate. Monthly Labor Review, 25-43.

Tüzemen, Didem, and Zandweghe, Willem Van. 2018 (Aug.). The Cyclical Behavior of Labor Force Participation. Research Working Paper RWP 18-8. Federal Reserve Bank of Kansas City.

Veracierto, Marcelo. 2008. On the Cyclical Behavior of Employment, Unemployment and Labor Force Participation. Journal of Monetary Economics, 55(6), 1143-1157.

White, Neil. 2018. Gross Worker Flows, Job Loss, and Monetary Policy. Tech. rept. 
Yellen, Janet. 2014. Labor Market Dynamics and Monetary Policy: a speech at the Federal Reserve Bank of Kansas City Economic Symposium, Jackson Hole, Wyoming, August 22, 2014. Tech. rept. Board of Governors of the Federal Reserve System (US).

Zandweghe, Willem Van. 2012. Interpreting the recent decline in labor force participation. Economic Review, 97(Q I), 5-34. 


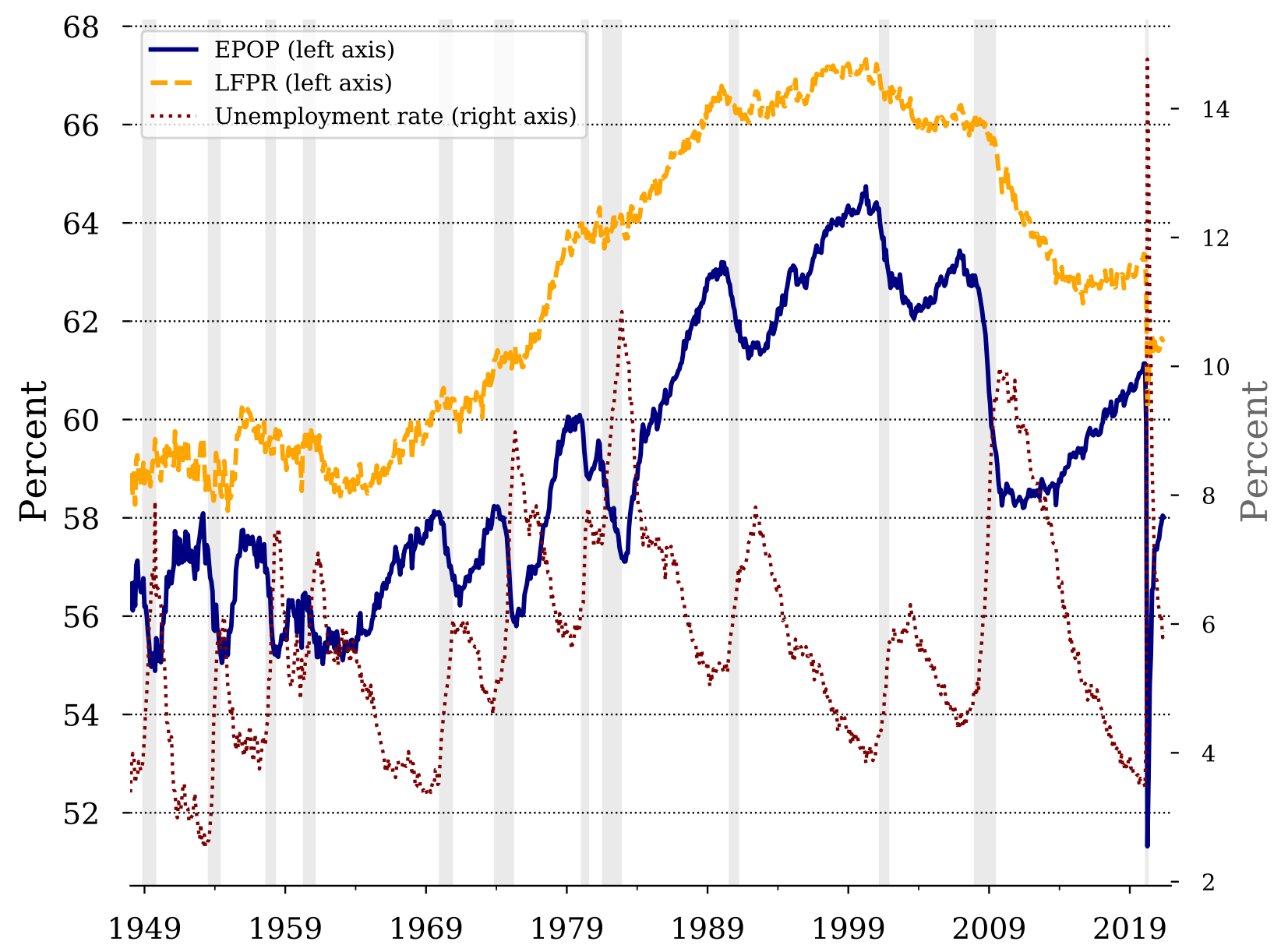

Figure 1: Employment-population ratio, labor force participation rate, and unemployment rate Source: BLS.

Note: Seasonally adjusted monthly data. 


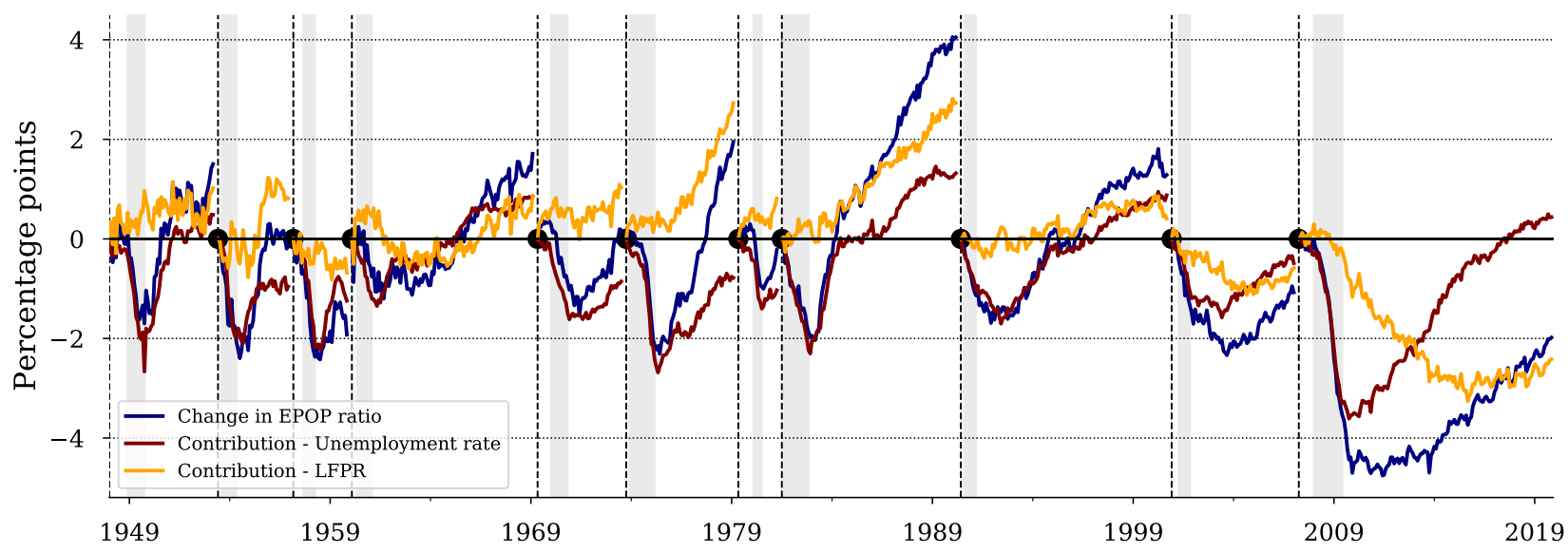

(a) Total

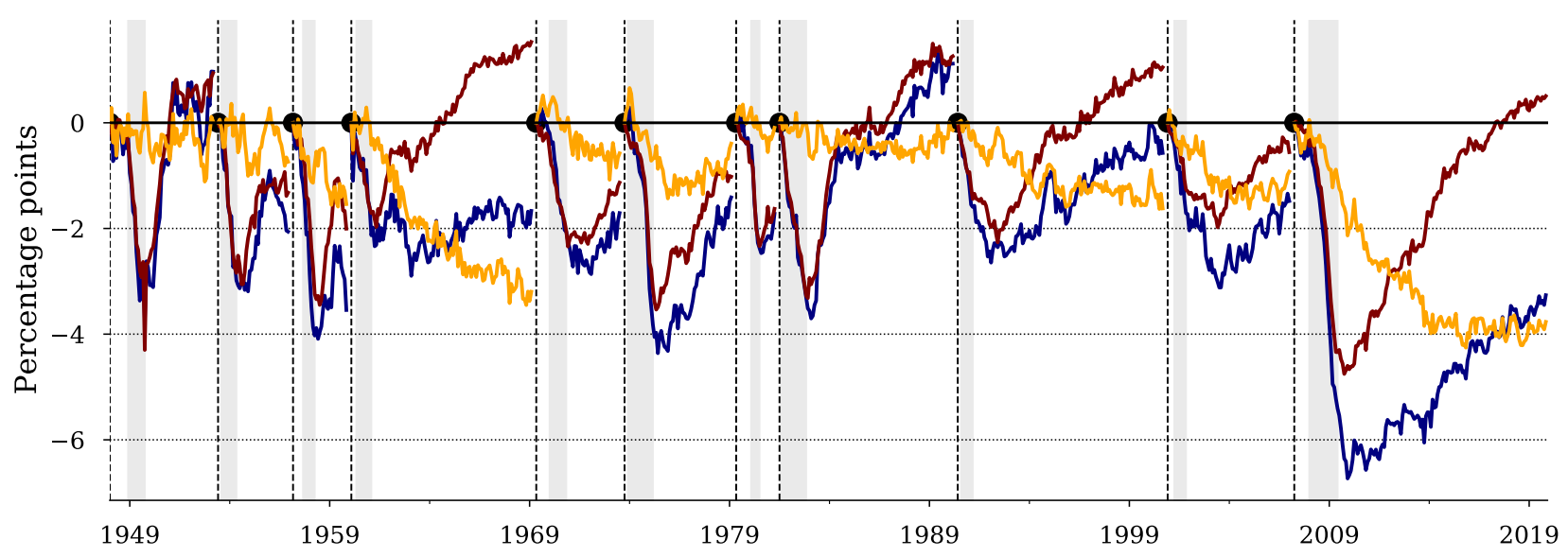

(b) Men

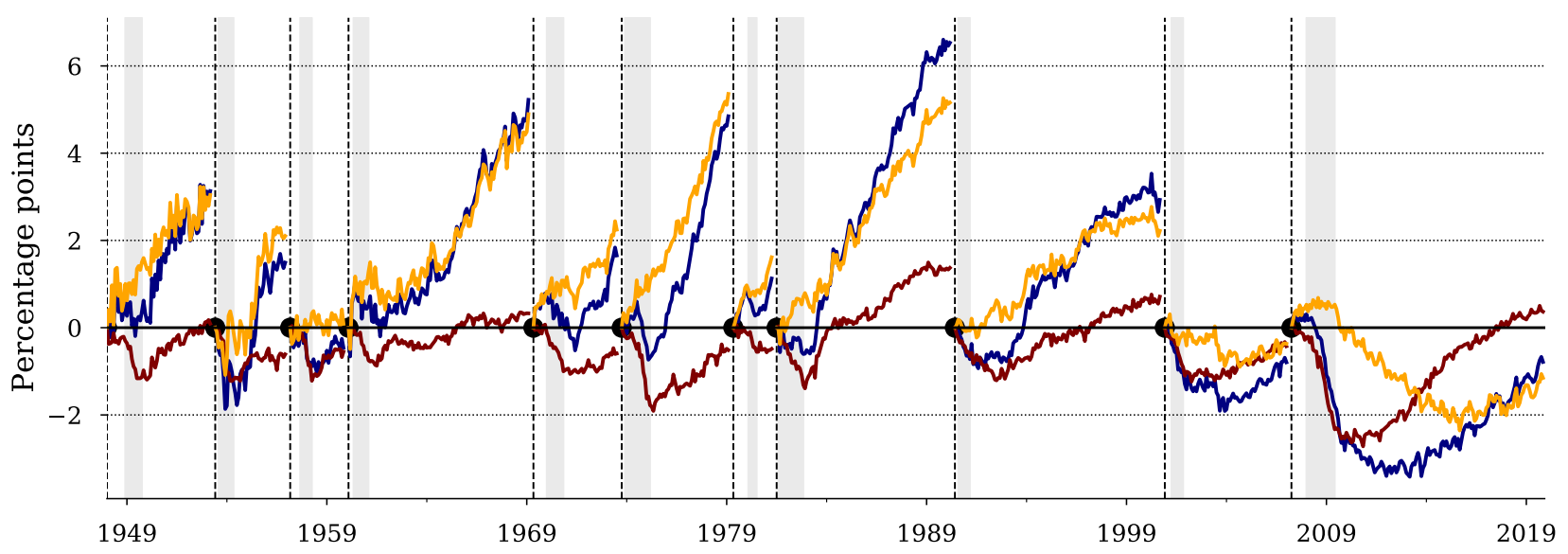

(c) Women

Figure 2: Changes in EPOP decomposed by business cycle, 1948-2019 Source: Bureau of Labor Statistics and authors' calculations. 


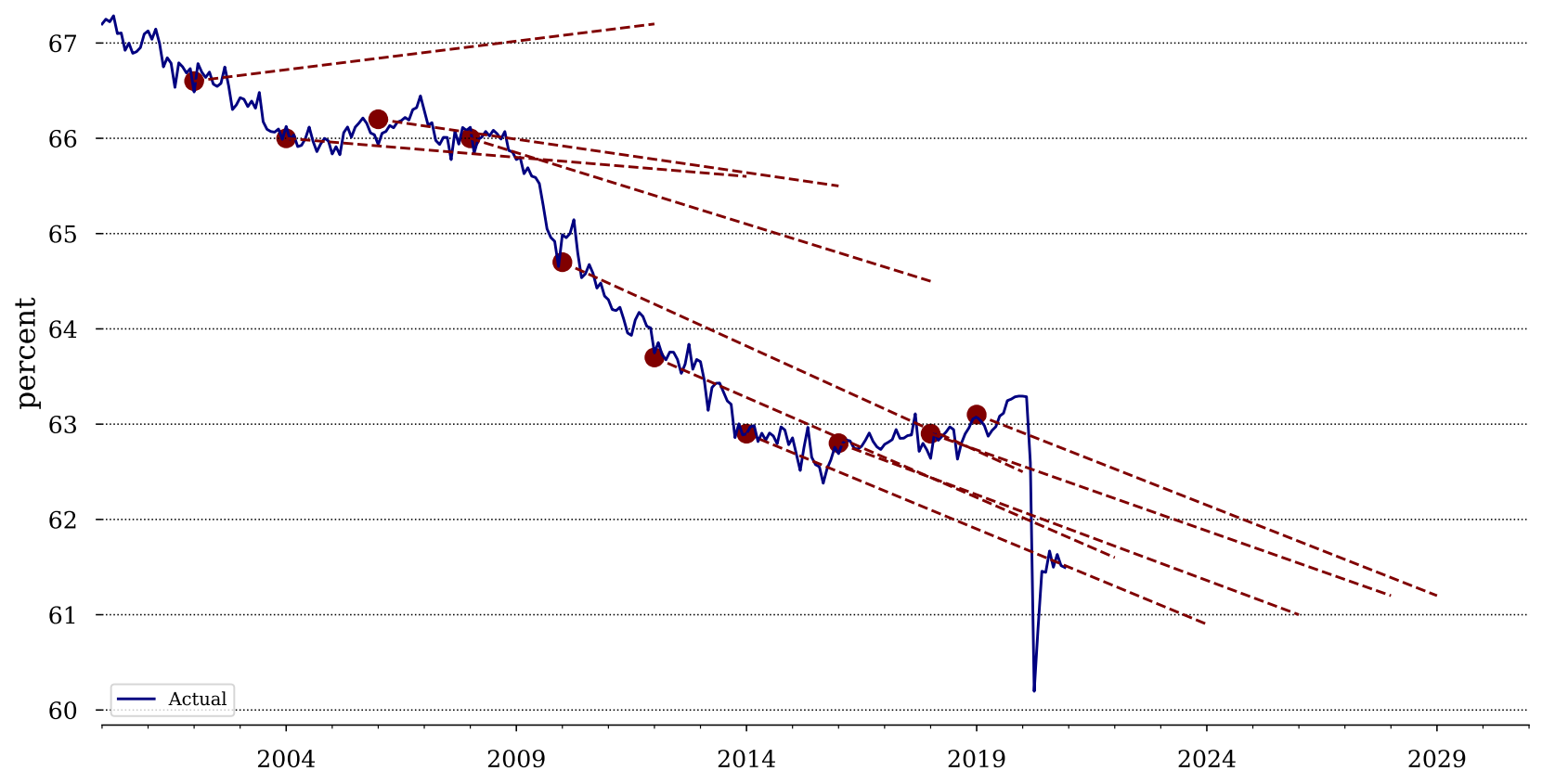

(a) BLS forecasts of actual LFPR

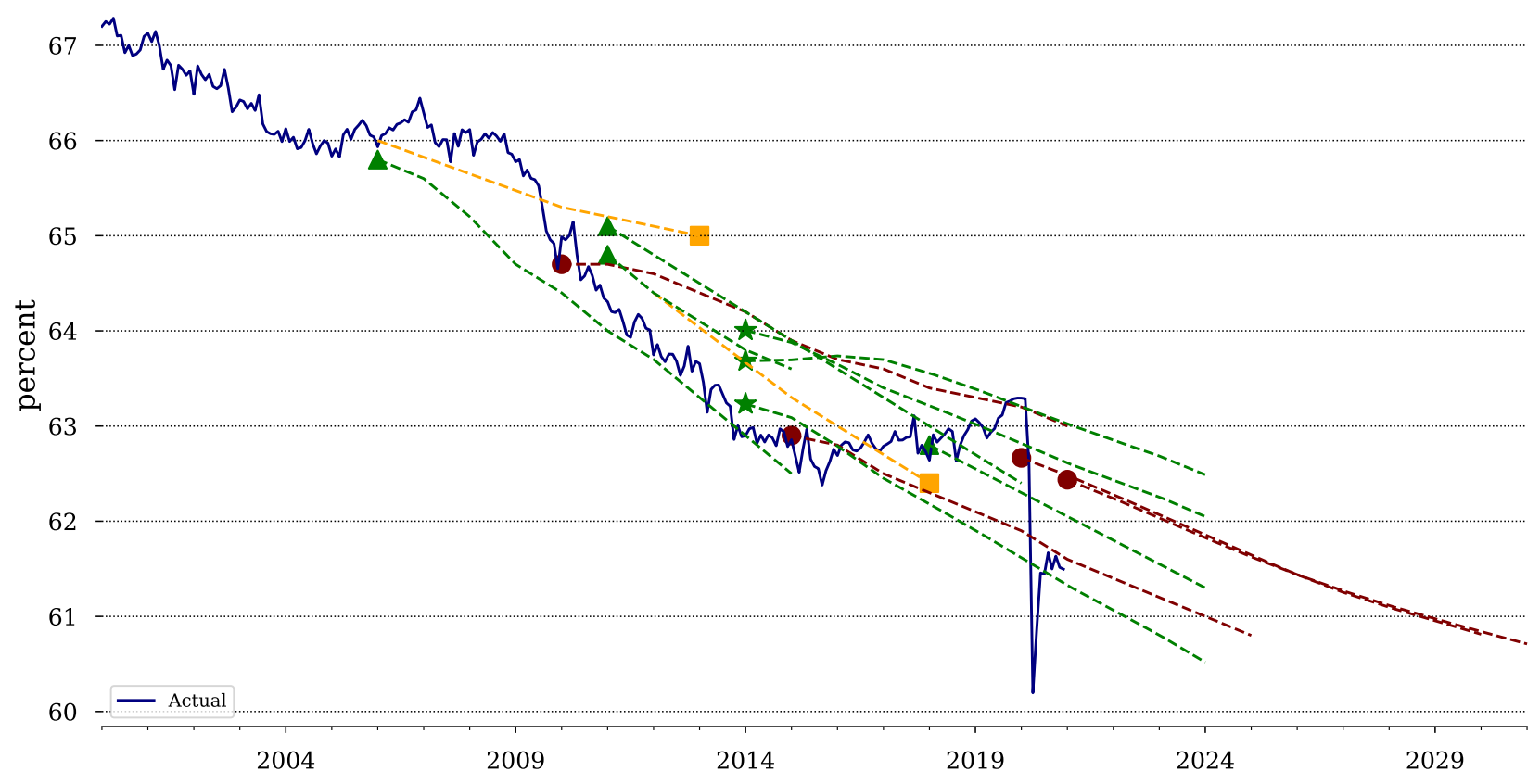

(b) Estimates of trend LFPR, different vintages and sources

Figure 3: Actual LFPR, vintages of BLS forecast, and various trend estimates

Source: BLS Labor Force Projections, CPS, and authors' calculations.

Note: Vintage of forecast is indicated by dot. Actual is seasonally adjusted monthly observations. BLS forecasts in top panel are linearly interpolated between beginning and end of 10-year forecast period. Trend estimates in bottom panel by source: •: CBO trend estimates $(2011,2015,2020,2021)$, $\mathbf{n}:$ Tealbook estimates (backwardlooking, Jan 2011 and Jan 2015), «: Aaronson et al. (2014), and s: from Aaronson et al. (2006), Aaronson et al. (2012), Zandweghe (2012), and Hornstein et al. (2018). 


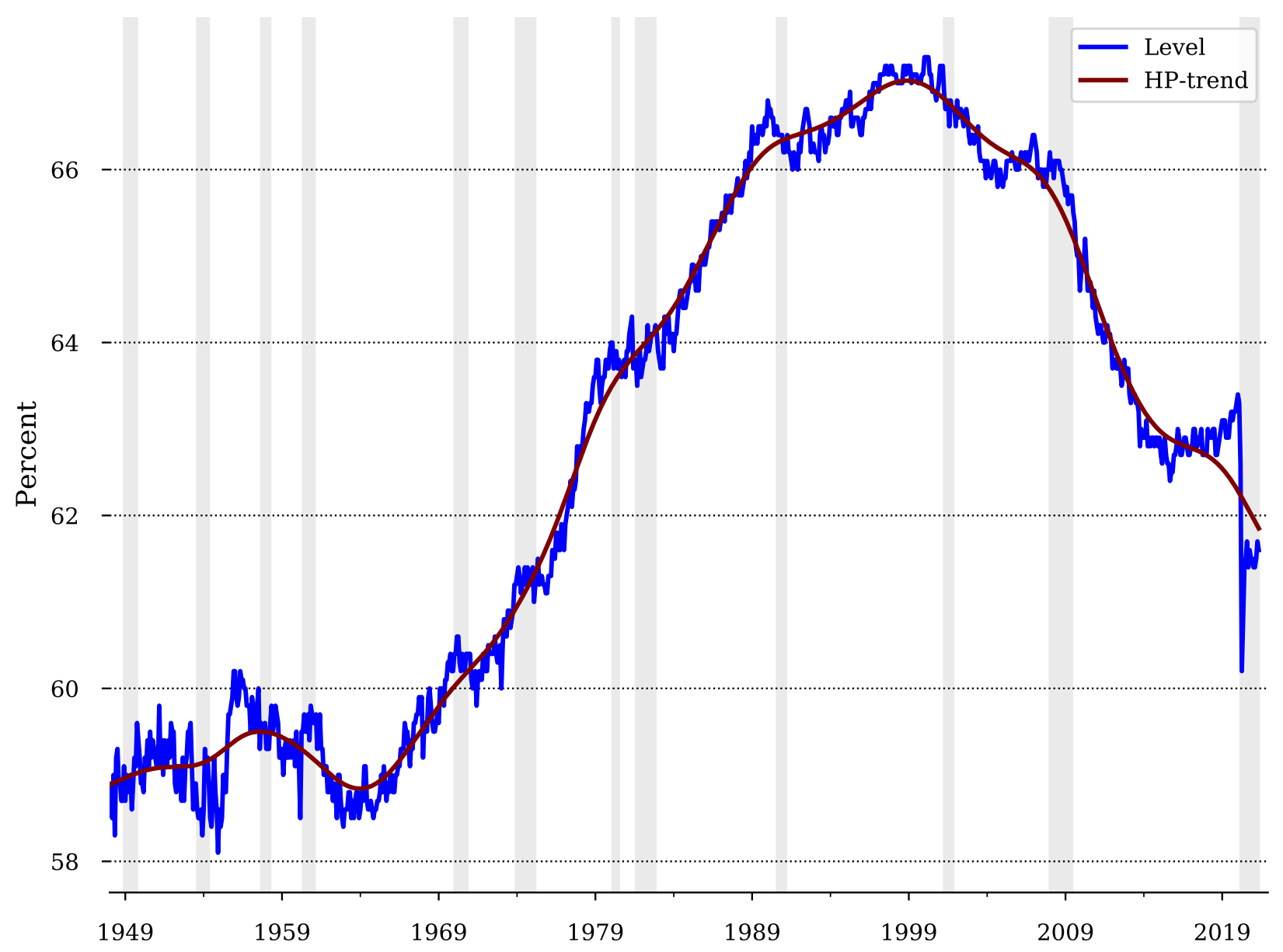

Figure 4: Actual and HP-filtered trend of LFPR

Source: BLS and author's calculations.

Note: HP filtered with smoothing parameter $\lambda=129600$, following Ravn and Uhlig (2002). 


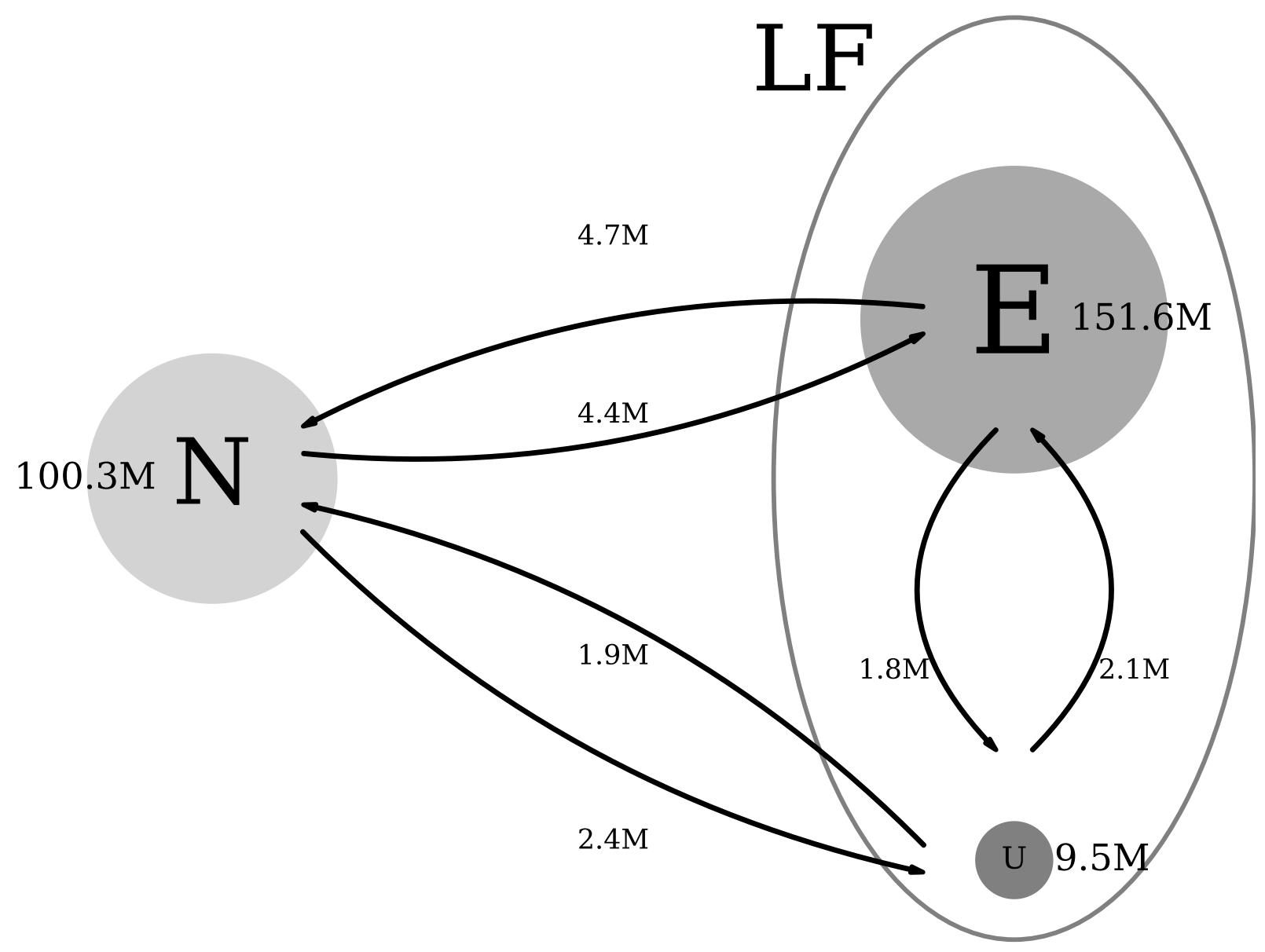

Figure 5: Flow origins of labor force fluctuations

Source: BLS Labor Force Status Flows.

Note: $E$ is employed, $U$ is unemployed, and $N$ is non participants. Seasonally adjusted stocks and monthly flows in June 2021 are shown in figure. 

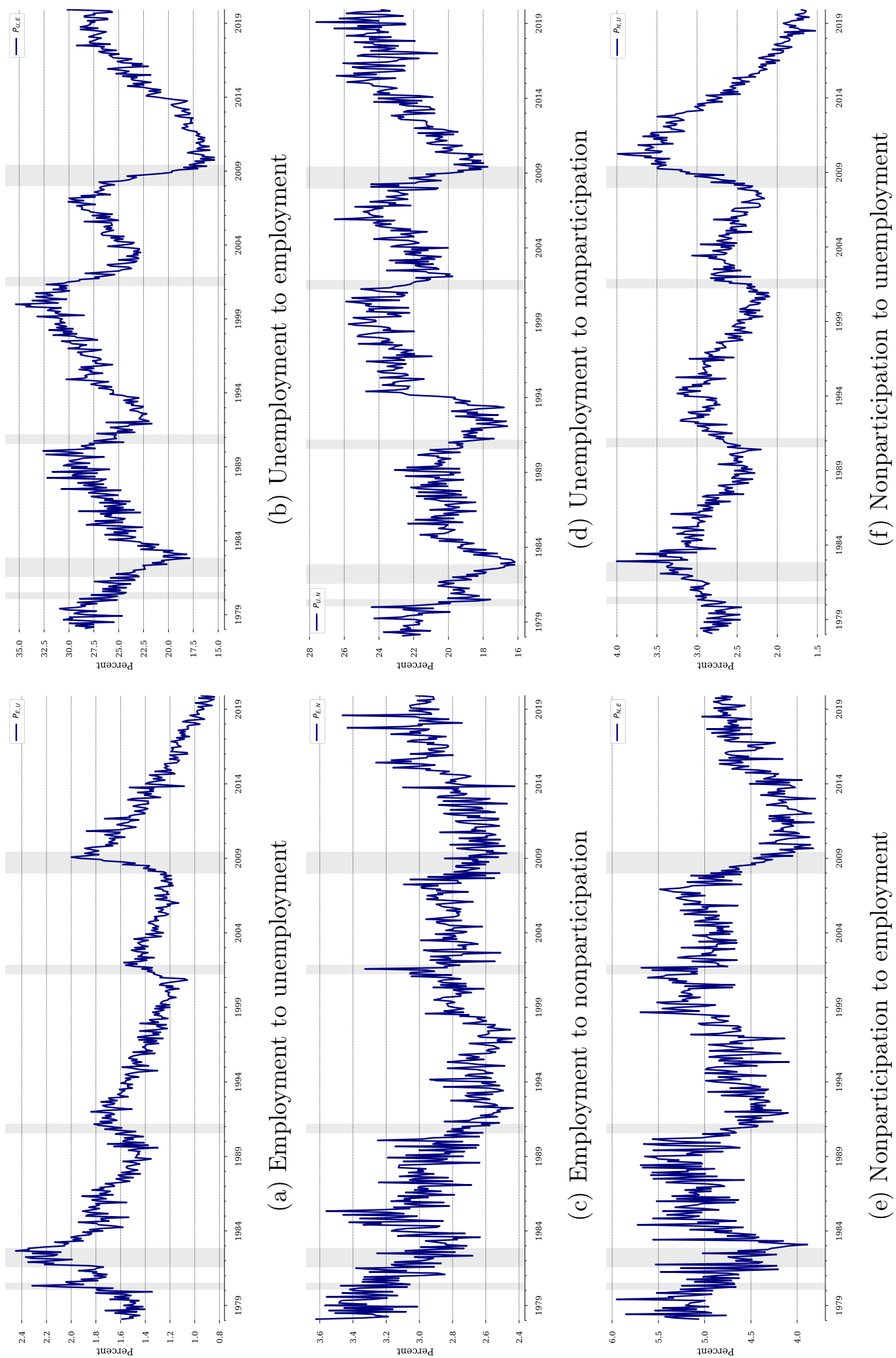


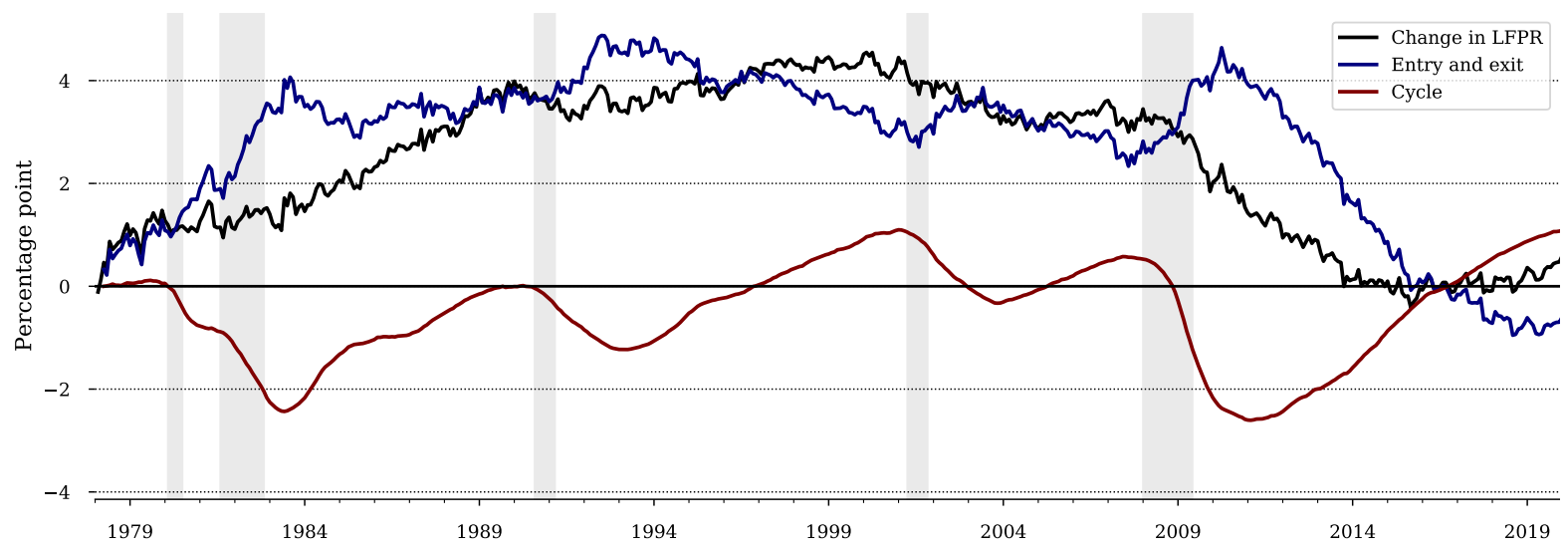

(a) Total

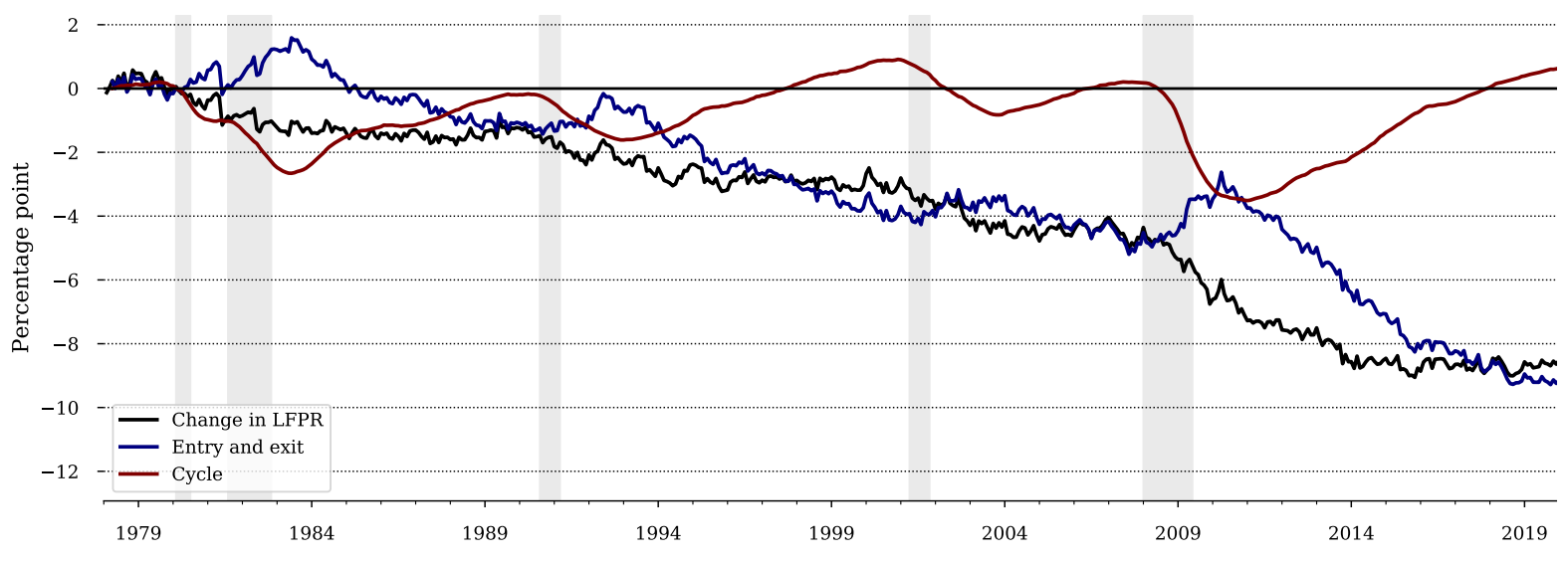

(b) Men

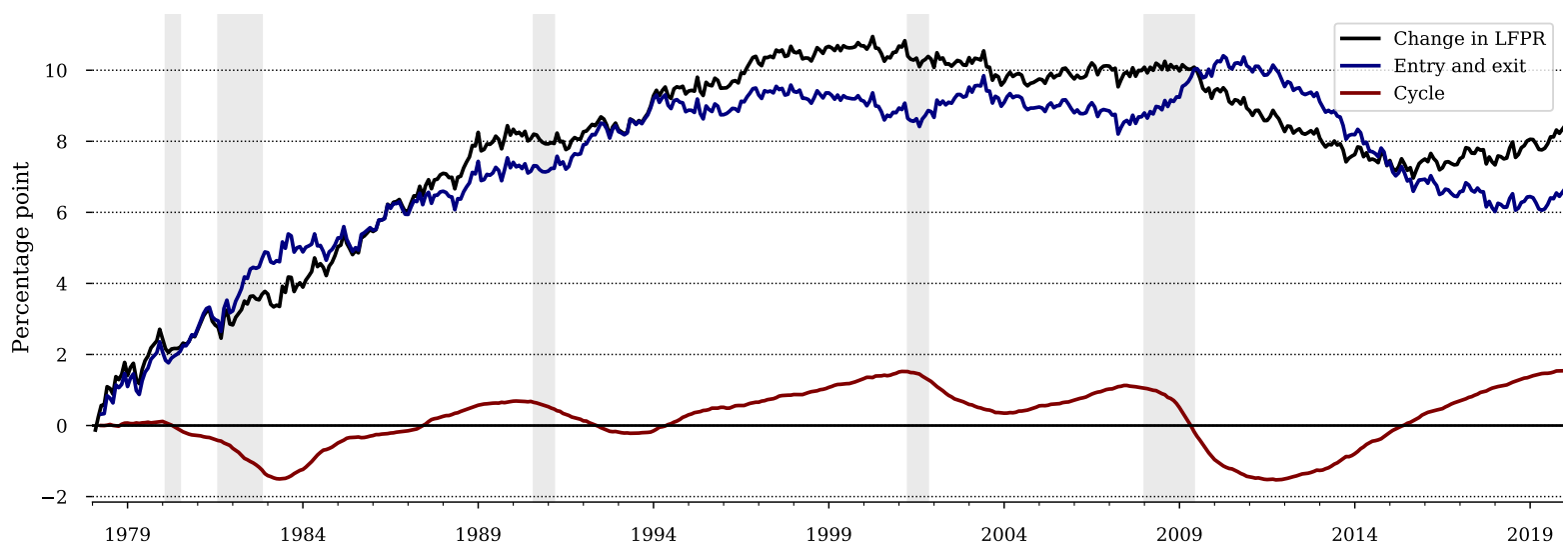

(c) Women

Figure 7: Change in LFPR since January 1978 decomposed, 1978-2019

Source: BLS and author's calculations. Update of Elsby et al. (2019).

Note: Seasonally adjusted monthly data. Cumulative effect on EPOP ratio since January 1978. Entry is contribution from $P_{N, U}$ and $P_{N, E}$, exit is contribution from $P_{U, N}$ and $P_{E, N}$, and cycle from flows between $U$ and $E$, i.e., $P_{E, U}$ and $P_{U, E}$. 


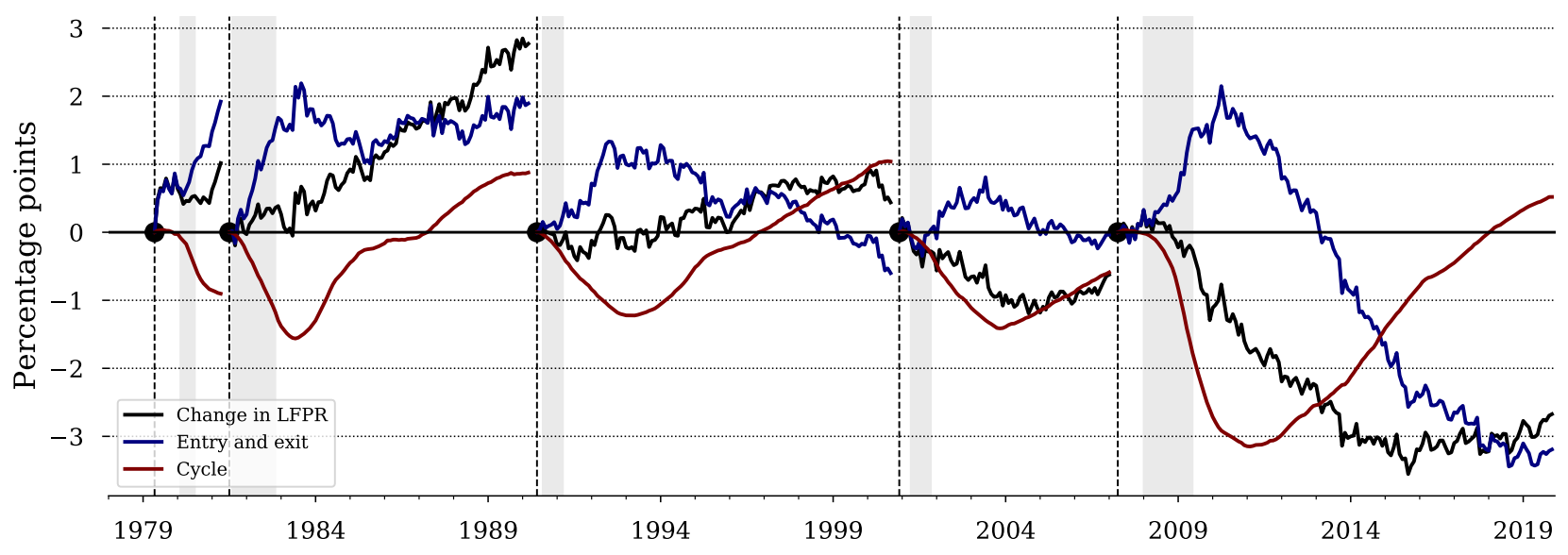

(a) Total

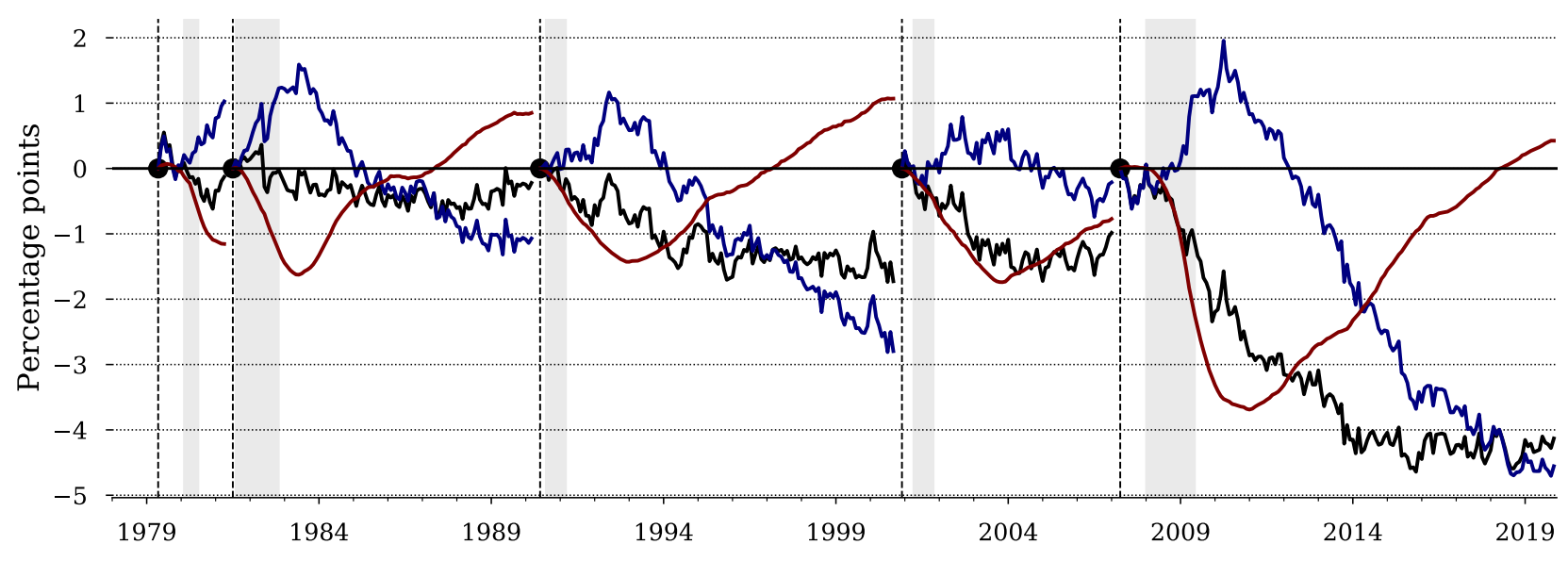

(b) Men

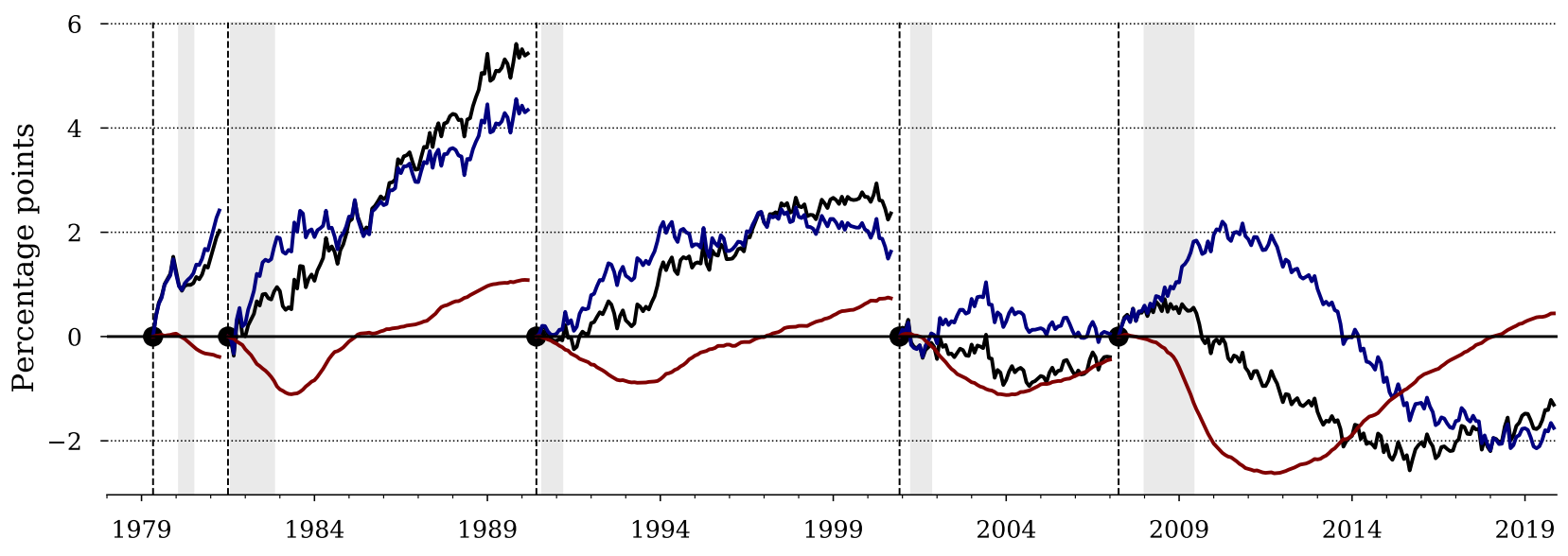

(c) Women

Figure 8: Changes in LFPR by business cycle decomposed into flow sources, 1979-2019 Source: BLS and author's calculations. Update of Elsby et al. (2019).

Note: Seasonally adjusted monthly data. Cumulative effect on LFPR from every trough in the unemployment rate (dashed vertical lines). Entry is contribution from $P_{N, U}$ and $P_{N, E}$, exit is contribution from $P_{U, N}$ and $P_{E, N}$, and cycle from flows between $U$ and $E$, i.e., $P_{E, U}$ and $P_{U, E}$. 


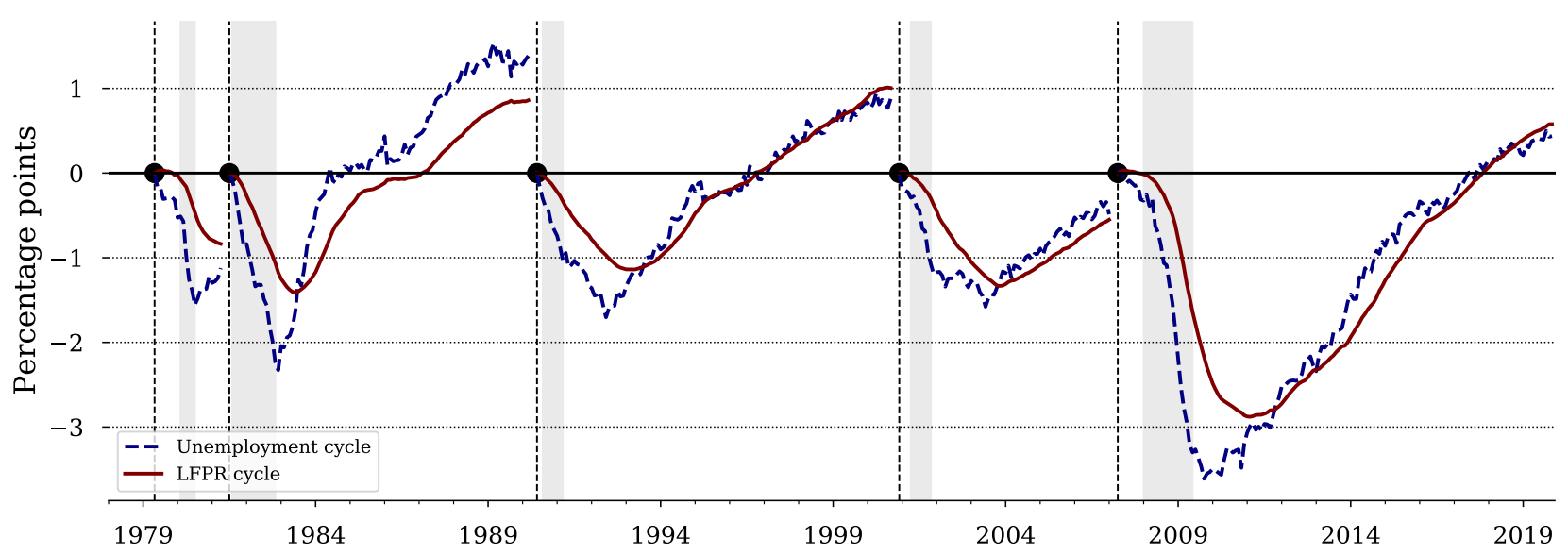

(a) Total

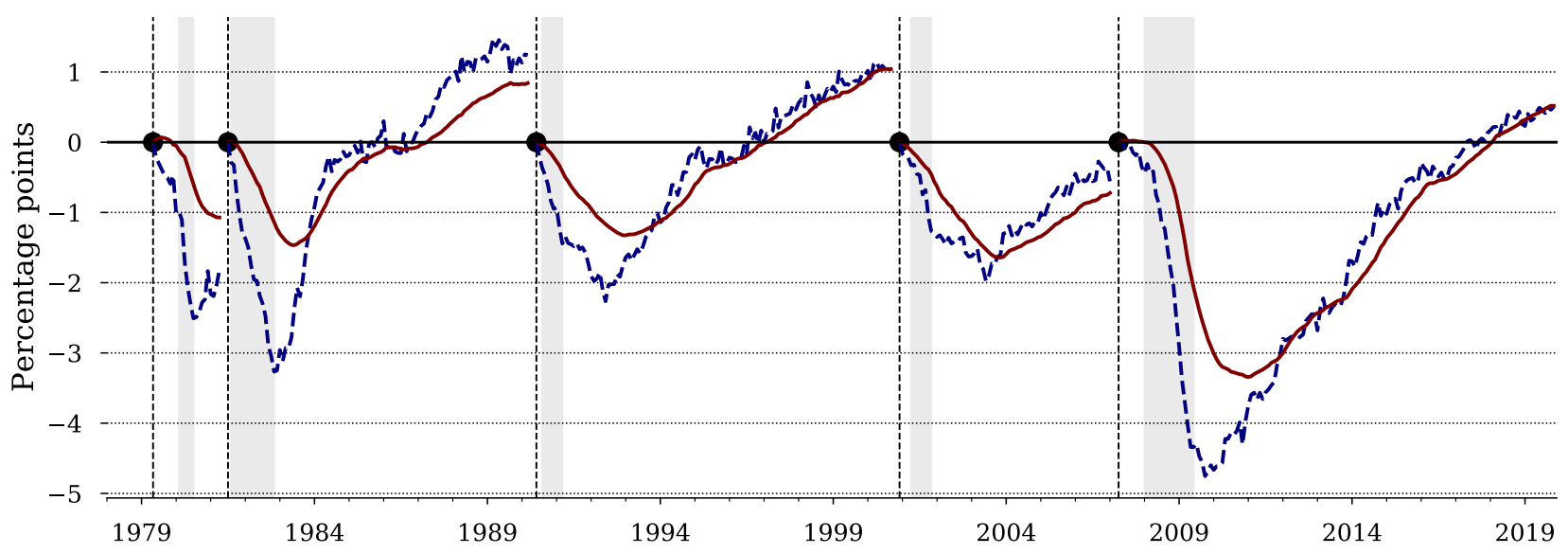

(b) Men

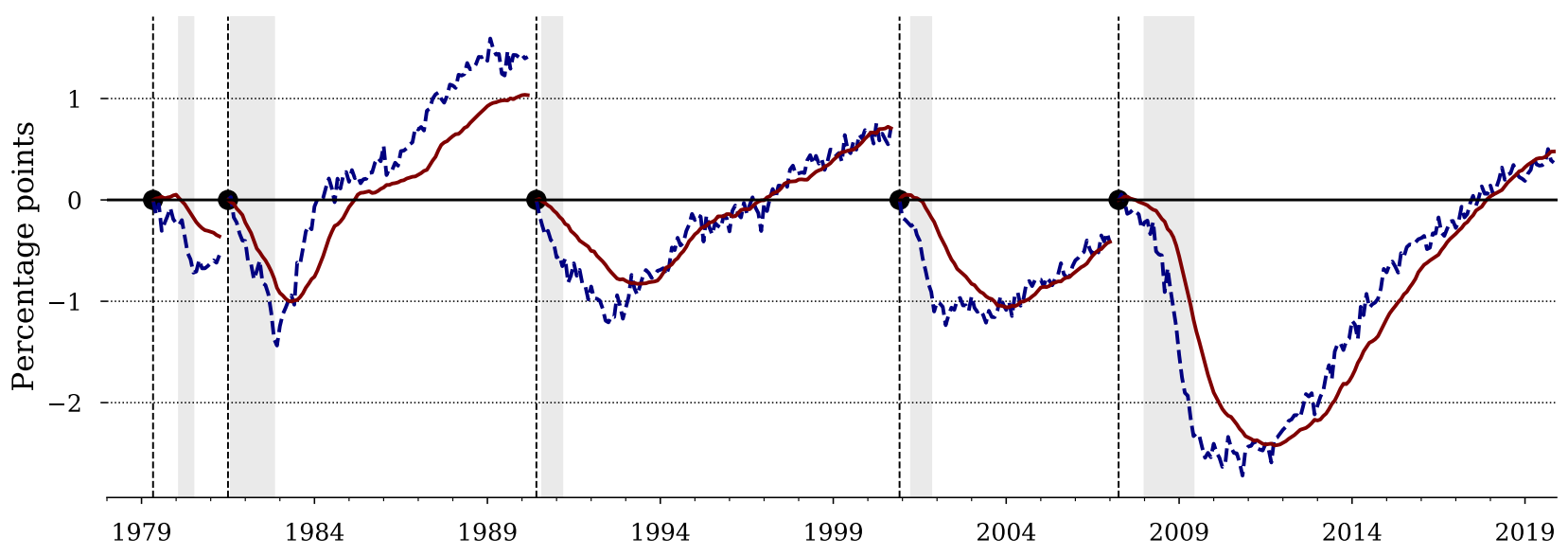

(c) Women

Figure 9: Cyclical pressures on EPOP ratio by cycle, 1979-2019

Source: BLS, CBO, and author's calculations.

Note: Seasonally adjusted monthly data. Cumulative effect on EPOP ratio from every trough in the unemployment rate (dashed vertical lines). Unemployment gap is cumulative sum of $-\overline{L F P R}_{t} \Delta u_{t}$ and LFPR cycle is cumulative sum of $\left(1-\bar{u}_{t}\right) \triangle L F P R_{t}^{c}$. See equation (19). $u_{t}^{*}$ is the CBO's natural rate of unemployment (long-term). 


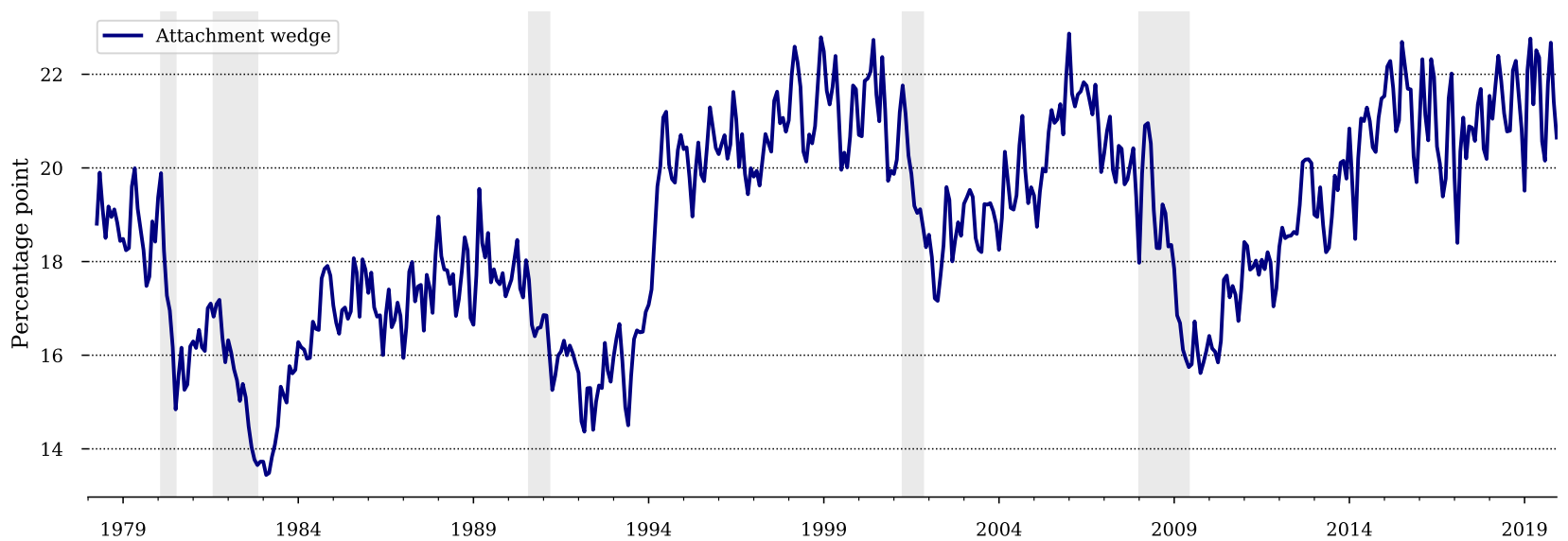

(a) Total

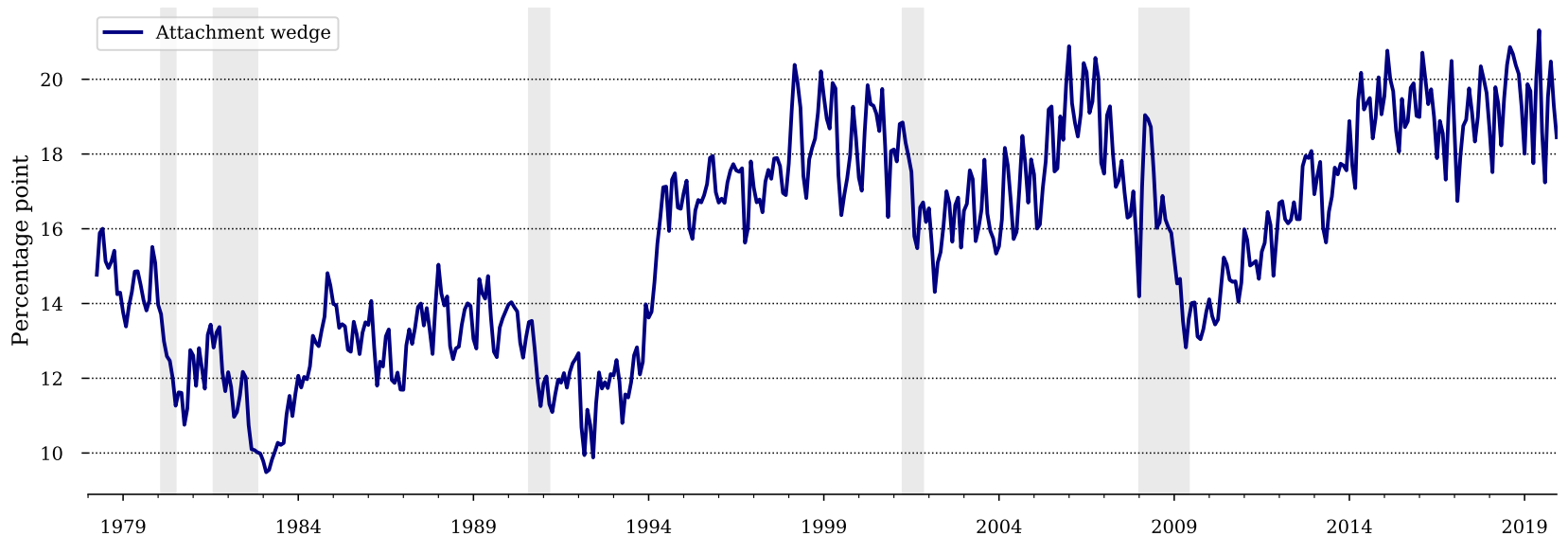

(b) Men

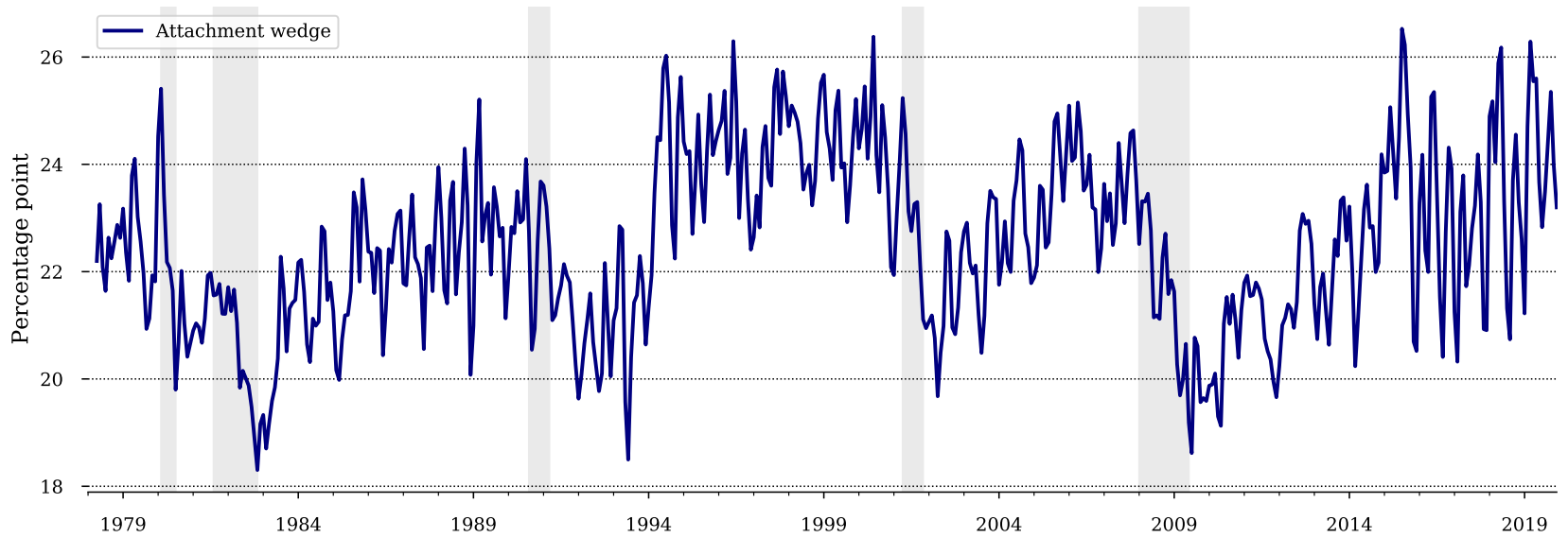

(c) Women

Figure 10: Attachment wedge, total and by gender, 1978-2019

Source: BLS and author's calculations. Seasonally adjusted monthly data. Attachment wedge is difference between margin-adjusted $p_{u, n, t}$ and $p_{e, n, t}$. 


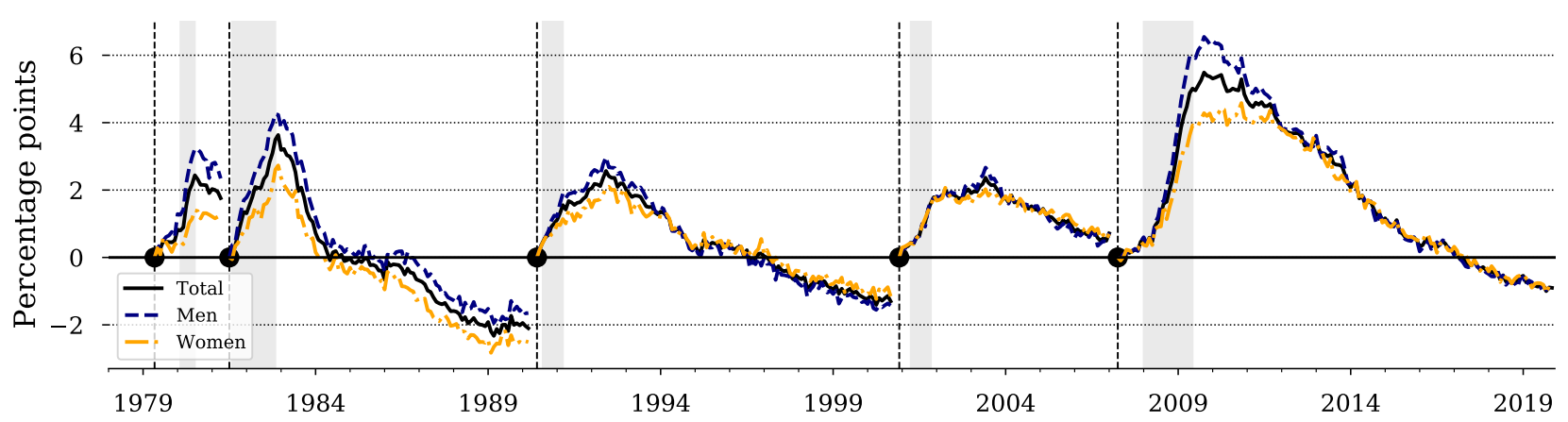

(a) Sex

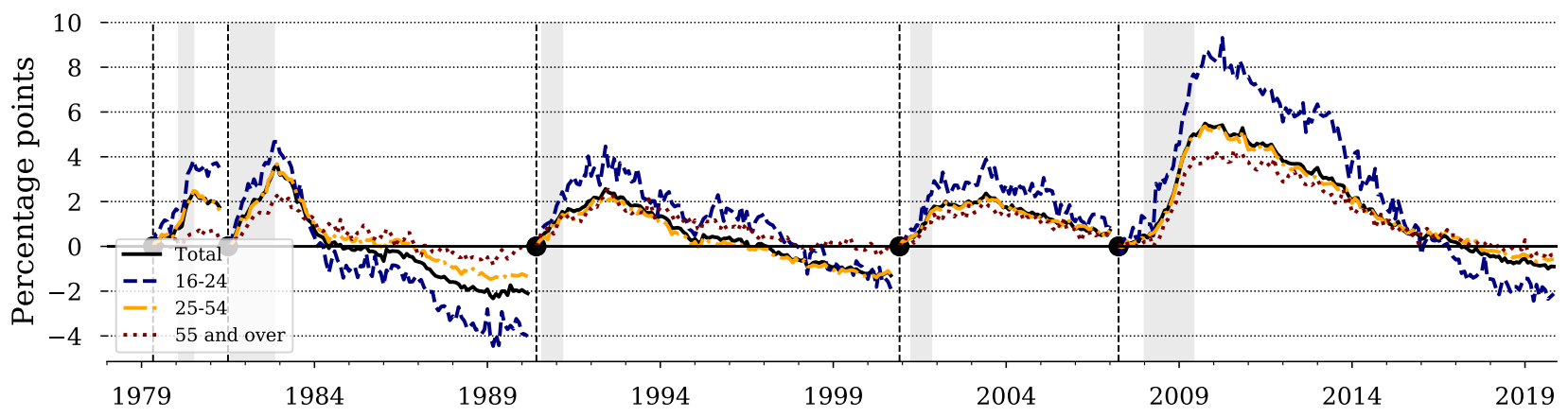

(b) Age

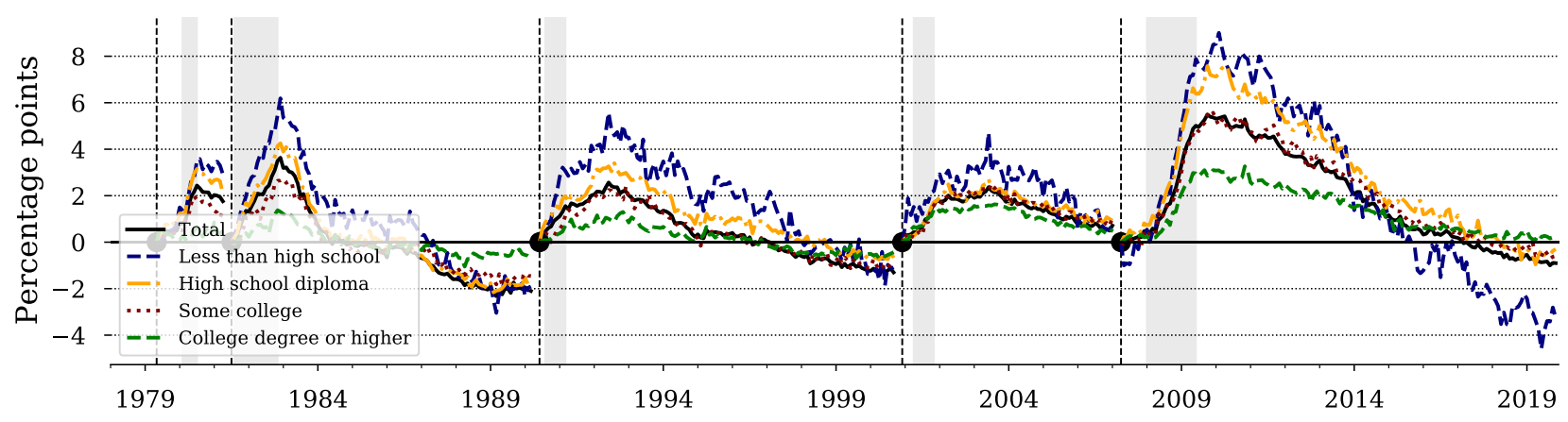

(c) Education

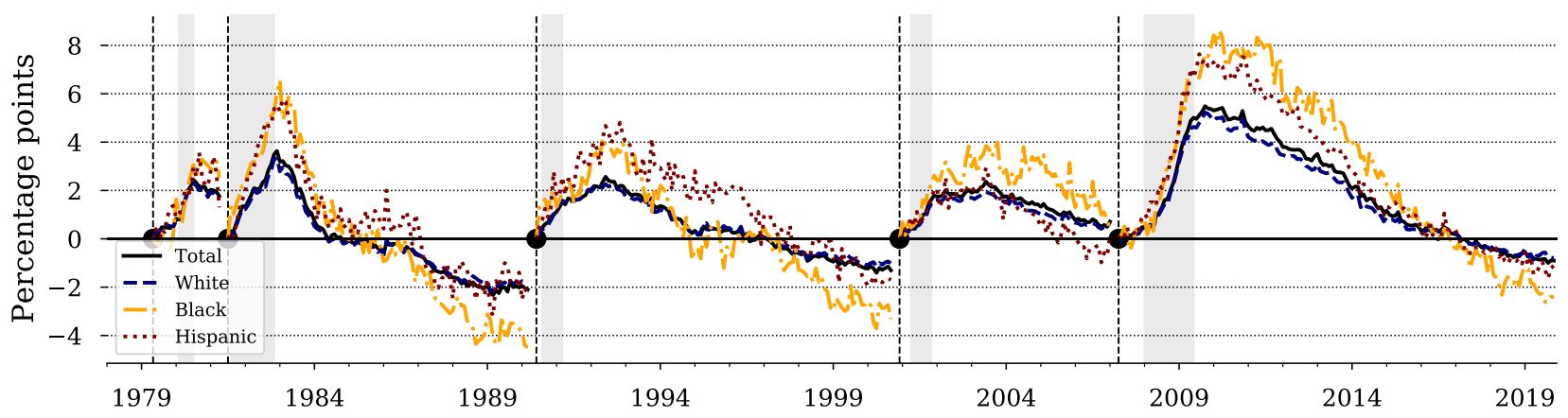

(d) Race and ethnicity

Figure 11: Change in unemployment rate across recessions by different demographics, 1978-2019 Source: BLS and author's calculations. 


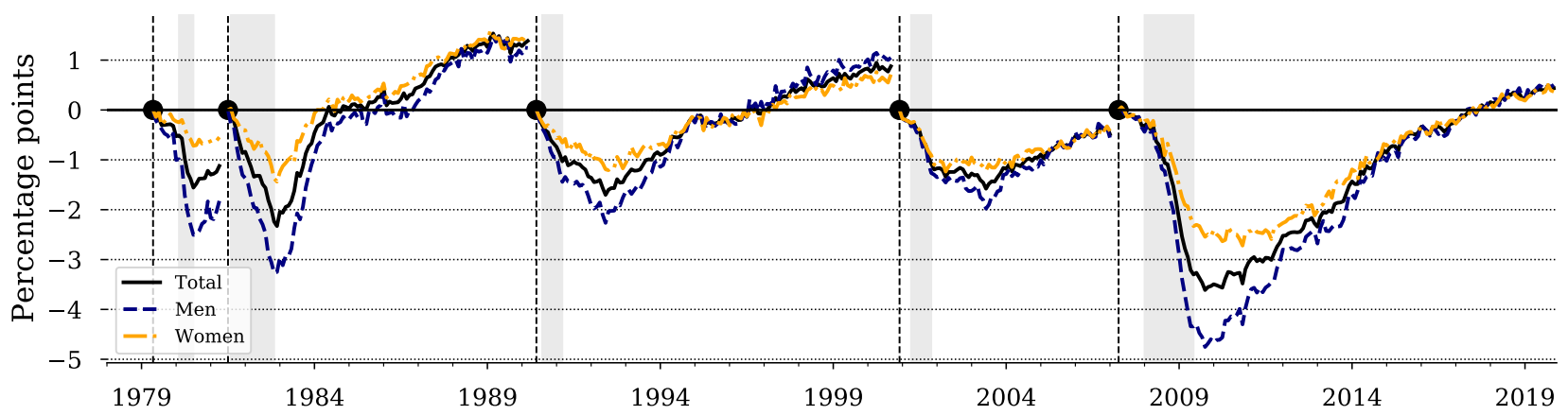

(a) Sex

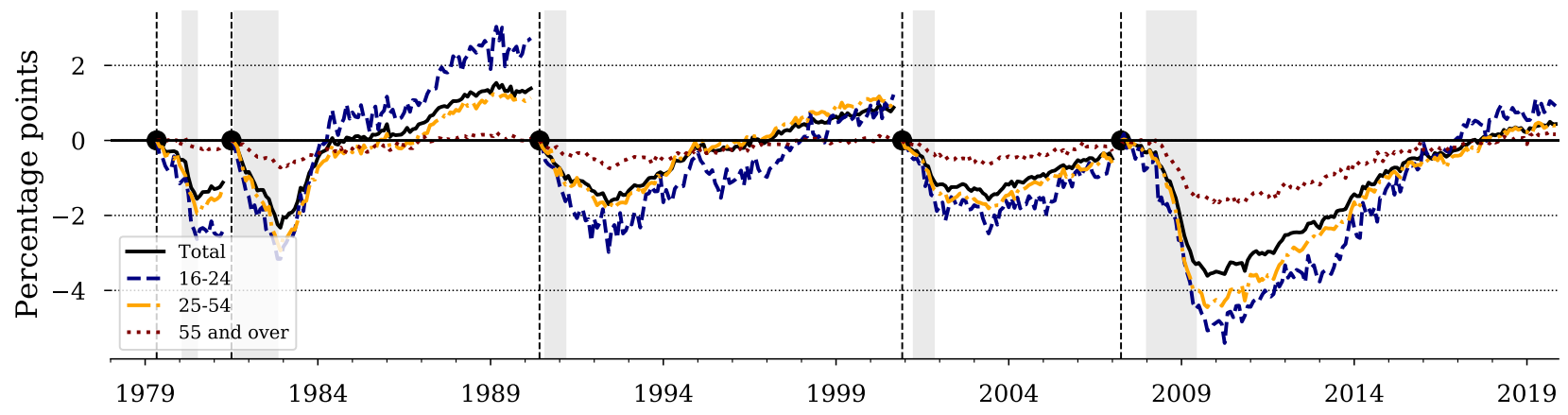

(b) Age

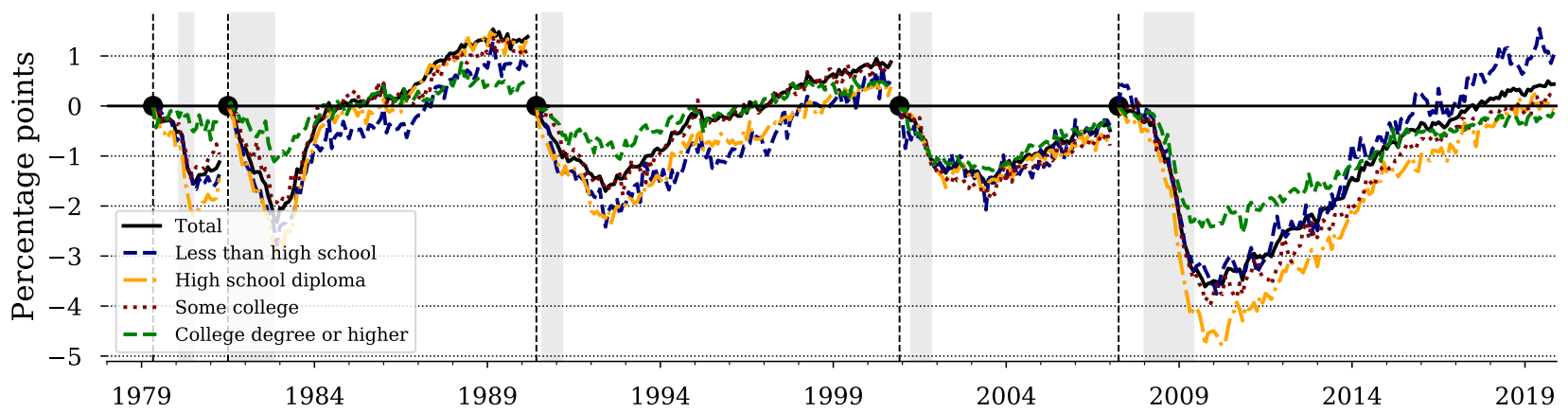

(c) Education

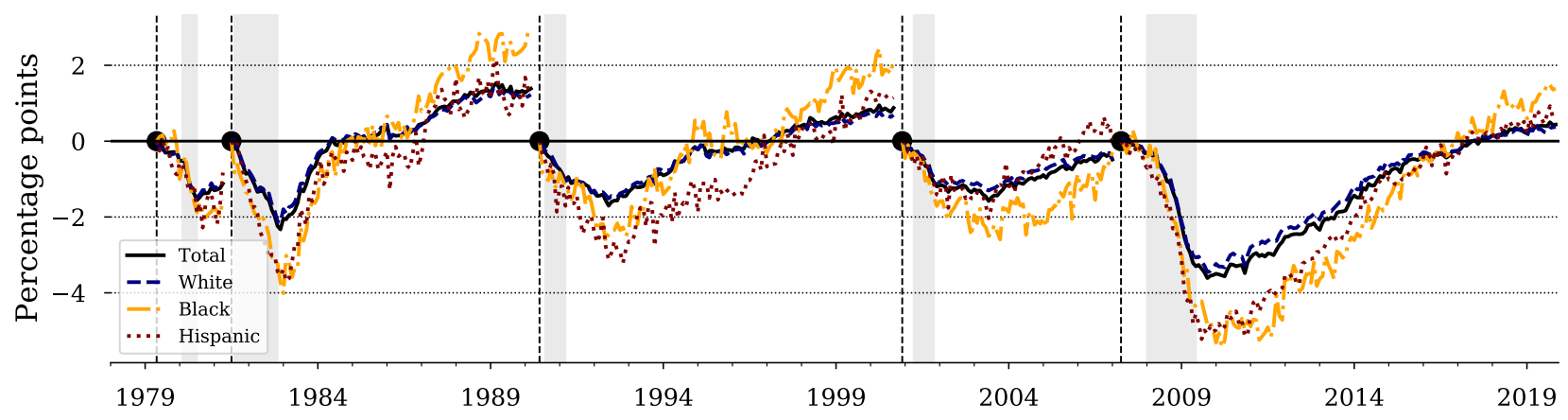

(d) Race and ethnicity

Figure 12: Unemployment cycles of EPOP ratio, $\Delta u$ cycle, by different demographics, 19782019

Source: BLS and author's calculations. 


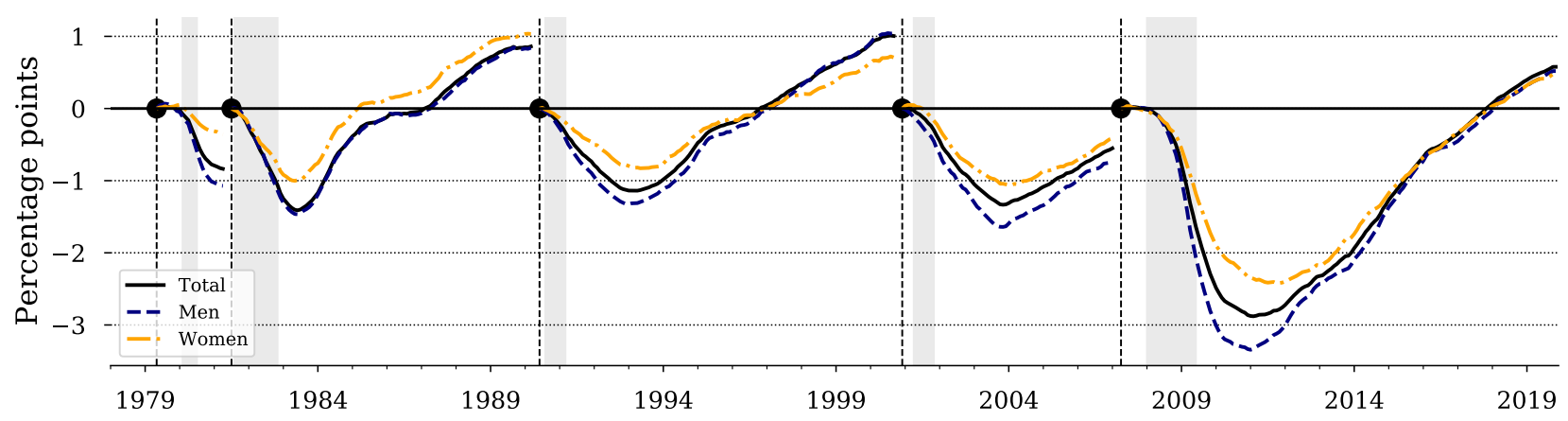

(a) Sex

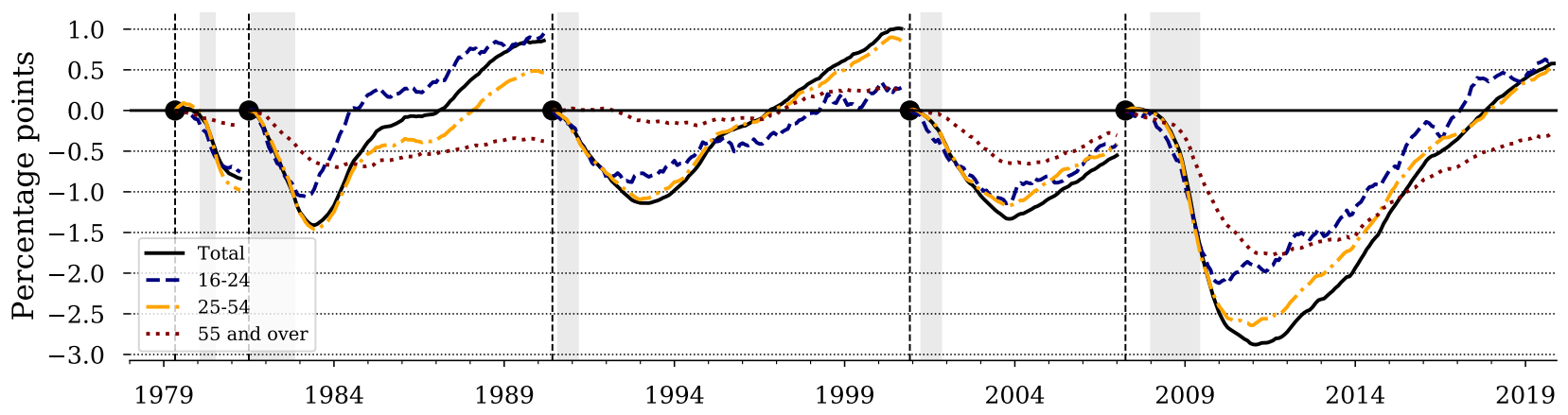

(b) Age

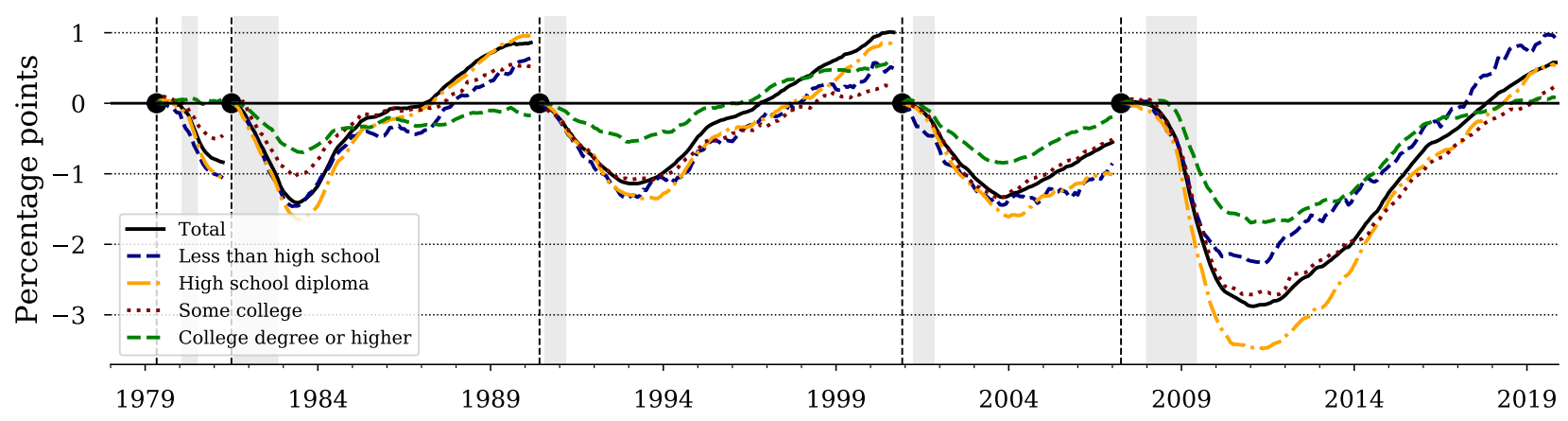

(c) Education

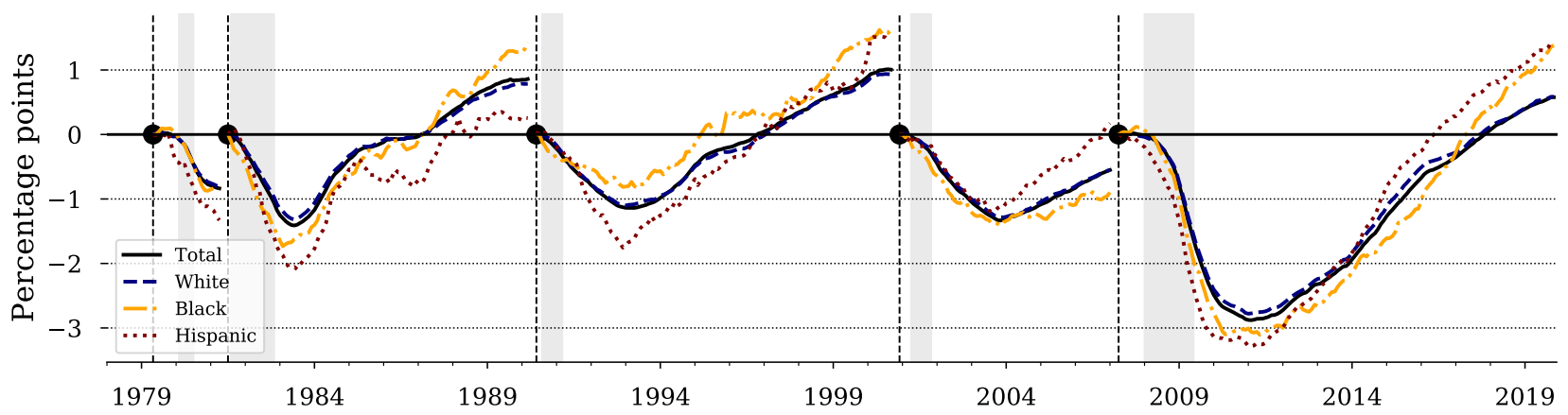

(d) Race and ethnicity

Figure 13: Participation cycles of EPOP ratio, $L F P R^{c}$, by different demographics, 1978-2019 Source: BLS and author's calculations. 

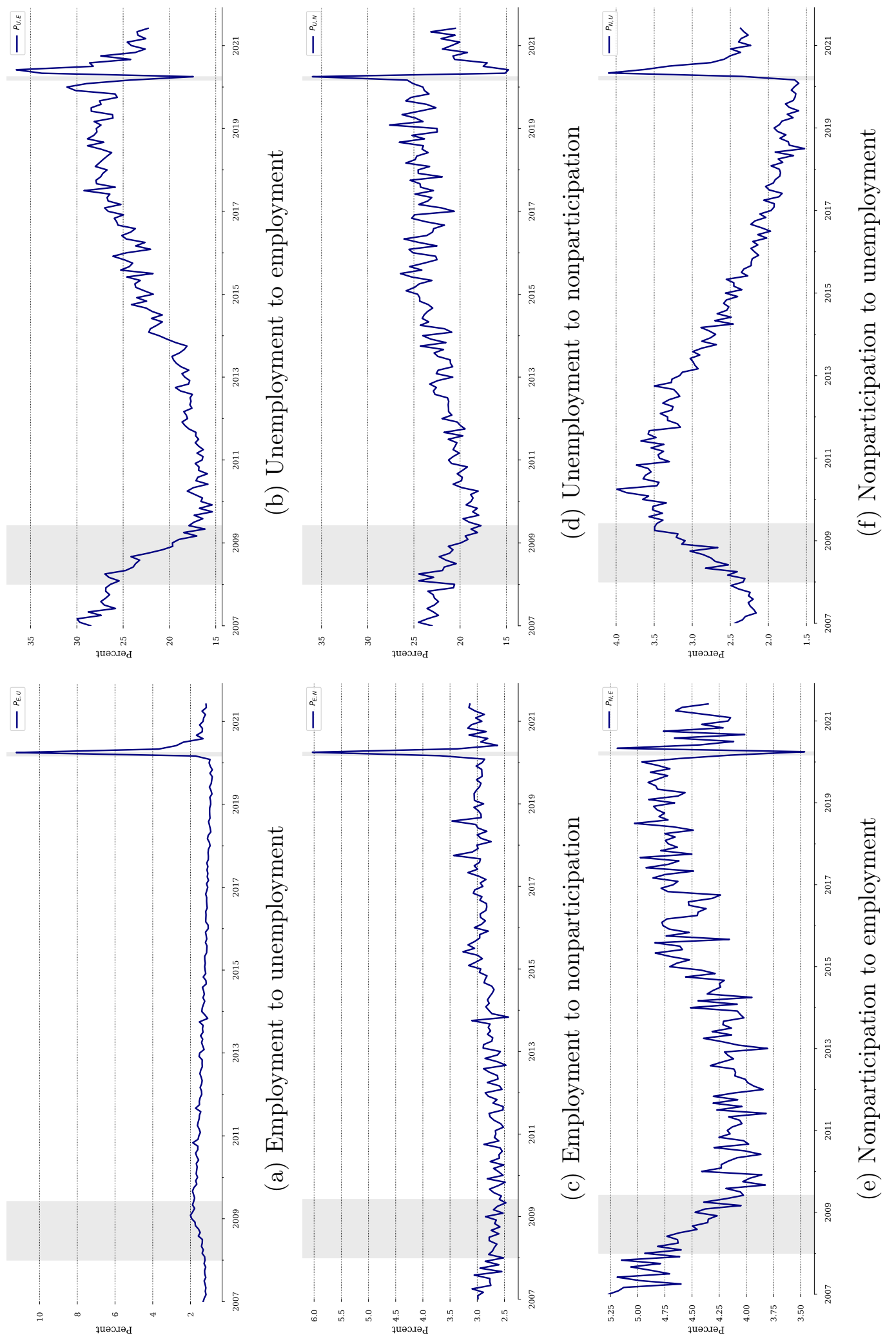




(a) unemployment-to-population (UPOP)

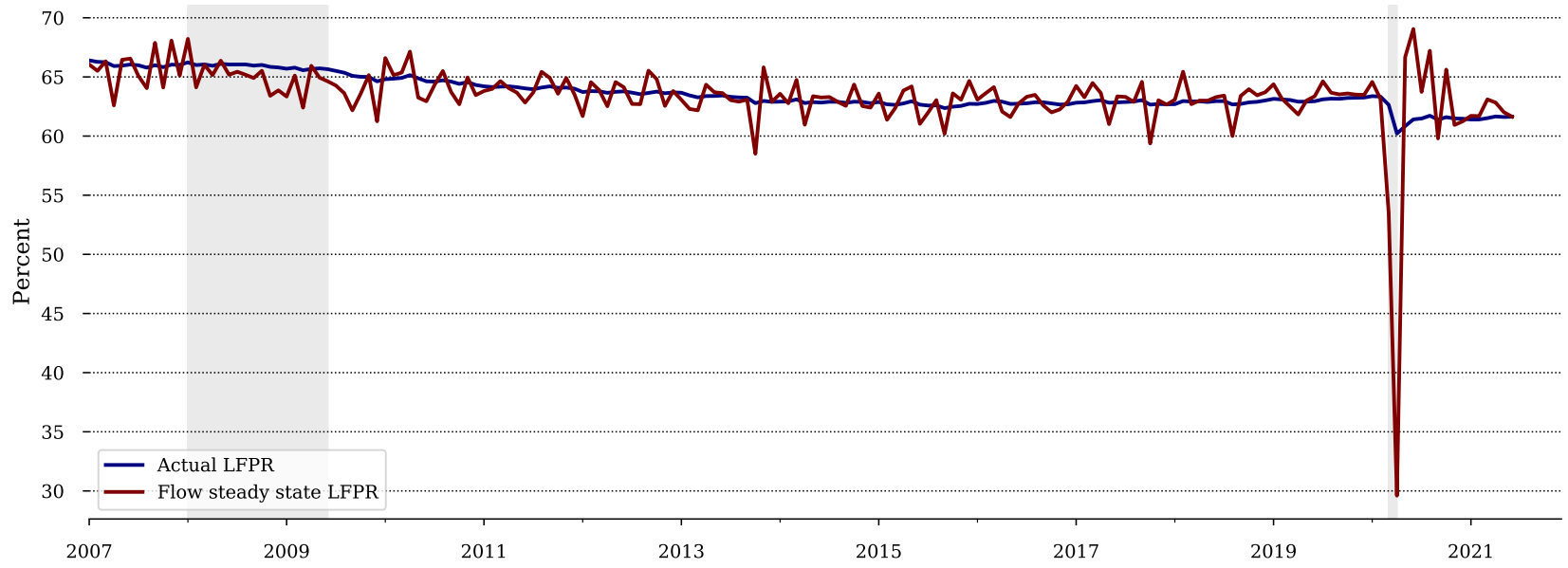

(b) labor force participation rate (LFPR)

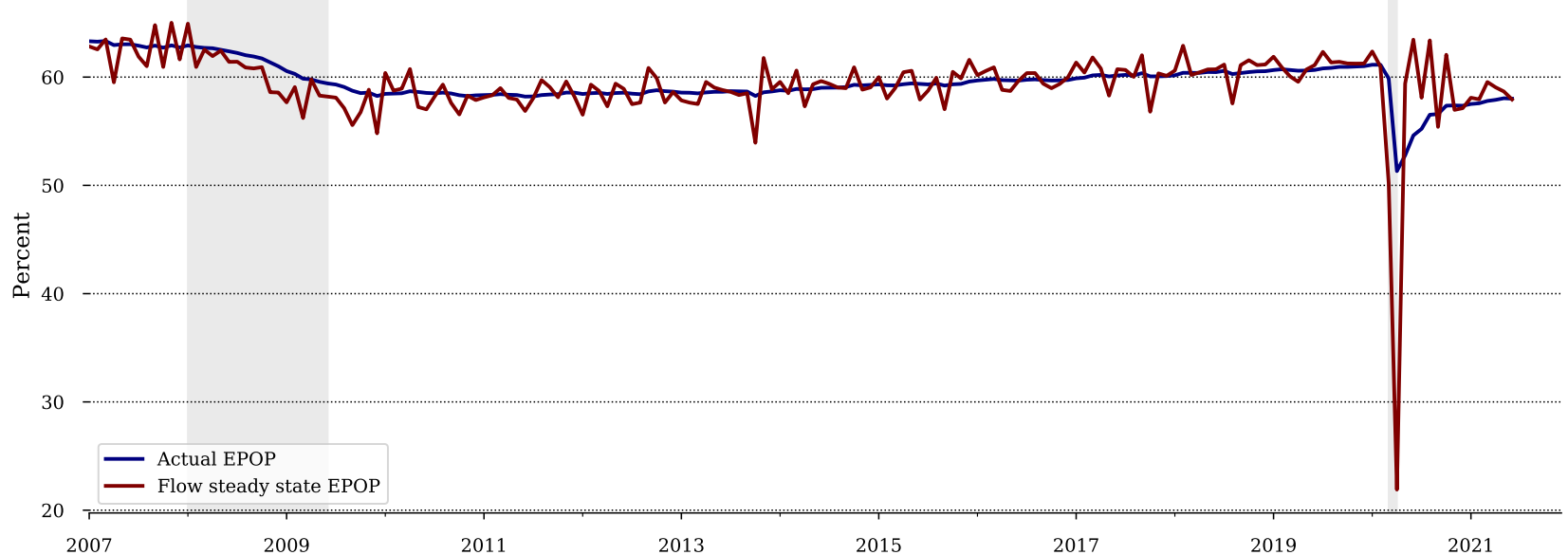

(c) employment-to-population (EPOP)

Figure 15: Actual and flow steady-state UPOP ratio, EPOP ratio, LFPR, Jan 2007-Jun 2021 Source: BLS, CPS, and authors' calculations. 


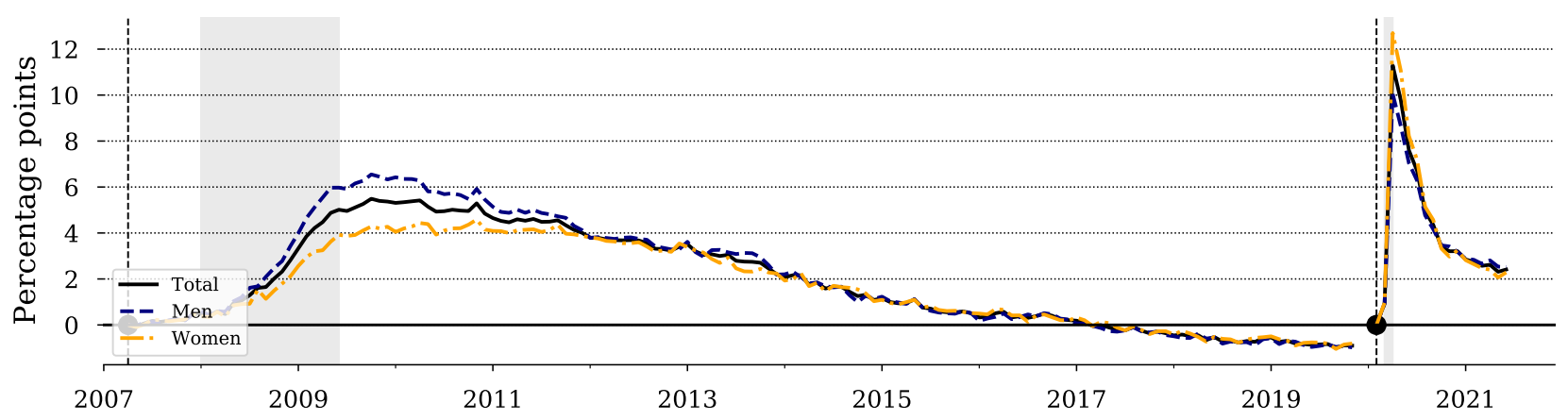

(a) Sex

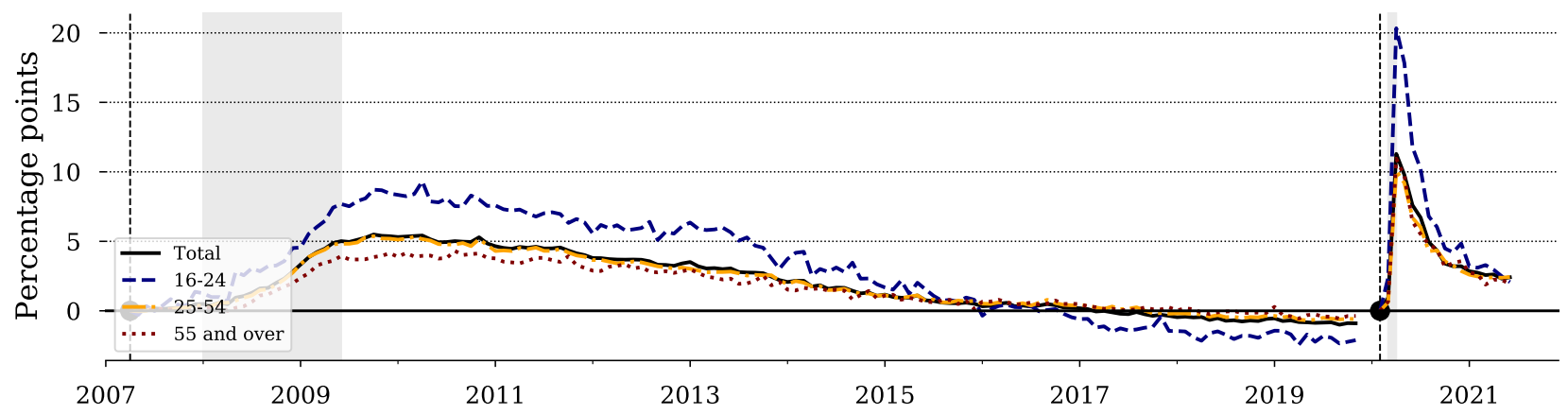

(b) Age

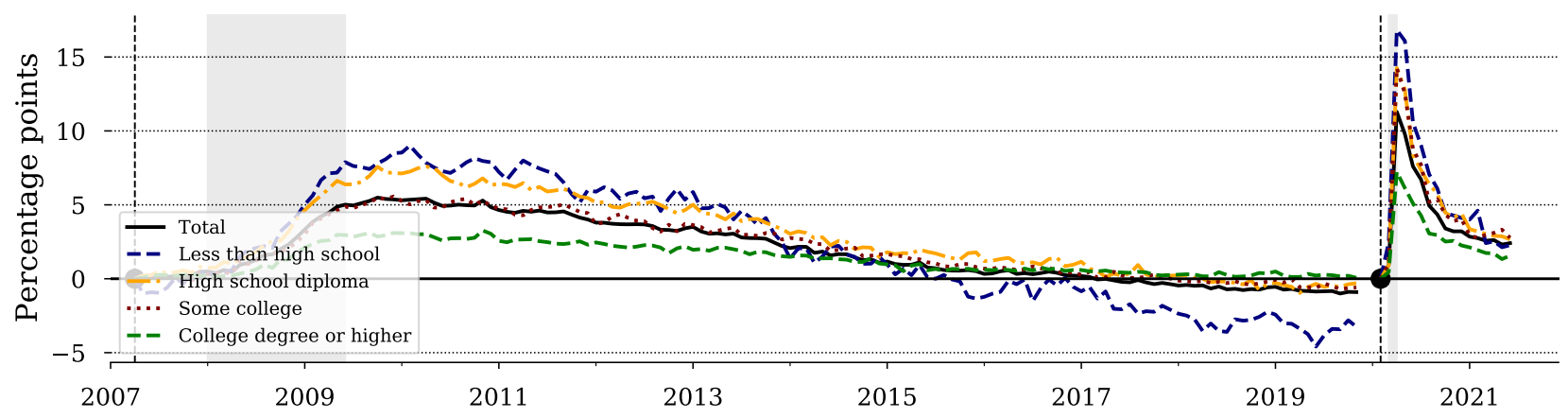

(c) Education

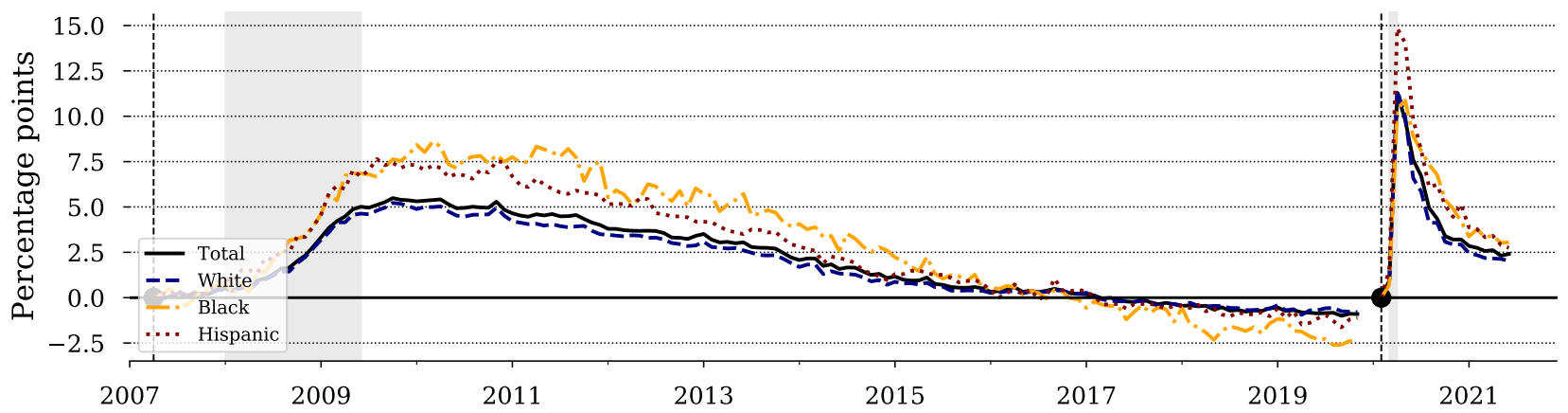

(d) Race and ethnicity

Figure 16: Change in unemployment rate across in Great and COVID-19 Recessions Source: BLS and author's calculations. 


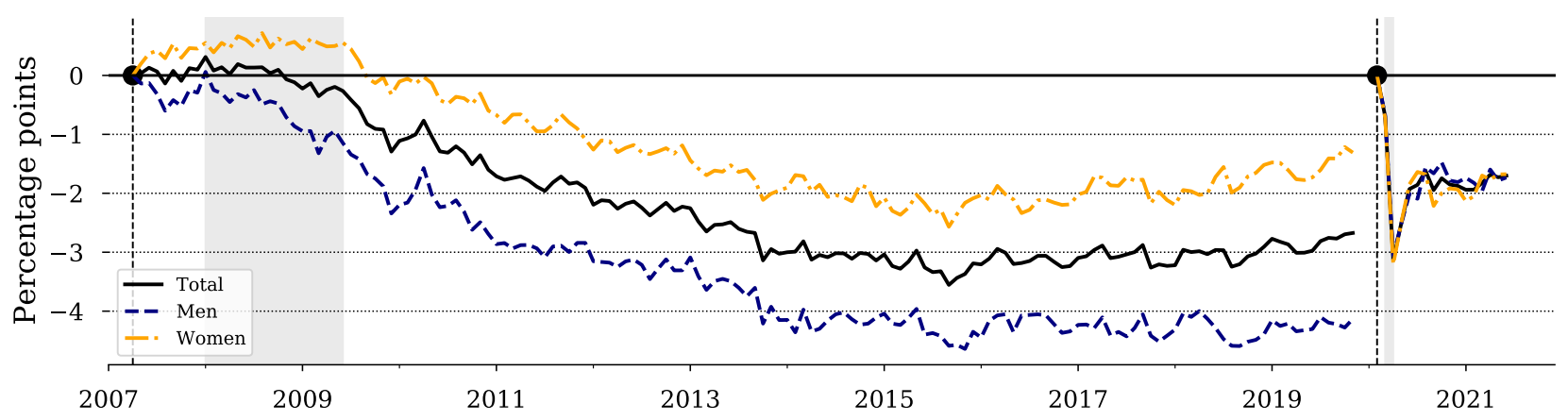

(a) Sex



(b) Age

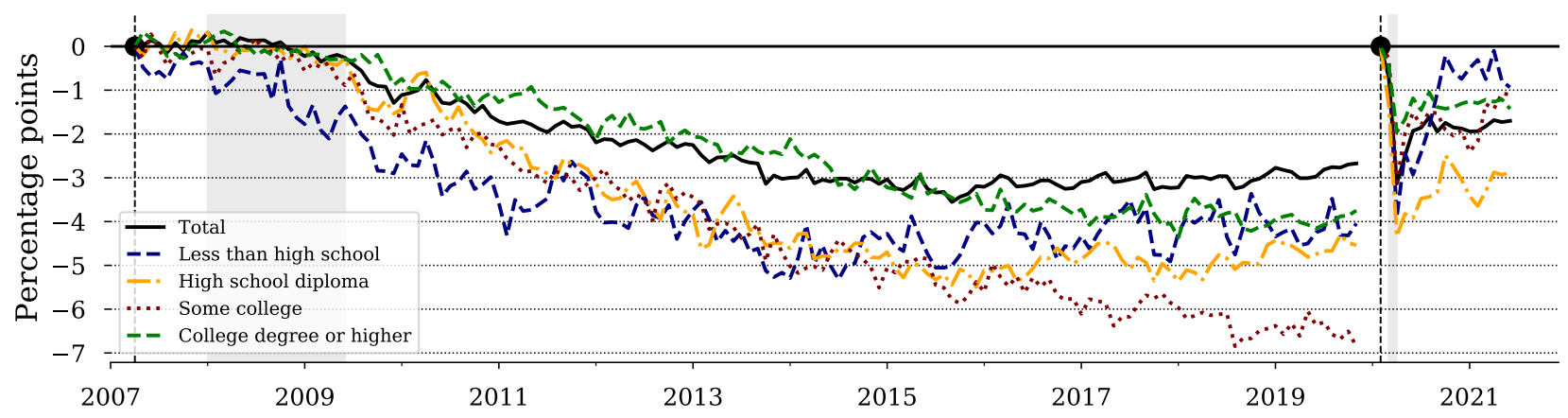

(c) Education

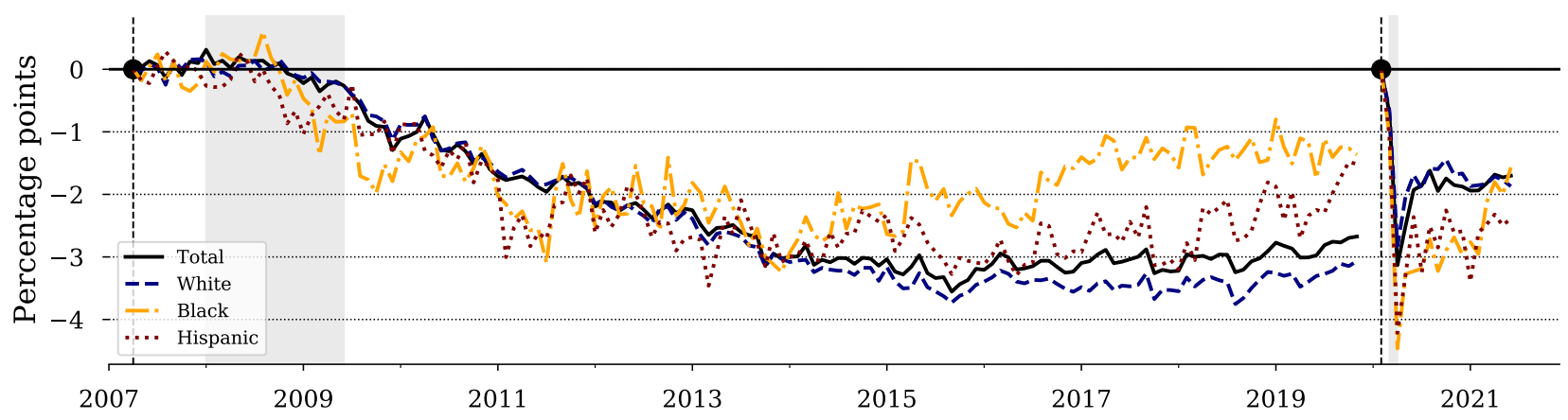

(d) Race and ethnicity

Figure 17: Change in participation rate in Great and COVID-19 Recessions Source: BLS and author's calculations. 


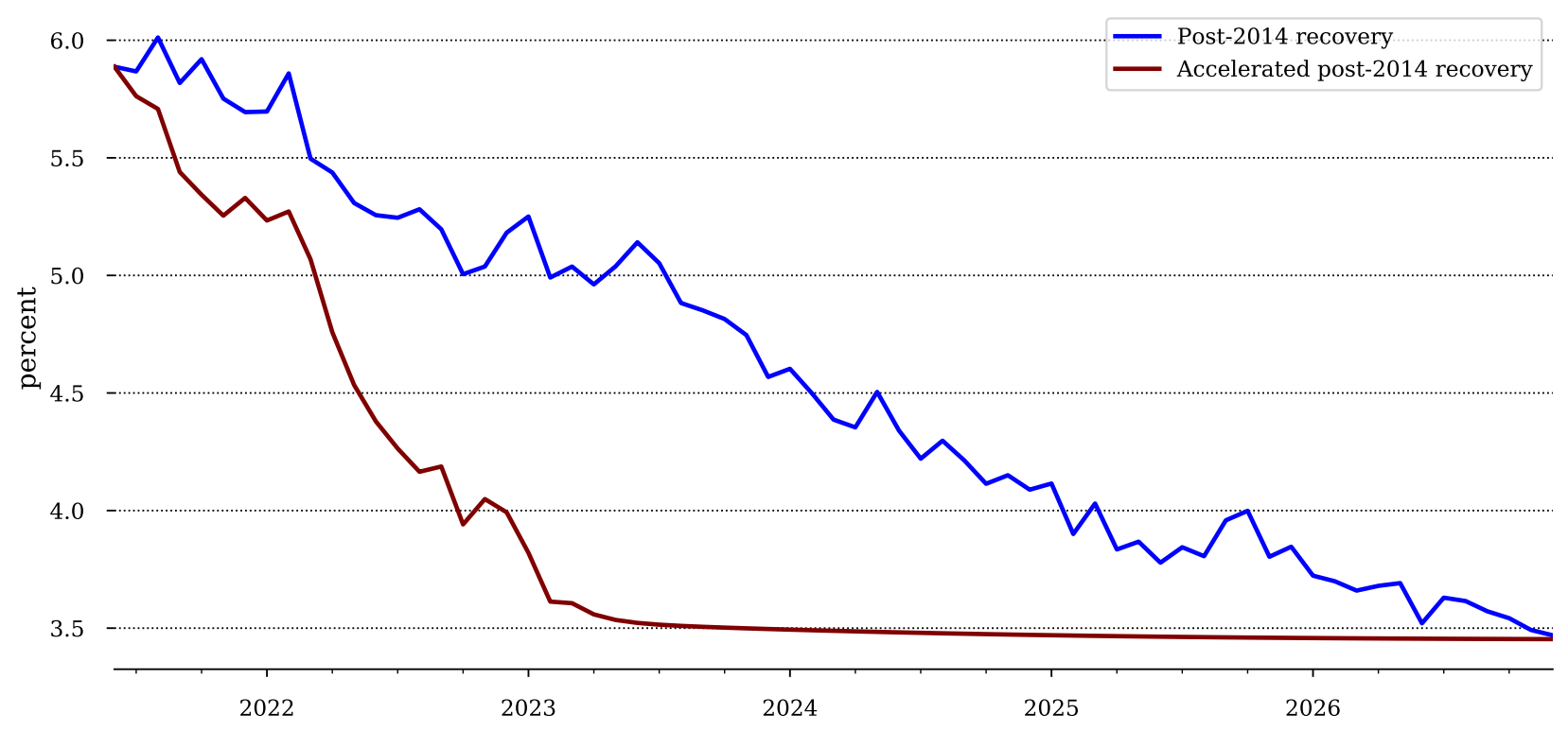

(a) Unemployment rate

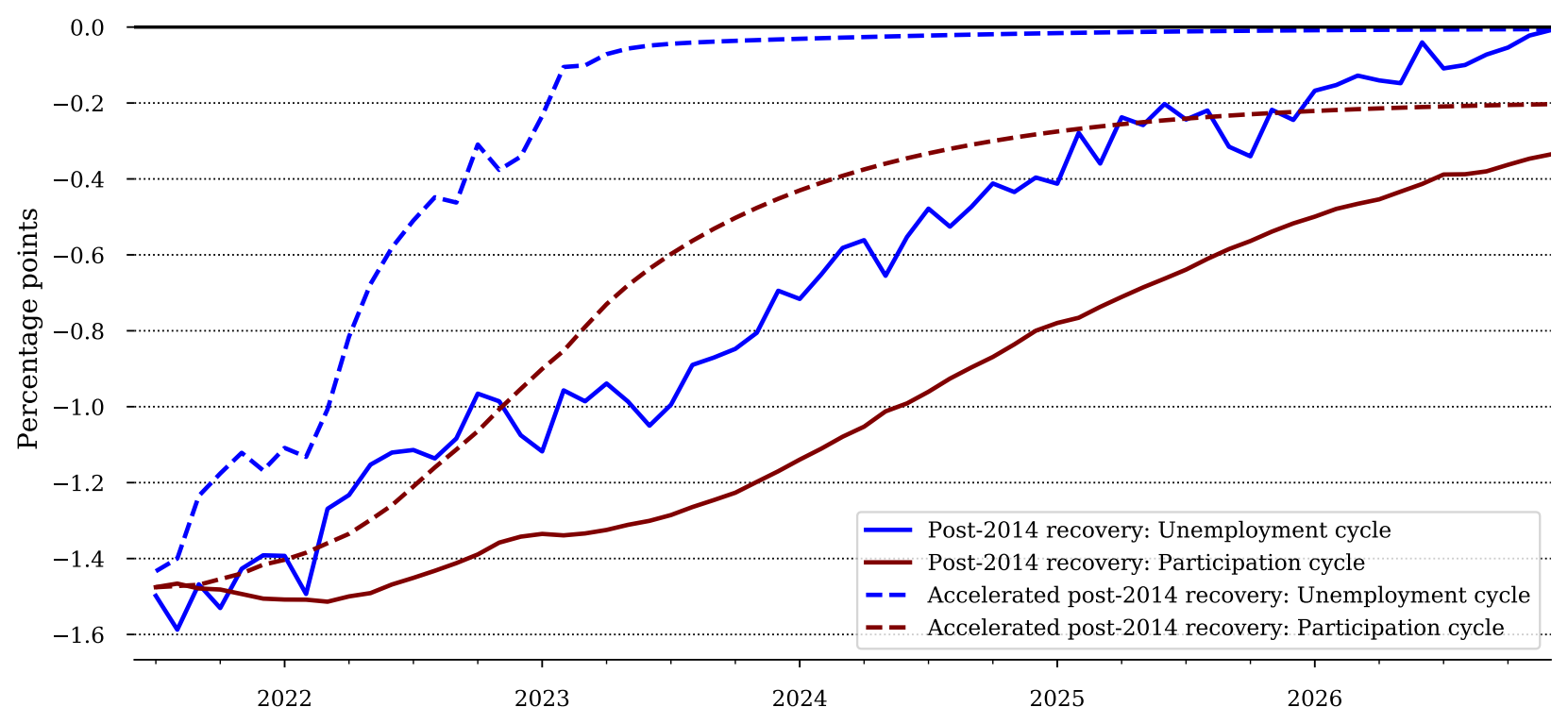

(b) Unemployment and participation cycles

Figure 18: Projections based on post-2014 recovery in flow rates

Source: BLS and author's calculations.

Note: Unemployment and participation cycles plotted in terms of percentage point cyclical pressures on the EPOP ratio."Post-2014 recovery" based on path of flow rates from Sep 2014 - Feb 2020. In case of "Accelerated post-2014 recovery"path of flow rates is three times faster than the baseline case. Transition probabilities for projections calculated using equations (38)-(40) explained in the Appendix. These projections are not meant as forecasts but to illustrate the potential labor market dynamics during the recovery going forward. 

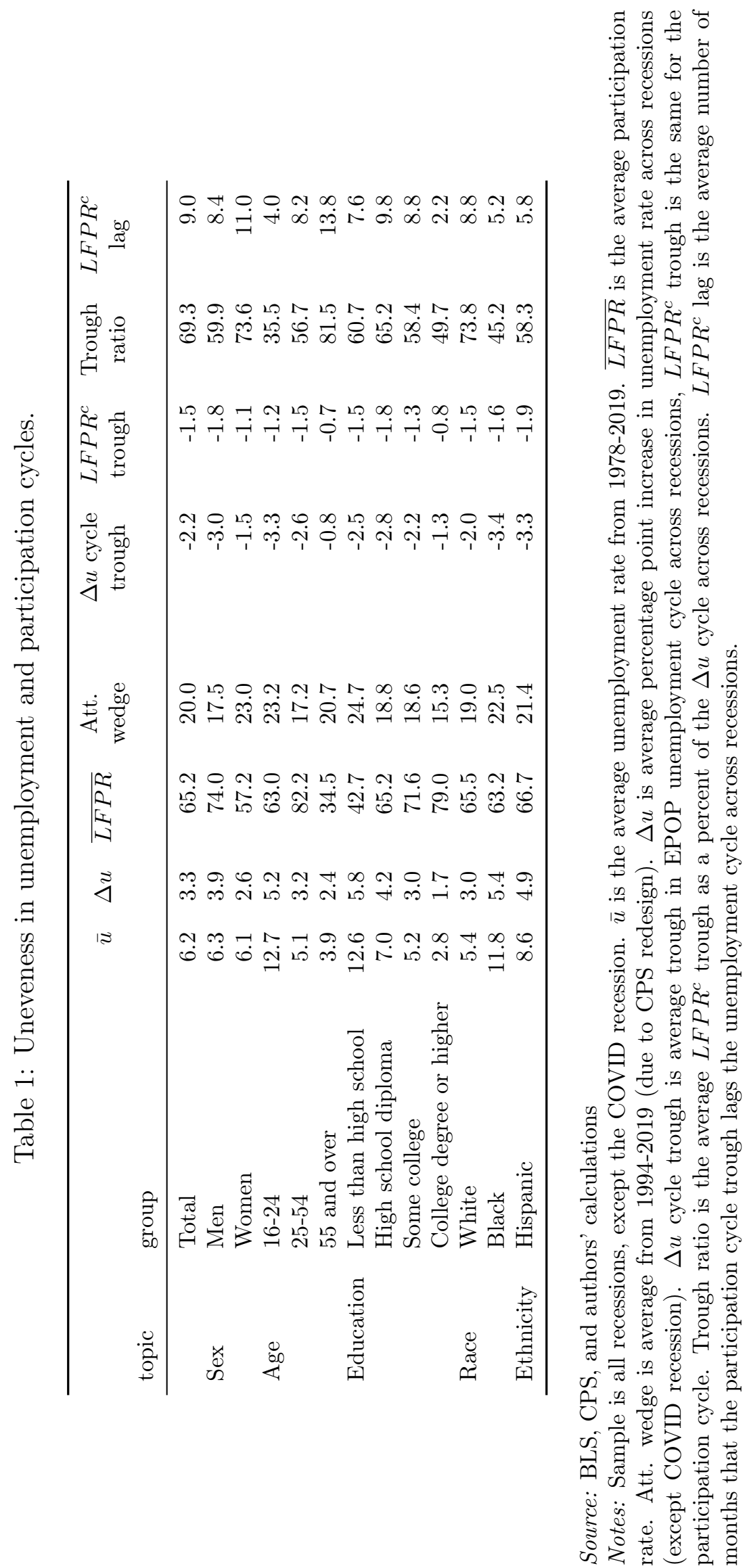
Table 2: Deviations from the Perry-Okun rule by group.

\begin{tabular}{llrl}
\hline \multirow{2}{*}{ topic } & group & mean & std \\
\hline \multirow{3}{*}{ Sex } & Total & & \\
\multirow{4}{*}{ Age } & Men & 0.03 & 0.17 \\
& Women & 0.00 & 0.24 \\
& $16-24$ & 0.02 & 0.15 \\
Education & -0.22 & 0.39 \\
& $25-54$ & -0.04 & 0.20 \\
& Less than high school & -0.01 & 0.11 \\
& High school diploma & 0.32 \\
Race & Some college & -0.04 & 0.25 \\
& College degree or higher & -0.00 \\
Ethnicity & White & 0.19 \\
& Black & -0.12 & 0.18 \\
& Hispanic & 0.50 \\
& & -0.05 & 0.48 \\
\hline
\end{tabular}

Source: BLS, CBO, CPS, and authors' calculations

Notes: Mean and standard deviation of the residual from the Perry-Okun rule (in percentage points of EPOP ratio). Perry-Okun rule is calculated as difference between cumulative 12-month change in participation cycle and unemployment cycle of EPOP during labor market expansions when the unemployment rate is less than half a percentage point higher than the long-run natural rate of the CBO. 
Table 3: Sources of change in LFPR between Sep-2014, Feb-2020, and Jun-2021

\begin{tabular}{|c|c|c|c|c|c|c|c|}
\hline from & topic & group & Actual & Cycle & Entry & Exit & Adj.dyn. \\
\hline \multirow[t]{13}{*}{$02 / 20$} & & Total & -1.7 & -1.5 & 0.0 & -0.0 & -0.2 \\
\hline & \multirow{2}{*}{ Sex } & Men & -1.8 & -1.6 & 0.6 & -0.5 & -0.2 \\
\hline & & Women & -1.7 & -1.2 & -0.7 & 0.5 & -0.3 \\
\hline & \multirow[t]{3}{*}{ Age } & $16-24$ & -0.9 & -0.6 & -0.7 & 0.1 & 0.3 \\
\hline & & $25-54$ & -1.6 & -1.2 & 0.2 & -0.2 & -0.3 \\
\hline & & 55 and over & -1.9 & -1.0 & -0.5 & -0.1 & -0.3 \\
\hline & \multirow[t]{4}{*}{ Education } & Less than high school & -0.5 & -0.6 & 1.0 & -0.2 & -0.7 \\
\hline & & High school diploma & -2.9 & -1.5 & -0.3 & -1.2 & 0.1 \\
\hline & & Some college & -1.7 & -1.7 & 1.6 & 0.4 & -2.0 \\
\hline & & College degree or higher & -1.5 & -0.9 & -1.0 & 0.7 & -0.3 \\
\hline & \multirow[t]{2}{*}{ Race } & White & -1.8 & -1.5 & -0.3 & -0.5 & 0.4 \\
\hline & & Black & -1.9 & -1.2 & 0.0 & 0.6 & -1.2 \\
\hline & Ethnicity & Hispanic & -2.1 & -1.6 & 0.7 & -1.5 & 0.3 \\
\hline \multirow[t]{13}{*}{$9 / 14$} & & Total & -1.3 & 0.4 & 0.1 & $\begin{array}{ll}-1.1 \\
\end{array}$ & -0.7 \\
\hline & \multirow[t]{2}{*}{ Sex } & Men & -1.8 & 0.3 & 0.0 & -1.8 & -0.2 \\
\hline & & Women & -0.9 & 0.5 & 0.1 & -0.2 & -1.2 \\
\hline & \multirow[t]{3}{*}{ Age } & $16-24$ & 0.4 & 1.0 & -0.1 & 0.1 & -0.5 \\
\hline & & $25-54$ & 0.4 & 0.1 & 2.3 & -1.4 & -0.6 \\
\hline & & 55 and over & -1.5 & 0.2 & 0.1 & -1.9 & 0.1 \\
\hline & \multirow[t]{4}{*}{ Education } & Less than high school & 0.2 & 1.2 & 2.1 & -2.1 & -1.0 \\
\hline & & High school diploma & -2.5 & 0.2 & 0.7 & -2.6 & -0.8 \\
\hline & & Some college & -3.7 & 0.2 & -0.9 & -2.0 & -1.0 \\
\hline & & College degree or higher & -2.6 & 0.1 & -0.6 & -0.8 & -1.2 \\
\hline & \multirow[t]{2}{*}{ Race } & White & -1.6 & 0.1 & -0.4 & -1.3 & -0.1 \\
\hline & & Black & -0.4 & 1.5 & 1.3 & -1.9 & -1.3 \\
\hline & Ethnicity & Hispanic & -0.7 & 0.2 & 1.9 & -2.5 & -0.4 \\
\hline
\end{tabular}

Source: BLS, CPS, and authors' calculations

Notes: Decomposition of $\triangle L F P R_{t}$ between date in 'from' column and June 2021. 'Actual' is the percentage point change in the LFPR between the 'from' date and June 2021. The 'Cycle' column is the part of 'ActualSS' due to EU and UE transitions, the 'Exit' part due EN and UN, and the 'Entry' part due to NE and NU.'Adj.dyn.' is the percentage point difference between the change actual and in the flow steady-state LFPR. Steady state evaluated over 6-month moving average of flow rates. 


\section{A Mathematical and computational details}

\section{Distributed Lag of Past Changes in Flow Steady State}

Recursively solving (11) forward we obtain

$$
\begin{aligned}
\Delta \boldsymbol{s}_{t} & =\boldsymbol{P}_{t}\left(\boldsymbol{I}+\boldsymbol{P}_{t-1}\right) \boldsymbol{P}_{t-1}^{-1} \Delta \boldsymbol{s}_{t-1}-\boldsymbol{P}_{t} \Delta \overline{\boldsymbol{s}}_{t} \\
& =\boldsymbol{P}_{t}\left(\boldsymbol{I}+\boldsymbol{P}_{t-1}\right)\left(\boldsymbol{I}+\boldsymbol{P}_{t-2}\right) \boldsymbol{P}_{t-2} \Delta \boldsymbol{s}_{t-2}-\boldsymbol{P}_{t}\left(\boldsymbol{I}+\boldsymbol{P}_{t-1}\right) \Delta \overline{\boldsymbol{s}}_{t-1}-\boldsymbol{P}_{t} \Delta \overline{\boldsymbol{s}}_{t} \\
& =-\boldsymbol{P}_{t}\left(\boldsymbol{I}+\boldsymbol{P}_{t}\right)^{-1} \sum_{l=0}^{\infty} \prod_{j=0}^{l}\left(\boldsymbol{I}+\boldsymbol{P}_{t-j}\right) \Delta \overline{\boldsymbol{s}}_{t-l}
\end{aligned}
$$

The minus sign in the last line of this equation might be confusing, but most elements of $\boldsymbol{P}_{t}$, except the first row second column, are negative. Thus, the current change in the labor market state vector is a complicated lag structure of the past changes in the flow steady-state.

Substituting in (14) yields

$$
\begin{aligned}
\Delta \boldsymbol{s}_{t}= & \boldsymbol{P}_{t}\left(\boldsymbol{I}+\boldsymbol{P}_{t}\right)^{-1} \sum_{l=0}^{\infty} \prod_{j=0}^{l}\left(\boldsymbol{I}+\boldsymbol{P}_{t-j}\right)\left[\frac{1}{2}\left(\boldsymbol{P}_{t-l}+\boldsymbol{P}_{t-l-1}\right)\right]^{-1} \\
& \times\left[\Delta \boldsymbol{d}_{t-l}+\frac{1}{2} \Delta \boldsymbol{P}_{t-l}\left(\overline{\boldsymbol{s}}_{t-l}+\overline{\boldsymbol{s}}_{t-l-1}\right)\right]
\end{aligned}
$$

\section{Participation cycle and the attachment wedge}

The LFPR cycle is the changes in $\boldsymbol{\iota}_{2}^{\prime} \boldsymbol{s}_{t}$ due changes in $P_{E, U, t}$ and $P_{U, E, t}$. The main intuition of what is driving this cycle is to ignore the lagged effects because of deviations from the steady state and, instead, focus on the effect of $P_{E, U, t}$ and $P_{U, E, t}$ on $\iota^{\prime} \overline{\boldsymbol{s}}_{t}$.

This involves identifying the parts of (14) associated with $\Delta P_{E, U, t}$ and $\Delta P_{U, E, t}$. For this, it is important to realize that

$$
\frac{\partial \boldsymbol{d}_{t}}{\partial P_{E, U, t}}=\frac{\partial \boldsymbol{d}_{t}}{\partial P_{U, E, t}}=\mathbf{0}, \frac{\partial \boldsymbol{P}_{t}}{\partial P_{E, U, t}}=\left[\begin{array}{cc}
-1 & 0 \\
1 & 0
\end{array}\right] \text {, and } \frac{\partial \boldsymbol{P}_{t}}{\partial P_{U, E, t}}=\left[\begin{array}{cc}
0 & 1 \\
0 & -1
\end{array}\right]
$$

Using equation (14) this yields that

$$
\begin{aligned}
\frac{\partial \overline{\boldsymbol{s}}_{t}}{\partial P_{E, U, t}}=\left(\boldsymbol{P}_{t}+\boldsymbol{P}_{t-1}\right)^{-1}\left[\begin{array}{c}
\left(\bar{E}_{t}+\bar{E}_{t-1}\right) \\
-\left(\bar{E}_{t}+\bar{E}_{t-1}\right)
\end{array}\right] \text { and } \\
\frac{\partial \overline{\boldsymbol{s}}_{t}}{\partial P_{u, e, t}}=\left(\boldsymbol{P}_{t}+\boldsymbol{P}_{t-1}\right)^{-1}\left[\begin{array}{c}
-\left(\bar{U}_{t}+\bar{U}_{t-1}\right) \\
\left(\bar{U}_{t}+\bar{U}_{t-1}\right)
\end{array}\right],
\end{aligned}
$$


The change in the LFPR cycle is given by

$$
\begin{aligned}
\Delta L F P R_{t}^{c} & =\iota_{2}^{\prime}\left(\frac{\partial \overline{\boldsymbol{s}}_{t}}{\partial P_{E, U, t}} \Delta p_{E, U, t}+\frac{\partial \overline{\boldsymbol{s}}_{t}}{\partial P_{U, E, t}} \Delta p_{U, E, t}\right) \\
& =\boldsymbol{\iota}_{2}^{\prime}\left(\boldsymbol{P}_{t}+\boldsymbol{P}_{t-1}\right)^{-1}\left[\begin{array}{c}
1 \\
-1
\end{array}\right]\left(\left(\bar{E}_{t}+\bar{E}_{t-1}\right) \Delta p_{e, u, t}-\left(\bar{U}_{t}+\bar{U}_{t-1}\right) \Delta p_{U, E, t}\right) \\
& =\iota_{2}^{\prime}\left(\boldsymbol{P}_{t}+\boldsymbol{P}_{t-1}\right)^{-1}\left[\begin{array}{c}
1 \\
-1
\end{array}\right] \overline{L F P R}_{t}\left(\left(1-\bar{u}_{t}\right) \Delta p_{e, u, t}-\bar{u}_{t} \Delta p_{u, e, t}\right),
\end{aligned}
$$

where,

$$
\overline{L F P R}_{t}=1 / 2\left(\bar{E}_{t}+\bar{E}_{t-1}+\bar{U}_{t}+\bar{U}_{t-1}\right) \text { and } \bar{u}_{t}=\frac{1 / 2\left(\bar{U}_{t}+\bar{U}_{t-1}\right)}{\overline{L F P R}_{t}} .
$$

$\overline{L F P R}_{t}$ is the flow steady-state labor force participation rate and $\bar{u}_{t}$ is the flow steady-state unemployment rate, both averaged across periods $t$ and $t-1$. Solving for the matrix expression at the beginning of this equation yields

$$
\boldsymbol{\iota}_{2}^{\prime} \overline{\boldsymbol{P}}_{t}^{-1}\left[\begin{array}{c}
1 \\
-1
\end{array}\right]=\frac{1}{D_{t}}\left(\bar{P}_{E, N, t}-\bar{P}_{U, N, t}\right)
$$

Where $D_{t}$ is the determinant of $\overline{\boldsymbol{P}}_{t}=1 / 2\left(\boldsymbol{P}_{t}+\boldsymbol{P}_{t-1}\right), \bar{P}_{E, N, t}=1 / 2\left(P_{E, N, t}+P_{E, N, t-1}\right)$, and $\bar{P}_{U, N, t}=1 / 2\left(P_{U, N, t}+P_{U, N, t-1}\right)$.

This gives that the part of the change in the LFPR cycle that works through the contemporaneous effect on the flow steady state equals

$$
\Delta L F P R_{t}^{c}=-\frac{1}{D_{t}} \overline{L F P R}_{t}\left(\bar{P}_{U, N, t}-\bar{P}_{E, N, t}\right)\left(\left(1-\bar{u}_{t}\right) \Delta P_{E, U, t}-\bar{u}_{t} \Delta P_{U, E, t}\right)
$$

\section{Perry-Okun rule residuals}

The mean of the Perry-Okun residual for group $i, \mu_{i}$, reported in Table 2, is calculated as

$$
\mu_{i}=\frac{1}{n_{H}} \sum_{t \in H} \varepsilon_{i, t}, \varepsilon_{i, t}=[\sum_{j=0}^{12} \underbrace{\left(1-\bar{u}_{i, t-j}\right) \Delta L F P R_{i, t-j}^{c}}_{\text {participation cycle }}]-[\sum_{j=0}^{12} \underbrace{-\overline{L F P R}_{i, t-j} \Delta u_{i, t-j}}_{\text {unemployment cycle }}],
$$

Here $H$ is the set of months, $t$ that occur in a hot labor market that has lasted for more than a year. This consists of months $t$ during labor market expansions when the unemployment rate, $u_{t}$, is smaller than the natural rate, $u_{t}^{*}$, plus 0.5 percentage points and the same is true for $t-12 . n_{H}$ is the number of months in this set. The standard deviations are calculated in a 
similar way.

\section{Path of transition probabilities for projections}

The assumed paths of the transition probabilities for the projections presented in Subsection 6.4 are calculated using

$$
\begin{aligned}
P_{S, S^{\prime}, t} & =\phi_{t}^{\delta}\left(P_{S, S^{\prime}, J u n-21}-P_{S, S^{\prime}, \text { Sep-14 }}\right)+P_{S, S^{\prime}, \tau}, \text { where } \\
\tau & =\min \{\text { Sep }-14+\delta \times m(t, J u n-21), F e b-2020\}, \text { and } \\
\phi & =m(t, \text { Jun }-21) / m(t, \text { Jun }-21)
\end{aligned}
$$

Here $m\left(t^{\prime}, t\right)$ measures the distance between two dates in months. The parameter $\delta$ determines the speed of the recovery in the projections. For the baseline case, labeled the "Post-2014 recovery", $\delta=1$. For the accelerated recovery case $\delta=3$.

\section{B Data details}

\section{Reason for nonparticipation}

The reason for nonparticipation is constructed by combining data on an individuals' employment status, reason for not looking for work, and major activity while not in the labor force. Retired persons are the nonparticipants who report their employment status as retired. For those who are not retired, we first classify non-participants based on the reasons they report for not looking for work. Those who do not report such a reason are then classified based on their main activity while not participating in the labor market. ${ }^{45}$

\section{Additional empirical results}

\footnotetext{
${ }^{45}$ The results in this paper are calculated using the CPS-IPUMS extracts described in Flood et al. (2020).
} 


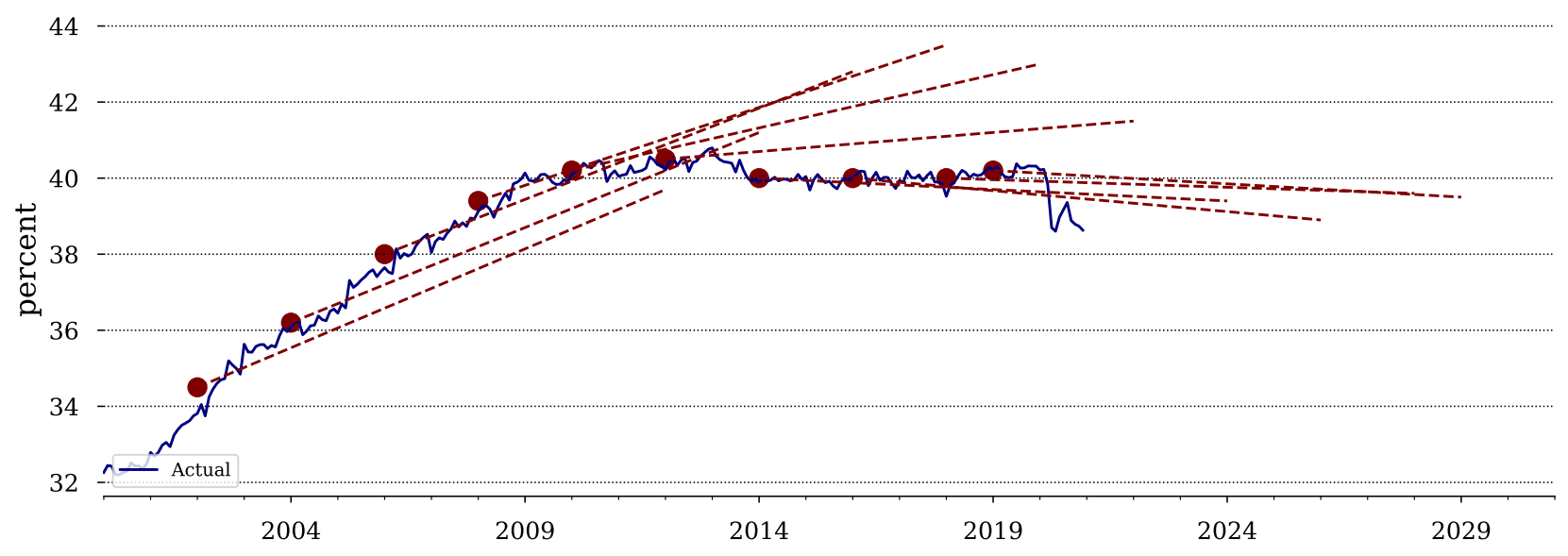

(a) Total, 65 and over

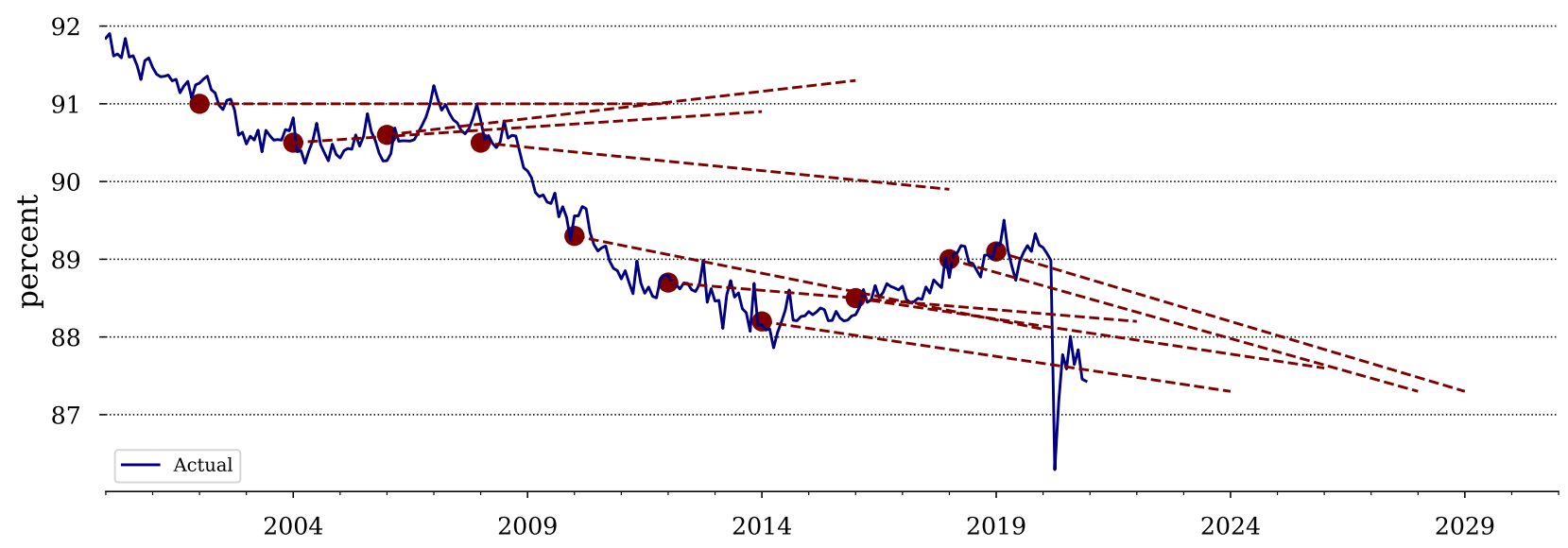

(b) Men, prime age (25-54)

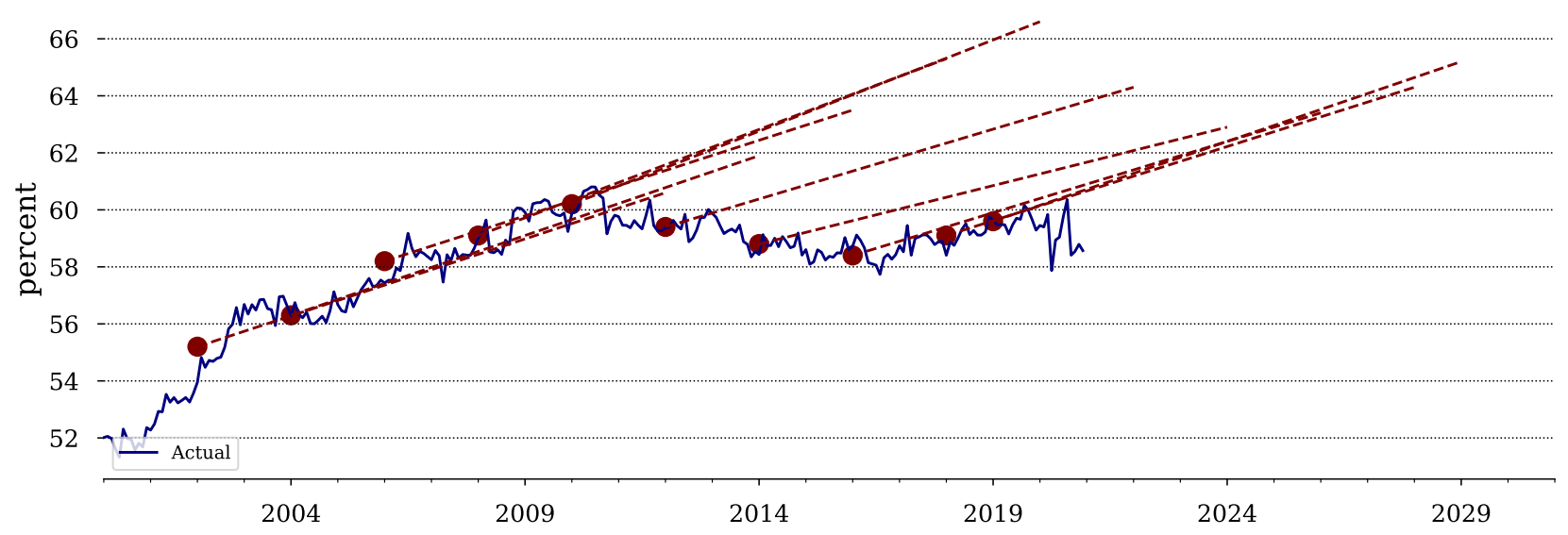

(c) Women, 55 to 64

Figure C.1: BLS LFPR projections for different age-gender groups.

Source: BLS Labor Force Projections, CPS, and authors' calculations.

Notes: Vintage of forecast is indicated by dot. Actual is seasonally adjusted monthly observations. Forecasts are linearly interpolated between beginning and end of 10-year forecast period. 

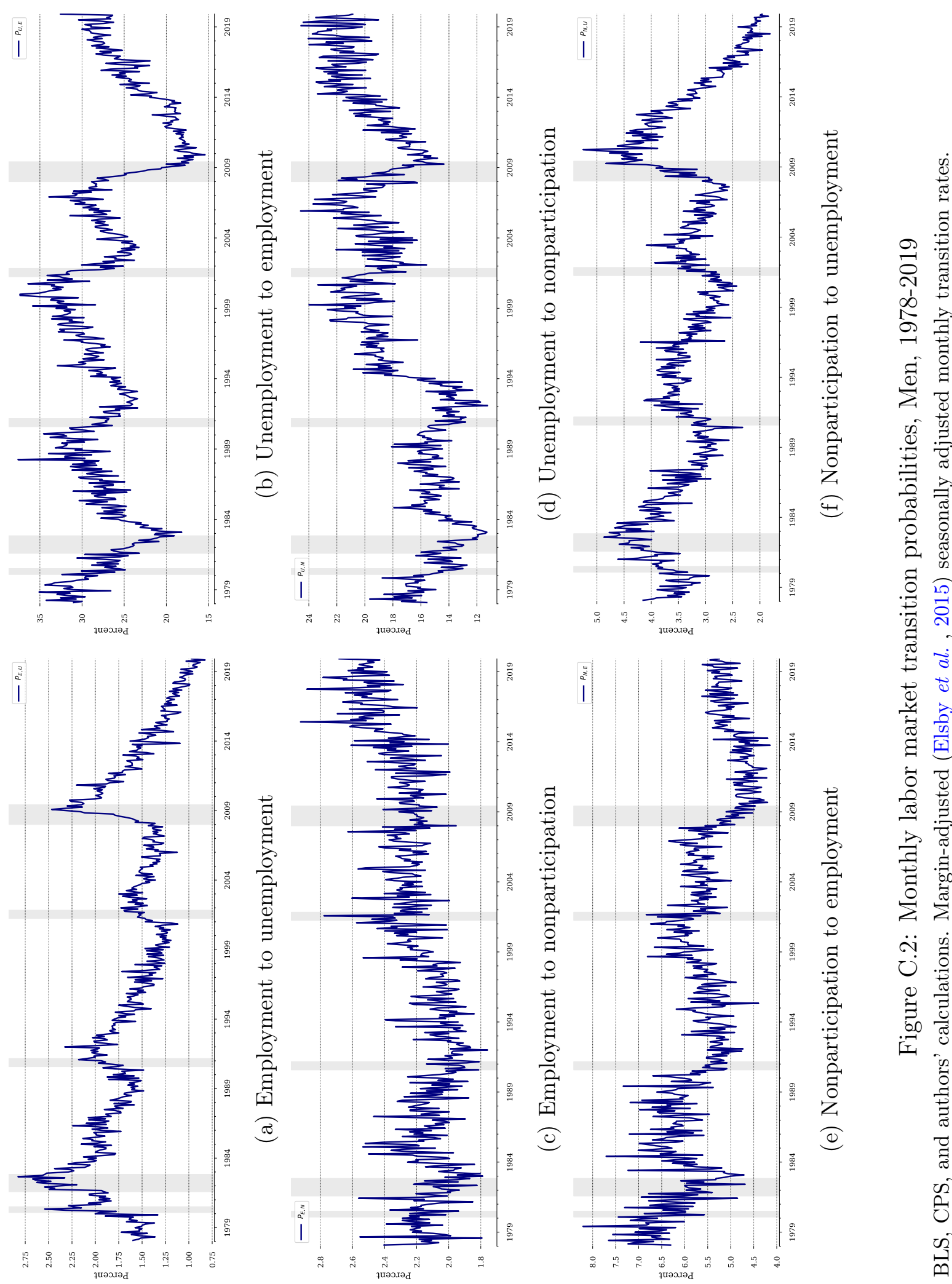

$\varpi$ वे

武

密

¿-1

D.

핑.

$\sum_{i}^{\circ}$

ণิ อี

0.

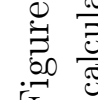

[I

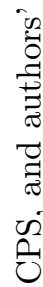

क 

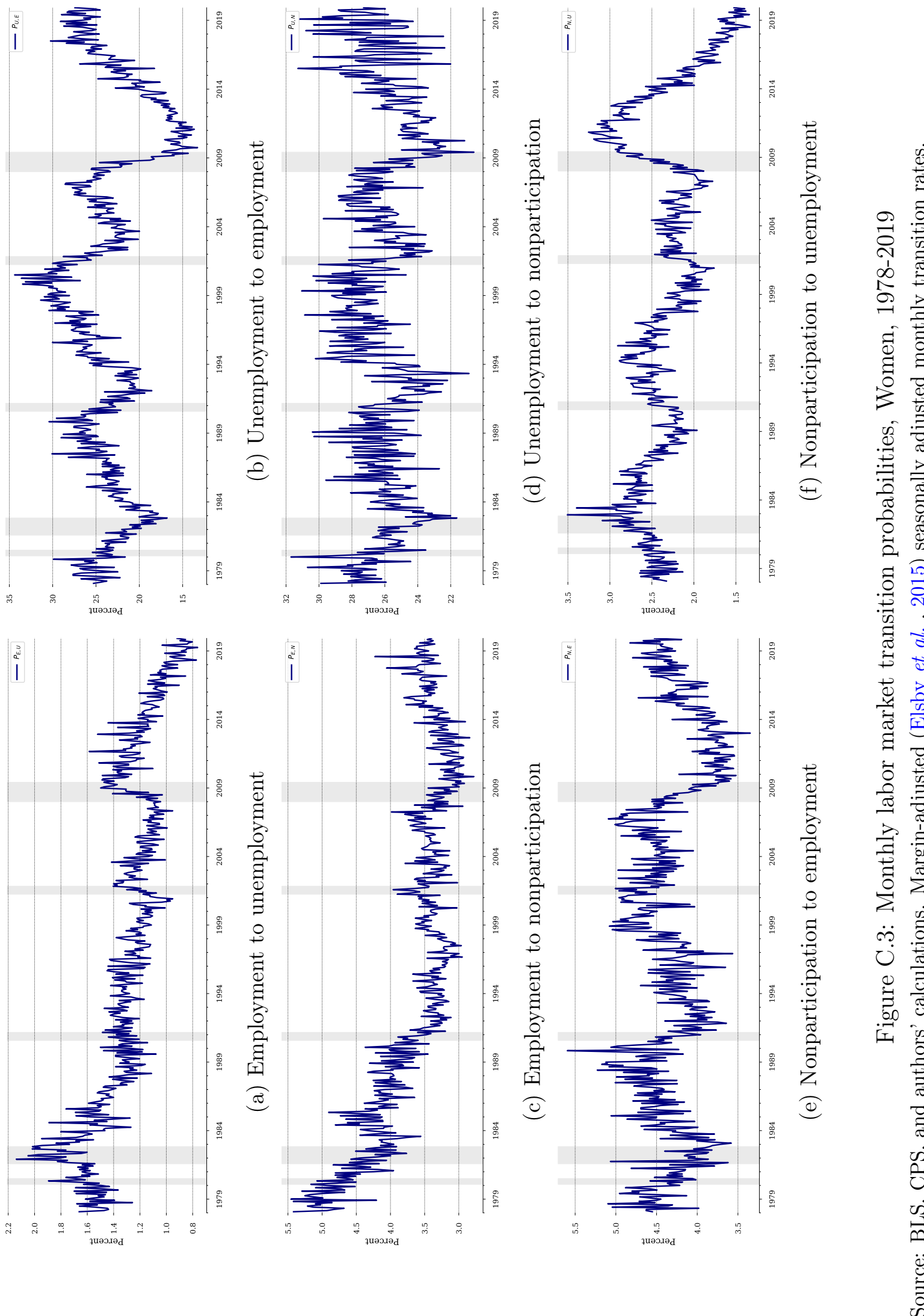

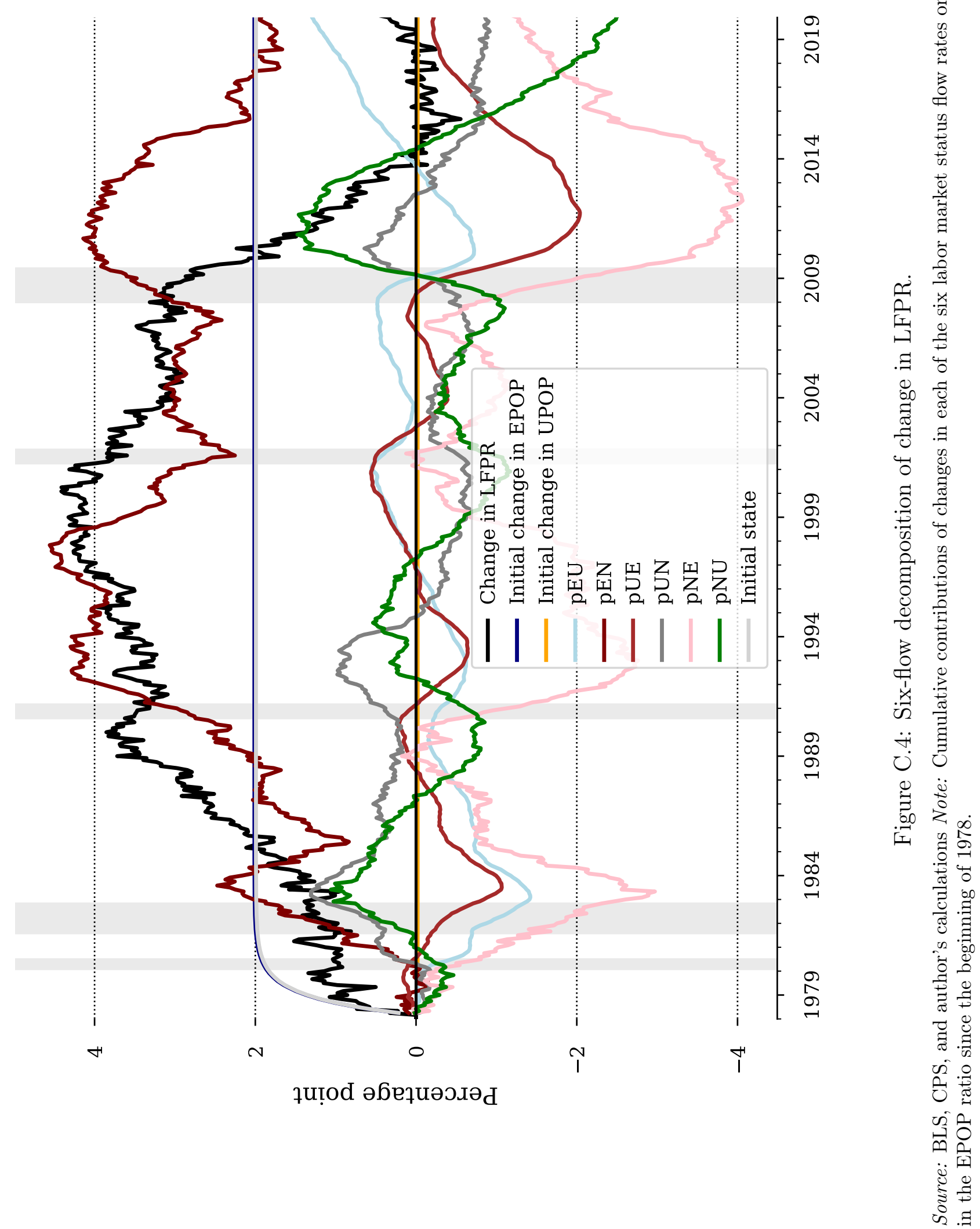


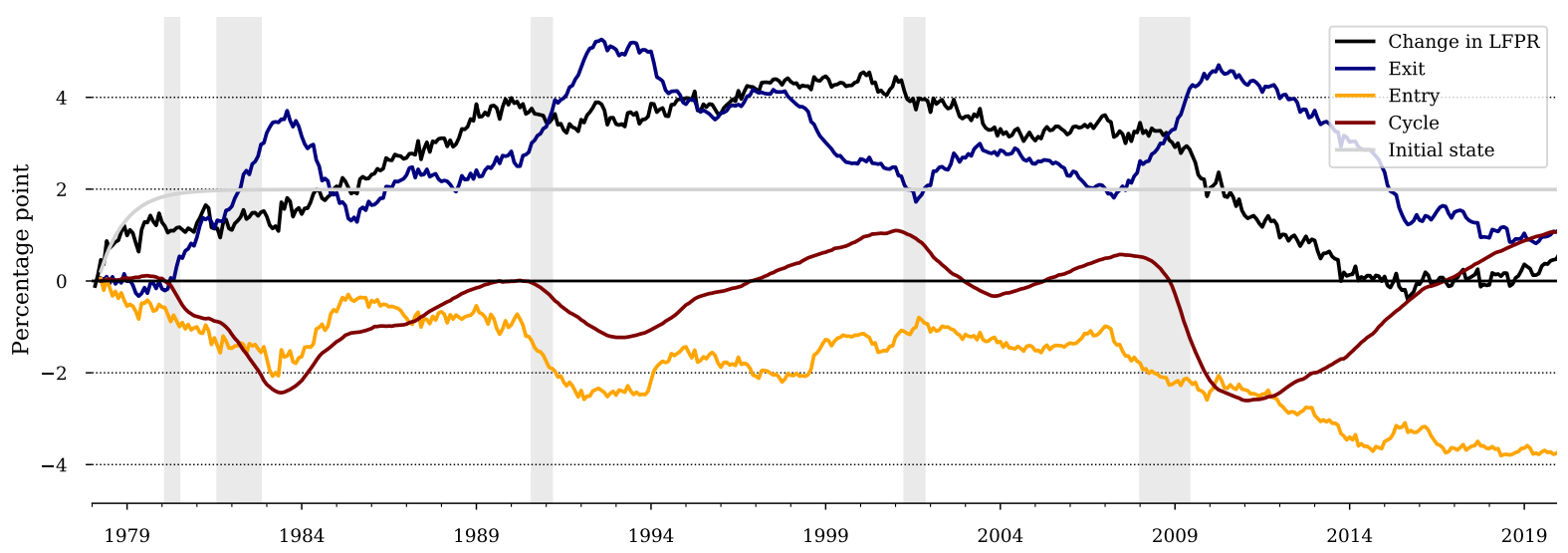

(a) Total

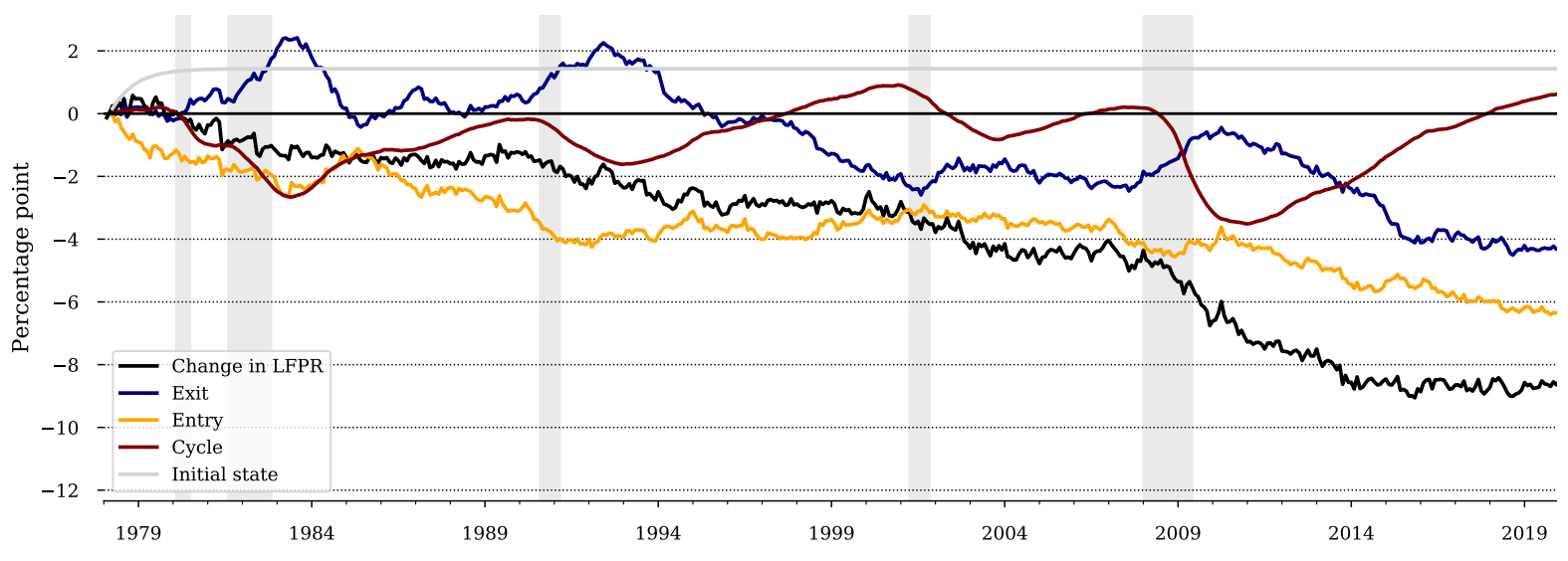

(b) Men

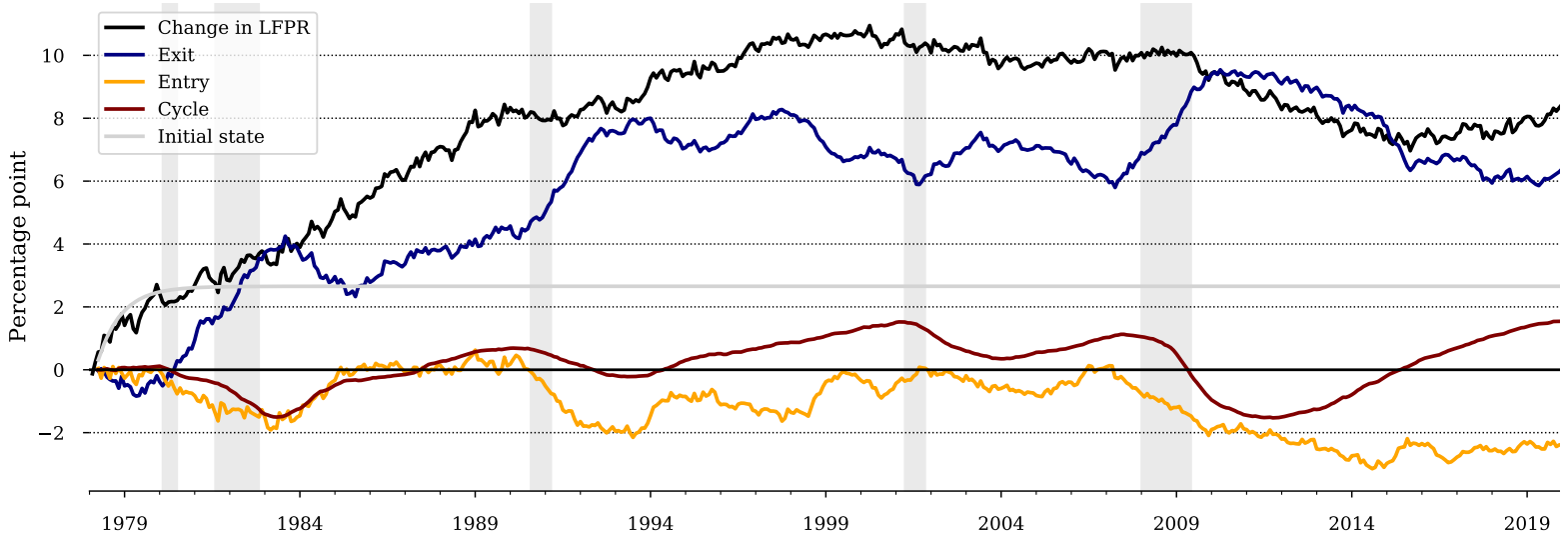

(c) Women

Figure C.5: Change in LFPR since January 1978 decomposed, 1978-2019

Source: BLS and author's calculations. Update of Elsby et al. (2019).

Note: Seasonally adjusted monthly data. Cumulative effect on EPOP ratiosince January 1978. Entry is contribution from $P_{N, U}$ and $P_{N, E}$, exit is contribution from $P_{U, N}$ and $P_{E, N}$, and cycle from flows between $U$ and $E$, i.e., $P_{E, U}$ and $P_{U, E}$. 


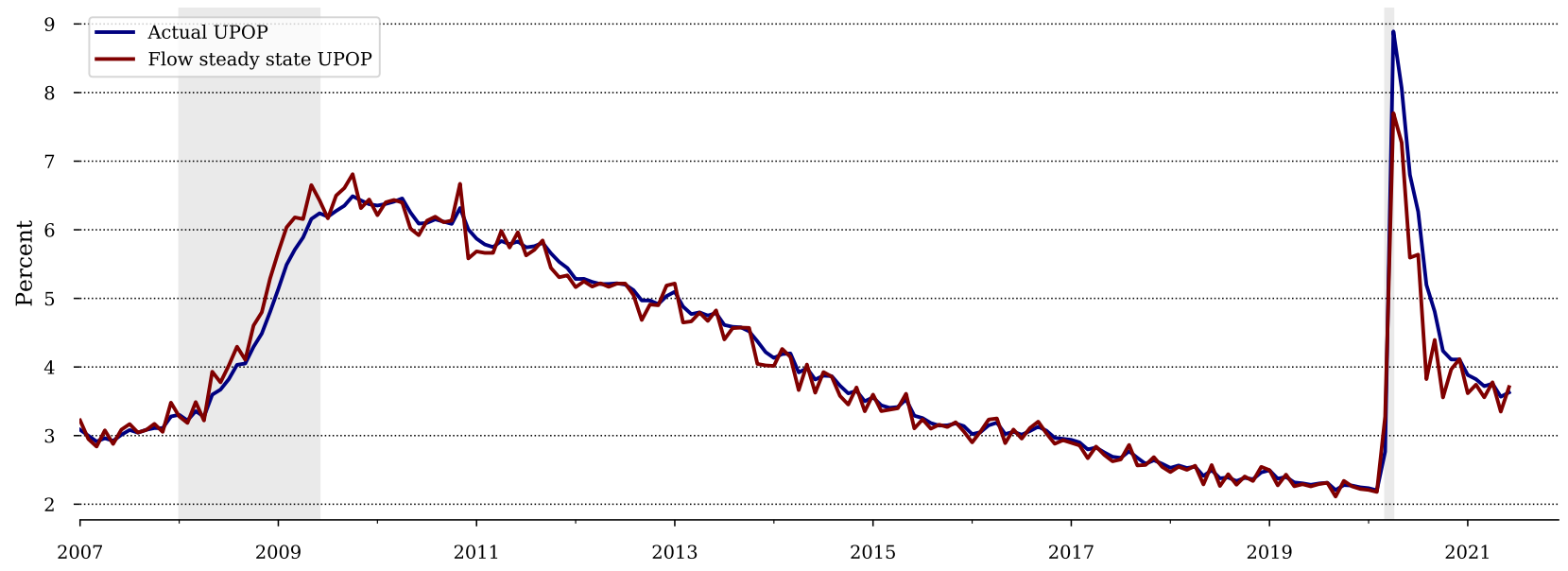

(a) Total

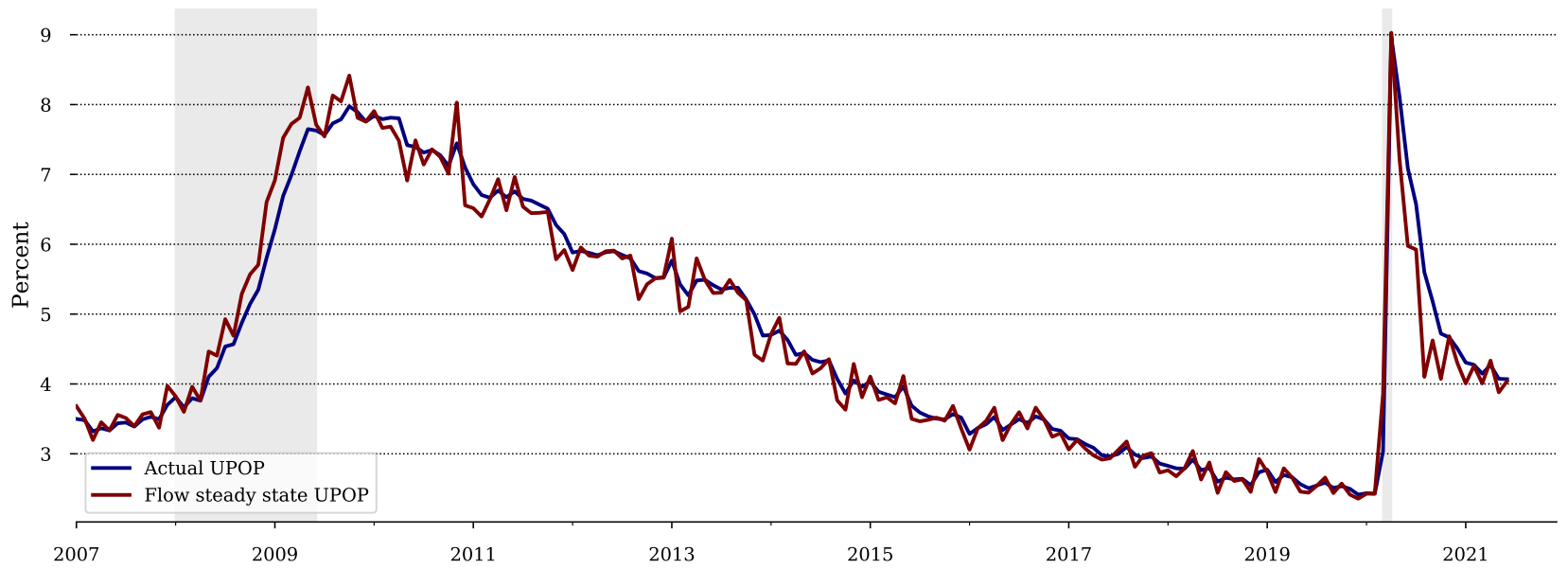

(b) Men

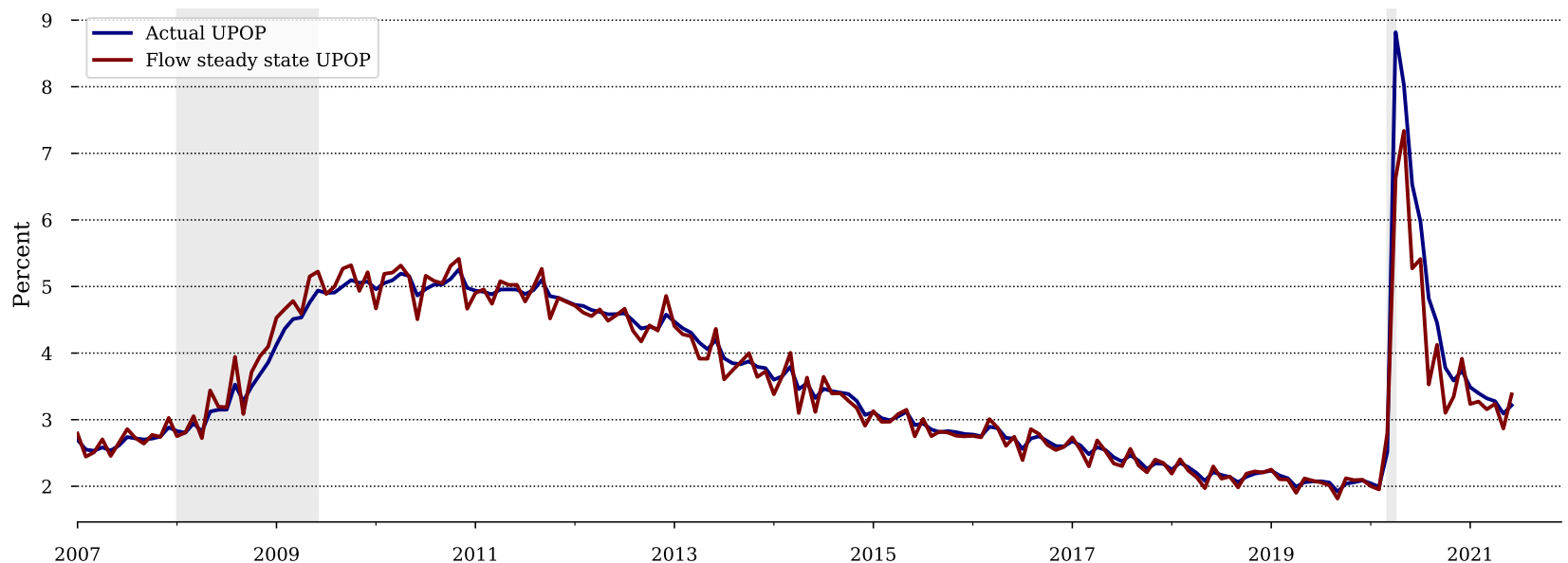

(c) Women

Figure C.6: Actual and flow steady-state UPOP ratio, Jan 2007-Jun 2021 Source: BLS, CPS, and authors' calculations. 
Table C.4: Sources of change in UPOP between Sep-2014, Feb-2020, and Jun-2021

\begin{tabular}{|c|c|c|c|c|c|c|c|}
\hline from & topic & group & Actual & Cycle & Entry & Exit & Adj.dyn. \\
\hline \multirow{13}{*}{$02 / 20$} & & Total & 1.5 & 0.7 & 0.5 & 0.2 & 0.1 \\
\hline & \multirow[t]{2}{*}{ Sex } & Men & 1.7 & 0.9 & 0.5 & 0.2 & 0.1 \\
\hline & & Women & 1.3 & 0.5 & 0.5 & 0.2 & 0.1 \\
\hline & \multirow[t]{3}{*}{ Age } & $16-24$ & 1.3 & 0.6 & 0.4 & 0.2 & 0.1 \\
\hline & & $25-54$ & 1.9 & 1.0 & 0.6 & 0.2 & 0.1 \\
\hline & & 55 and over & 0.8 & 0.3 & 0.3 & 0.1 & 0.1 \\
\hline & \multirow[t]{4}{*}{ Education } & Less than high school & 0.9 & 0.3 & 0.2 & 0.3 & 0.0 \\
\hline & & High school diploma & 1.5 & 0.7 & 0.5 & 0.1 & 0.2 \\
\hline & & Some college & 1.8 & 0.9 & 0.7 & 0.1 & 0.2 \\
\hline & & College degree or higher & 1.2 & 0.5 & 0.4 & 0.2 & 0.1 \\
\hline & \multirow[t]{2}{*}{ Race } & White & 1.3 & 0.7 & 0.4 & 0.2 & 0.1 \\
\hline & & Black & 1.9 & 0.7 & 0.8 & 0.1 & 0.2 \\
\hline & Ethnicity & Hispanic & 2.2 & 1.1 & 0.6 & 0.3 & 0.3 \\
\hline \multirow[t]{13}{*}{$9 / 14$} & & Total & -0.1 & -0.2 & -0.2 & 0.2 & 0.0 \\
\hline & \multirow[t]{2}{*}{ Sex } & Men & -0.1 & -0.1 & -0.3 & 0.3 & -0.0 \\
\hline & & Women & -0.1 & -0.2 & -0.2 & 0.2 & 0.0 \\
\hline & \multirow[t]{3}{*}{ Age } & $16-24$ & -1.5 & -0.9 & -1.2 & 0.5 & 0.1 \\
\hline & & $25-54$ & 0.2 & -0.1 & 0.1 & 0.2 & 0.0 \\
\hline & & 55 and over & 0.1 & -0.1 & 0.1 & 0.0 & 0.1 \\
\hline & \multirow{4}{*}{ Education } & Less than high school & -1.0 & -0.6 & -0.6 & 0.2 & 0.0 \\
\hline & & High school diploma & -0.2 & -0.1 & -0.2 & 0.1 & 0.1 \\
\hline & & Some college & -0.1 & -0.1 & -0.3 & 0.2 & 0.1 \\
\hline & & College degree or higher & 0.3 & -0.0 & 0.1 & 0.1 & 0.1 \\
\hline & \multirow[t]{2}{*}{ Race } & White & -0.0 & -0.1 & -0.2 & 0.2 & 0.0 \\
\hline & & Black & -1.3 & -0.9 & -0.7 & 0.2 & 0.0 \\
\hline & Ethnicity & Hispanic & 0.1 & -0.1 & -0.3 & 0.4 & 0.2 \\
\hline
\end{tabular}

Source: BLS, CPS, and authors' calculations

Notes: Decomposition of $\triangle U P O P_{t}$ between date in 'from' column and June 2021. 'Actual' is the percentage point change in the UPOP between the 'from' date and June 2021. The 'Cycle' column is the part of 'ActualSS' due to EU and UE transitions, the 'Exit' part due EN and UN, and the 'Entry' part due to NE and NU.'Adj.dyn.' is the percentage point difference between the change actual and in the flow steady-state UPOP. Steady state evaluated over 6-month moving average of flow rates. 